\author{
Universidade de São Paulo \\ Instituto de Astronomia, Geofísica e Ciências Atmosféricas
}

Departamento de Astronomia

Larissa Takeda

\title{
Sobre a origem dos sistemas de linhas estreitas no espectro de novas
}

São Paulo 

Larissa Takeda

\section{Sobre a origem dos sistemas de linhas estreitas no espectro de novas}

Dissertação apresentada ao Departamento de Astronomia do Instituto de Astronomia, Geofísica

e Ciências Atmosféricas da Universidade de São Paulo como requisito parcial para a obtenção do título de Mestre em Ciências.

Área de Concentração: Astronomia

Orientador: Prof. Dr. Marcos P. Diaz

São Paulo 

Dedico todo o meu trabalho ao meu querido pai. 



\section{Agradecimentos}

À minha mãe e à minha irmã, que sempre me apoiaram;

Ao meu orientador, Marcos Diaz, por toda ajuda e paciência;

Aos meus avós, por todo o carinho;

Aos meus amigos, em especial ao Hugo;

À FAPESP, pelo apoio financeiro, sob o projeto n ${ }^{o}$ 2012/10533-3.

Esta tese/dissertação foi escrita em $\mathrm{HAT}_{\mathrm{E}} \mathrm{X}$ com a classe IAGTESE, para teses e dissertações do IAG. 



\section{Resumo}

Nesse trabalho discutimos a formação de componentes estreitas de linhas de emissão observadas em espectros de algumas novas. Nós estudamos as possíveis fontes físicas no sistema binário responsável pela emissão das componentes estreitas de altos fluxos que apresentam velocidade radial, primeiramente identificadas nas linhas de recombinação da nova recorrente U Sco em sua erupção de 2010. Uma busca por novas candidatas a apresentarem o mesmo fenômeno em seus espectros é mostrada, indicando pelo menos 11 outras novas com espectros similares. Nós comparamos a presença dessas componentes com parâmetros básicos das novas e com a classificação espectral na fase inicial permitida da evolução espectral. Modelos de fotoionização mostram que a região emissora de tal radiação não deve ser restrita ao lóbulo de Roche, uma vez que seu volume é insuficiente para reproduzir os fluxos observados. Uma análise comparada também exclui o disco de acreção e a cromosfera da secundária como fontes da radiação. Nós sugerimos a região em torno de $L_{3}$ como uma possível região emissora, com base nas simulações de fotoionização. 



\section{Abstract}

In this paper we discuss the formation of peculiar narrow emission line components observed in the spectra of a few novae. We aim to identify the physical source in the binary system responsible for the emission of transient narrow components that present orbital radial velocity modulations, first observed in the post-outburst recombination lines of Nova U Sco 2010. A search for candidate novae showing similar narrow components is presented, indicating at least 11 other novae with similar spectra. We compared the presence of these components to nova basic parameters and to the spectral classification in the initial permitted phase of the spectral evolution. Photoionization simulations indicate that the forming region cannot be restricted to the primary Roche Lobe, as its volume is not large enough to reproduce the observed fluxes. A detailed analysis also excludes the accretion disk and the the secondary's cromosphere as sources of the radiation. We suggest the region around $L_{3}$ as a possible emitting region, based on photoionization simulations. 



\section{Lista de Figuras}

1.1 Estrutura do sistema binário visto do pólo da órbita, (Warner, 1995) . . .

1.2 Seções no plano orbital da binária das linhas equipotenciais de Roche para $q=0,25$. As linhas são numeradas de 1 a 7 em ordem crescente do valor do potencial. O ponto interno de Lagrange, $L_{1}$, corresponde ao ponto de sela por onde a matéria é transferida da secundária para a primária. Os pontos $L_{2}$ e $L_{3}$ são pontos semi-estáveis e $L_{4}$ e $L_{5}$ são pontos de máximo, mas a matéria nesse ponto é estabilizada pelas forças de Coriolis. Figura retirada de Frank et al. (2002) . . . . . . . . . . . . . . . . . . . . . .

1.3 Superfície representando o potencial de Roche para um sistema binário com $q=0,5$. É possível observar o formato do potencial nos pontos de Lagrange. Figura de Marc van der Sluys. . . . . . . . . . . . . . . . . . .

1.4 Exemplos de espectros característicos de novas do tipo "Fe II" (Williams, 1992).

1.5 Exemplos de espectros característicos de novas do tipo "He/N" (Williams, 1992

1.6 Diagrama da evolução espectral para as novas, do espectro permitido ao nebular $($ Williams, 1992) . . . . . . . . . . . . . . . .

1.7 Exemplo de espectro inicial da erupção da Nova Car 2008 (V679 Car) observado em dezembro de 2008 pelo SOAR Telescope Synoptic Survey of Novae.

1.8 Perfis sintéticos de linhas de emissão de um disco de acreção kepleriano conforme sua inclinação orbital (Horne e Marsh, 1986). 
1.9 Sequência temporal das componentes estreitas de $\mathrm{H} \alpha$ e de He II $4686 \AA$ na evolução espectral de U Sco em 2010 (Diaz et al., 2010). É possível observar a variação de velocidade radial em relação à posição da linha no dia 06/02/2010, representado pela linha tracejada. . . . . . . . . . . .

1.10 Variação de velocidade radial das linhas de He II $4686 \AA$ do espectro de U Sco na erupção de 2010 (Mason et al., 2012) . . . . . . . . . . . . . . . . .

4.1 Espectros na região de $\mathrm{H} \alpha$ para as novas que apresentam componentes estreitas transientes (com exceção de KT Eri, que não possui dados públicos disponíveis), dos bancos de dados do CTIO Nova Survey, Stony Brook/SMARTS Atlas e do SOAR Telescope Synoptic Survey of Novae. As velocidades sistêmicas foram removidas para facilitar a comparação das larguras das linhas. . . . . . . . . . . . . . . . . . .

4.2 Evolução espectral da linha de He II 4686Å de U Sco na erupção de 2010 feita com os dados do SOAR. A linha vermelha indica o comprimento de onda $4686 \AA$, mostrando a variação de posição das componentes estreitas. .

4.3 Evolução espectral da linha de $\mathrm{H} \delta$ com espectros de alta resolução do Stoony Brook/SMARTS Nova Atlas. A linha vermelha indica o comprimento de onda $4102 \AA$, mostrando a variação de posição das componentes estreitas. .

4.4 Razão entre o fluxo das componentes estreitas e o fluxo total das linhas em função do tempo normalizado por $t_{3} \ldots \ldots \ldots \ldots$. . . . . . . .

4.5 Distribuição de tempo de decaimento e distribuição de amplitude para as novas que apresentam componentes estreitas transientes, em contraste com as novas com espectros disponíveis na literatura e com as distribuições de todas as novas. . . . . . . . . . . . . . . . . . . . . . . 49

4.6 Curva de luz de U Sco (2010) na banda V, de acordo com os dados do AAVSO. Nas datas marcadas de 06/02/2010 a 20/03/2010, o espectro mostrou componentes estreitas (Diaz et al. 2010) . . . . . . . . . . . 50 50

4.7 Esquema ilustrativo da diferença entre os modelos de geometria aberta e fechada do CLOUDY $($ Ferland, 2006) . . . . . . . . . . . . . . . 
4.8 Resultados dos modelos para a nova V 394 CrA em 1987. Os símbolos de pontos, cruzes e triângulos representam os modelos para $\log (L)=36$, $\log (L)=37$ e $\log (L)=38 \mathrm{erg} / \mathrm{s}$, respectivamente. As linhas pretas tracejadas indicam os fluxos observados, com barras de erro de $40 \%$ em azul. . .

4.9 Resultados dos modelos para a nova KT Eri em 2009. Os pontos, as cruzes e os triângulos representam as simulações feitas com $\log (L)=36, \log (L)=37$ e $\log (L)=38 \mathrm{erg} / \mathrm{s}$. As linhas pretas tracejadas indicam os fluxos observados, com barras de erro de $40 \%$ em azul.

4.10 Resultados dos modelos para a nova U Sco em 2010. Os pontos e cruzes representam os modelos com $\log (L)=36,3$ e $\log (L)=37,3 \mathrm{erg} / \mathrm{s}$. As linhas pretas tracejadas indicam os fluxos observados, com barras de erro de $40 \%$ em azul. . . . . . . . . . . . . . . . . . . . . . .

4.11 Resultados dos modelos para U Sco (2010) com gás não homogêneo. Os símbolos de triângulos e cruz correspondem aos modelos com glóbulos de gás de $30 \%$ e $80 \%$ da massa total do envelope, respectivamente. As linhas pretas indicam os fluxos observados com barra de erro de $40 \%$. . . . . . .

4.12 Resultados dos modelos para U Sco (2010) para os modelos abertos. As linhas pretas indicam os fluxos observados com barra de erro de $40 \%$. . . .

4.13 Resultados dos modelos para U Sco (2010) cpara os modelos abertos. As linhas pretas indicam os fluxos observados com barra de erro de $40 \%$. . . .

4.14 Distribuição de densidade e campo de velocidade no plano equatorial do sistema binário resultantes das simulações de Bisikalo (2010) . . . . . . . . . 62

4.15 Espectro IUE da nova V394 CrA (1987) (Starrfield et al., 1988). . . . . . . 64

A.1 Evolução espectral de U Sco na erupção de 2010, acompanhada pelo telescópio SOAR (Diaz et al., 2010) . . . . . . . . . . . . . . 78

A.2 Evolução espectral de V394 CrA, acompanhada pelo CTIO Nova Survey (Williams et al., 1991) . . . . . . . . . . . . . . . . . 79

A.3 Evolução espectral de KT Eri (Munari et al., 2014) . . . . . . . . . . . . . 80

A.4 Evolução espectral de KT Eri na banda J (Raj et al., 2013). . . . . . . . . 81

A.5 Evolução espectral da Nova LMC $1990 n^{\circ} 2$, acompanhada pelo telescópio de $1,9 \mathrm{~m}$ no SAAO (Sekiguchi et al., 1990). . . . . . . . . . . . . 
A.6 Evolução espectral da Nova LMC $1988 n^{\circ} 2$, acompanhada pelo CTIO Nova Survey $($ Williams et al., 1991) . . . . . . . . . . . . . . . . 82

A.7 Evolução espectral da Nova LMC 2009 (Mason e Walters, 2013). . . . . . . 83

A.8 Evolução espectral de V444 Sct, acompanhada pelo CTIO Nova Survey (Williams et al., 1994). . . . . . . . . . . . . . 84

A.9 Espectro de DE Cir do dia 19 de outubro de 2003, dados do Stony Brooks/SMARTS Nova Atlas. . . . . . . . . . . . . . . . 85

A.10 Evolução espectral de YY Dor, acompanhada pelo Stony Brooks/SMARTS Nova Atlas. . . . . . . . . . . . . . . . . . . . . 86

A.11 Evolução espectral de Nova Sco $2011 n^{\circ} 2$, acompanhada pelo Stony Brooks/SMARTS Nova Atlas. . . . . . . . . . . . . . . 87

A.12 Evolução espectral de Nova Oph 2009, acompanhada pelo Stony Brooks/SMARTS Nova Atlas. . . . . . . . . . . . . . . . . . . . . . . . 88

A.13 Evolução espectral de V1280 Sco, ou Nova Sco 2007 (Naito et al., 2012a). . 89 


\section{Lista de Tabelas}

4.1 Propriedades básicas das novas pesquisadas. . . . . . . . . . . . . 42

4.2 Classificação de novas de acordo com o tempo de decaimento . . . . . . . . 48

4.3 Valores de entrada dos modelos simulados com o RAINY3D. . . . . . . . . 53 



\section{Sumário}

1. Introdução . . . . . . . . . . . . . . . . . . . . . . . 19

1.1 Novas . . . . . . . . . . . . . . . . . . . . . . . . . . . [19]

1.1.1 Erupções de novas . . . . . . . . . . . . . . . . 20

1.1.2 Geometria de Roche . . . . . . . . . . . . . . . . . 21

1.2 Espectroscopia de novas . . . . . . . . . . . . . . . . . . 24

1.2.1 Evolução espectral e classificação de novas . . . . . . . . . . 24 24

1.2.2 Perfis de linha . . . . . . . . . . . . . 27

1.2.2.1 Velocidade radial . . . . . . . . . . . . . . 27

1.2.2.2 Componentes estreitas transientes . . . . . . . . . . 29

2. Base de dados . . . . . . . . . . . . . . . . . . . . . . . . . . . 33

2.1 Nova Surveys . . . . . . . . . . . . . . . . . . . . . . . 33

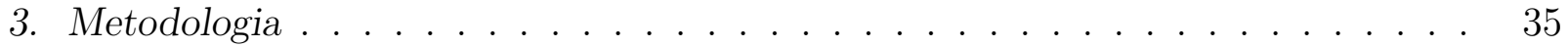

3.1 Redução de dados espectrofotométricos . . . . . . . . . . . . . 35

3.1 .1 Calibração básica . . . . . . . . . . . . . . . . 35

3.1 .2 Extração do espectro . . . . . . . . . . . . . . 36

3.1.3 Calibração em comprimento de onda . . . . . . . . . . 37

3.1 .4 Calibração em fluxo . . . . . . . . . . . . . . . . 37

3.1.5 Correção de velocidade radial . . . . . . . . . . . . . . . 38

3.1 .6 Identificação de linhas . . . . . . . . . . . . . . . . . . 38

3.2 Modelos de fotoionização . . . . . . . . . . . . . . . . . . 39

3.2 .1 Cloudy ............................. 39

3.2 .2 RAINY3D ............................. 40 
4. Resultados e discussão . . . . . . . . . . . . . . . . . . . . . . 41

4.1 A busca por componentes estreitas transientes em espectros de novas . . 41

4.2 Análise estatística . . . . . . . . . . . . . . . . . . . . 41

4.2.1 Comparação com propriedades básicas das novas . . . . . . . . . 47

4.2 .2 Testes de compatibilidade . . . . . . . . . . . . . . . 48

4.2.2.1 Nova Sco $2007 \ldots \ldots \ldots$

4.3 Simulações de fotoionização $\ldots \ldots \ldots \ldots$. . . . . . . . . . 51

4.3 .1 Geometria fechada . . . . . . . . . . . . . . . . 51

4.3 .1 .1 V394 CrA . . . . . . . . . . . . . 53

$4.3 .1 .2 \quad$ KT Eri . . . . . . . . . . . . . . . . . 54

4.3 .1 .3 U Sco . . . . . . . . . . . . . . . . 55

4.3.1.4 Influência de parâmetros principais nos resultados . . . . 556

4.3 .2 Geometria aberta . . . . . . . . . . . . . . . . . . . 59

4.3.3 Proposta de cenário de formação das componentes estreitas . . . . . 60

4.3.3.1 Sobre a possibilidade de formação no disco de acreção . . 62

5. Conclusões. . . . . . . . . . . . . . . . . . . . . . . . 65

6. Perspectivas ............................ 67

Referências . . . . . . . . . . . . . . . . . . . . 69 69

Apêndice 75

A. Evolução espectral das novas que apresentam componentes estreitas transientes 77 
Capítulo 1

\section{Introdução}

\subsection{Novas}

Novas são uma classe de Variáveis Cataclísmicas, formadas por binárias cerradas compostas por uma anã branca (estrela primária) e uma estrela menos evoluída (secundária), normalmente da sequência principal. Durante a rotação do sistema binário, o momento angular diminui e, portanto, o lóbulo de Roche da secundária se contrai. Quando o lóbulo de Roche se torna completamente preenchido pelo material da secundária, inicia-se a transferência de matéria para a primária por meio de um disco de acreção. No disco, o gás precisa perder momento angular para poder ser acretado na superfície da estrela primária. Essa perda pode ocorrer pela transformação de energia cinética em energia térmica ou magnética e pela redistribuição de matéria, como o vazamento de gás para fora do disco (Frank et al., 2002). No caso de anãs brancas magnéticas, ao invés do disco, a transferência é feita por colunas de acreção, que seguem as linhas de campo magnético da estrela.

Conforme a superfície da anã branca recebe o material da secundária, a temperatura e a pressão do gás de elétrons degenerado aumentam. No momento em que o gás superficial da anã branca atinge a pressão necessária para iniciar reações de fusão do hidrogênio, há uma detonação termonuclear e a erupção do material na forma de um envelope (Nomoto e Kondo, 1991). Esse fenômeno é observado no céu como o aumento de 6 a 19 magnitudes (Warner, 1995). A ejeção típica de uma nova ocorre com perda de matéria no intervalo entre $10^{-8}$ e $10^{-5} M_{\odot}$. A velocidade de expansão do gás logo após a erupção pode atingir valores entre centenas e poucos milhares de $\mathrm{km} / \mathrm{s}$.

Ao contrário das explosões de supernovas, a detonação das novas ocorre apenas na superfície da anã branca, mantendo o sistema binário intacto. Dessa maneira, após a 


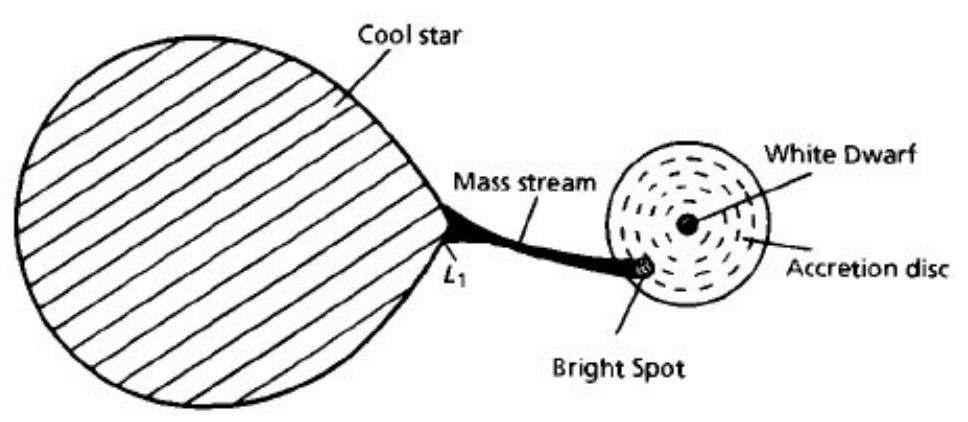

Figura 1.1: Estrutura do sistema binário visto do pólo da órbita, (Warner, 1995)

erupção, a transferência de massa da secundária para a primária continua, assim como a formação do disco de acreção. Com o tempo, a nova pode apresentar outras erupções. A nova que teve apenas uma erupção registrada é chamada de nova clássica. A que teve múltiplas erupções, por sua vez, é denominada nova recorrente. Atualmente, o grupo de novas recorrentes é povoado por 13 objetos observados, em contraste ao grupo de novas clássicas que supera 500 objetos observados.

Além do disco de acreção, há outras componentes importantes na estrutura do sistema binário: o hot spot (ou bright spot) e a boundary layer. O hot spot é a região de contato entre o gás da secundária e o disco de acreção. Como o gás tem velocidade supersônica, o hot spot é aquecido por ondas de choque e pode ter uma temperatura mais elevada que o disco. Já a boundary layer é a camada em que o material do disco entra em contato com a anã branca. Nela, o gás do disco é desacelerado para atingir a velocidade superficial do gás da primária. A figura 1.1 mostra a disposição das componentes do sistema binário.

\subsubsection{Erupções de novas}

A erupção do tipo nova é um evento complexo e pode ser dividido basicamente em 3 etapas (Gehrz, 1988). O início da erupção é chamado de "fireball" e corresponde à expansão da pseudo-fotosfera ocasionada pelas reações termonucleares na superfície da anã branca. O envelope possui alta luminosidade-podendo ser maior do que o limite de Eddington da primária (Shaviv e Dotan, 2012)-, alta densidade e alta opacidade. O nome "Pseudofotosfera" remete ao fato de que a distribuição de energia e a temperatura espectroscópica do envelope são semelhantes às de um modelo de corpo negro para a fotosfera de uma 
estrela do tipo F (Ney e Hatfield, 1978). A ejeção de material não ocorre de maneira constante, podendo ser aproximado a múltiplas erupções em camadas, que se dissipam com o tempo devido ao vento da primária acelerado pela pressão de radiação.

Nessa fase, chamada "Optically thin gas emission phase", o gás começa a ficar opticamente fino e as camadas inferiores, próximas à primária, se tornam visíveis. Devido à grande extensão física do envelope nesse momento, o gradiente de temperatura se torna elevado. Dessa maneira é possível observar vários íons diferentes dos mesmos elementos no espectro, que correspondem às diferentes camadas em diferentes temperaturas e densidades. As regiões de baixa densidade podem emitir linhas proibidas, de transições coronais e aurorais. Nesse momento a distribuição de energia deixa de ser ajustável ao modelo de corpo negro.

Uma última fase pode ser associada a algumas novas, que é a fase de formação de poeira. Com o decaimento da luminosidade no óptico, percebe-se um aumento na emissão térmica no infravermelho, derivado da formação de poeira. Nesse momento, a curva de luz nas bandas B, V e R costumam apresentar oscilações, além do decaimento de emissão. Uma nova pode apresentar envelopes de poeira opticamente finos ou espessos e em alguns casos, não apresentar formação de poeira. A distribuição dos grãos de um envelope de nova e, consequentemente, sua distribuição de densidades, podem ser obtidos por observações no IR.

\subsubsection{Geometria de Roche}

A interação gravitacional de sistemas binários é bem descrita pelas linhas equipotenciais e pelos pontos de Lagrange. O potencial do sistema pode ser escrito como a soma dos potenciais gravitacionais das estrelas primária e secundária e o potencial efetivo devido à força centrífuga. A equação 1.1 mostra o potencial em coordenadas cartesianas para a primária centralizada no ponto $(0,0,0)$ e a secundária no ponto $(a, 0,0)$. O parâmetro $a$ corresponde à separação orbital, $M_{1}$ e $M_{2}$ são as massas da primária e secundária, respectivamente, $\mu$ é a massa reduzida e $\Omega_{\text {orb }}=2 \pi / P_{\text {orb }}$.

$$
\Phi_{R}=-\frac{G M_{1}}{\left(x^{2}+y^{2}+z^{2}\right)^{1 / 2}}-\frac{G M_{2}}{\left[(x-a)^{2}+y^{2}+z^{2}\right]^{1 / 2}}-\frac{\Omega_{o r b}^{2}\left[(x-a \mu)^{2}+y^{2}\right]}{2}
$$

O lóbulo de Roche corresponde à maior linha equipotencial fechada que pode conter 


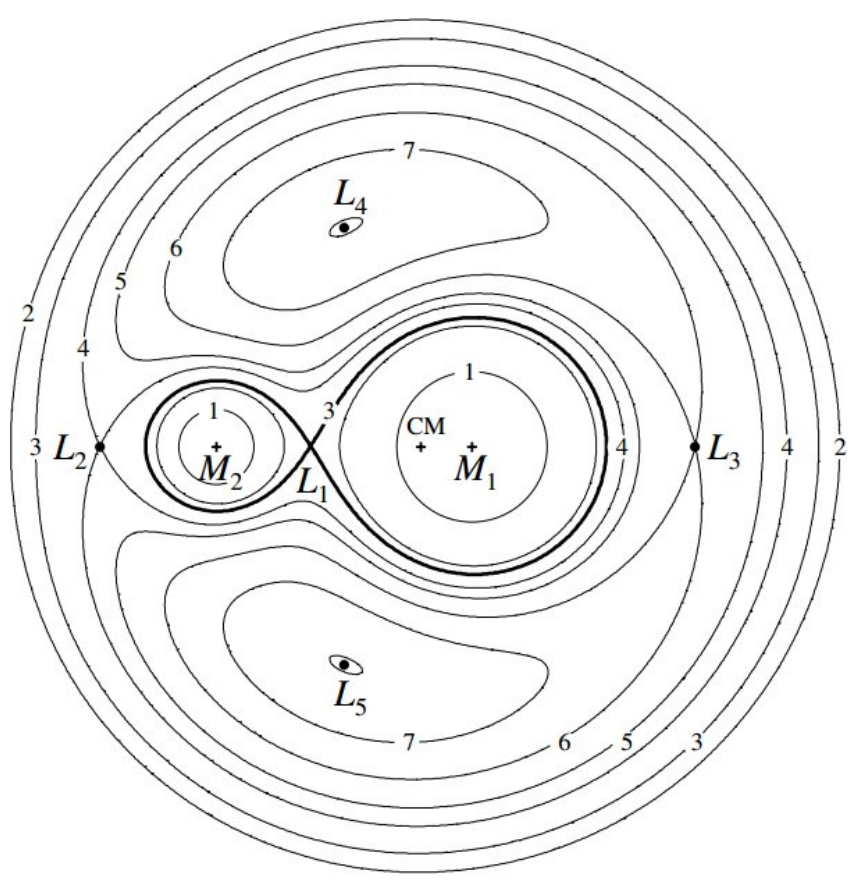

Figura 1.2: Seções no plano orbital da binária das linhas equipotenciais de Roche para $q=0,25$. As linhas são numeradas de 1 a 7 em ordem crescente do valor do potencial. O ponto interno de Lagrange, $L_{1}$, corresponde ao ponto de sela por onde a matéria é transferida da secundária para a primária. Os pontos $L_{2}$ e $L_{3}$ são pontos semi-estáveis e $L_{4}$ e $L_{5}$ são pontos de máximo, mas a matéria nesse ponto é estabilizada pelas forças de Coriolis. Figura retirada de Frank et al. (2002).

a massa da estrela. Os pontos de Lagrange são regiões em que há pontos de sela no potencial gravitacional, que correspondem a pontos de equilíbrio semi-estáveis. O ponto interno de Lagrange, $L_{1}$, é um ponto comum entre as linhas de equipotencial fechadas das duas estrelas e corresponde ao ponto em que a atração gravitacional efetiva das duas estrelas está em equilíbrio. É nesse ponto em que há a transferência de massa da secundária para a primária. Os pontos $L_{2}$ e $L_{3}$ também são localizados no eixo que liga os centros das duas estrelas, como mostra a figura 1.2. Os pontos $L_{4}$ e $L_{5}$ são localizados no eixo perpendicular, também mostrado na figura 1.2. A figura 1.3 apresenta uma superfície do potencial gravitacional da binária, indicando os pontos $L_{1}, L_{2}$ e $L_{3}$.

Como a primária e a secundária possuem rotação sincronizada, é possível estimar a distância de separação entre as duas componentes a partir do período orbital do sistema por meio da $3^{a}$ Lei de Kepler generalizada (equação 1.2). O período orbital pode ser determinado pela velocidade radial das linhas espectrais, ou pelas curvas de luz das novas, que também fornecem estimativas das massas da primária $\left(M_{1}\right)$ e secundária $\left(M_{2}\right)$. 


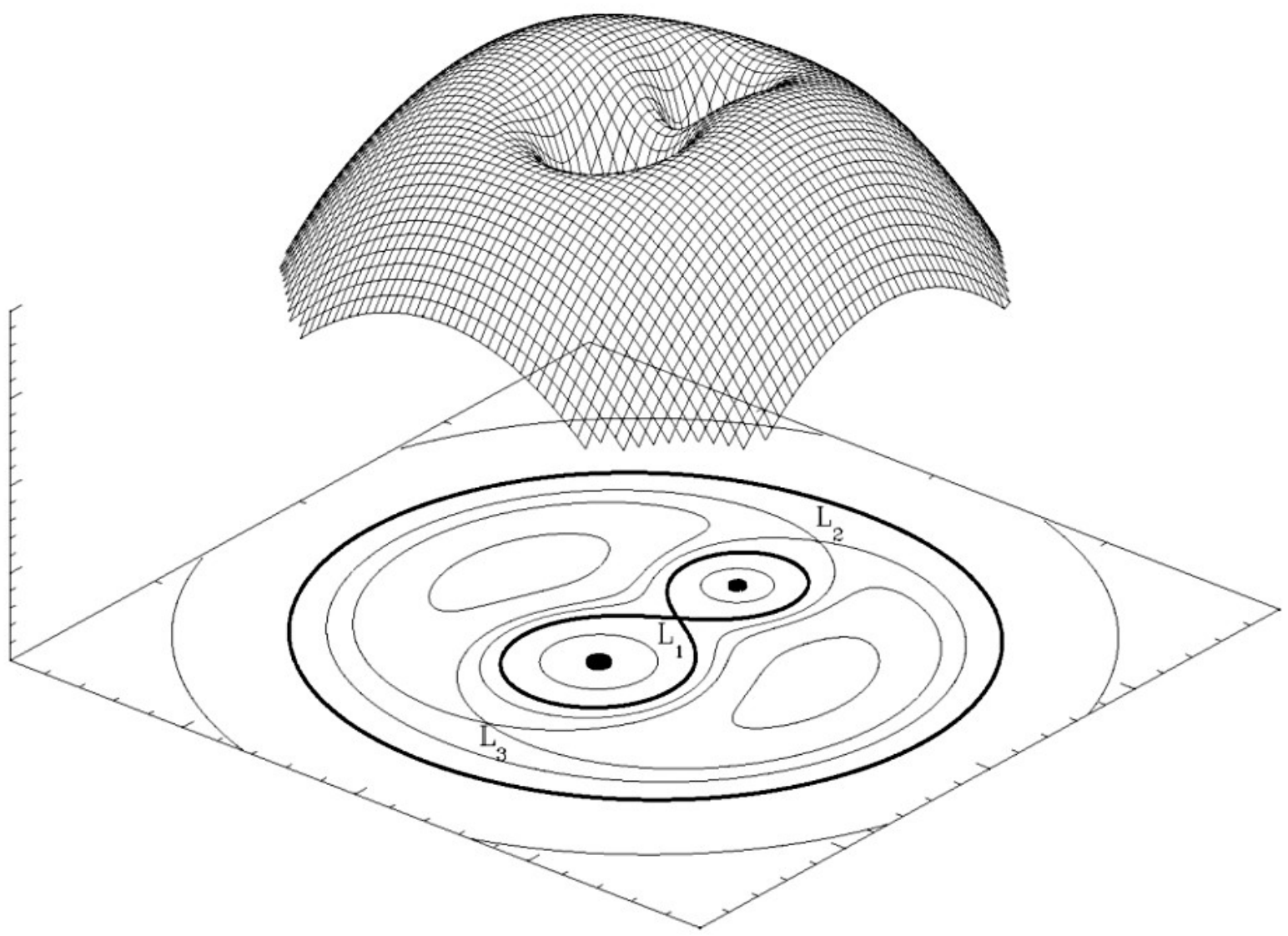

Figura 1.3: Superfície representando o potencial de Roche para um sistema binário com $q=0,5$. É possível observar o formato do potencial nos pontos de Lagrange. Figura de Marc van der Sluys. 


$$
P_{o r b}^{2}=\frac{4 \pi^{2} a^{3}}{G\left(M_{1}+M_{2}\right)}
$$

O raio do volume dos lóbulos de Roche da primária $\left(R_{L}(1)\right)$ e secundária $\left(R_{L}(2)\right)$ podem ser calculados pela relação de Eggleton (1983), com as equações $1.3 \mathrm{e} 1.4$, com erro de cerca de $1 \%$ para $0<q<\infty$, sendo $q$ a relação de massas $M_{2} / M_{1}$.

$$
\begin{aligned}
\frac{R_{L}(1)}{a} & =\frac{0.49 q^{-2 / 3}}{0.6 q^{-2 / 3}+\ln \left(1+q^{-1 / 3}\right)} \\
\frac{R_{L}(2)}{a} & =\frac{0.49 q^{2 / 3}}{0.6 q^{2 / 3}+\ln \left(1+q^{1 / 3}\right)}
\end{aligned}
$$

\subsection{Espectroscopia de novas}

A espectroscopia pode fornecer diferentes informações para diferentes regiões do espectro. Nas regiões óptica, IR e UV, é possível obter informações sobre velocidade do gás do envelope, sua composição química, densidade e temperatura. A emissão no IR também mostra a presença de poeira no sistema binário e é fundamental para o estudo de envelopes evoluídos. Observações em raios-X são usadas para identificar fontes supersoft e primárias magnéticas.

No caso deste projeto, foram analisadas apenas novas não magnéticas, de forma que não foram consideradas observações em raios-X. Os principais espectros analisados são na região óptica.

\subsubsection{Evolução espectral e classificação de novas}

No início da erupção da nova, o gás do envelope é opticamente espesso e o espectro apresenta apenas linhas de emissão de transições permitidas, devido à alta densidade local. Segundo a classificação de Williams (Williams, 1992), além da presença do hidrogênio, o espectro inicial após a erupção pode apresentar duas situações distintas. Ele pode ser da classe "Fe II", em que as linhas de Fe II aparecem em diversos comprimentos de onda no óptico, ou "He/N", em que as linhas de He I e He II e/ou N II e N III aparecem na mesma região. As novas do tipo "Fe II" tendem a apresentar linhas espectrais mais finas, com $H W Z I<2.500 \mathrm{~km} / \mathrm{s}$, perfil de absorção P Cygni e decaimento lento. A classe "Fe II" também pode ser dividida em dois subgrupos de acordo com as larguras das linhas 


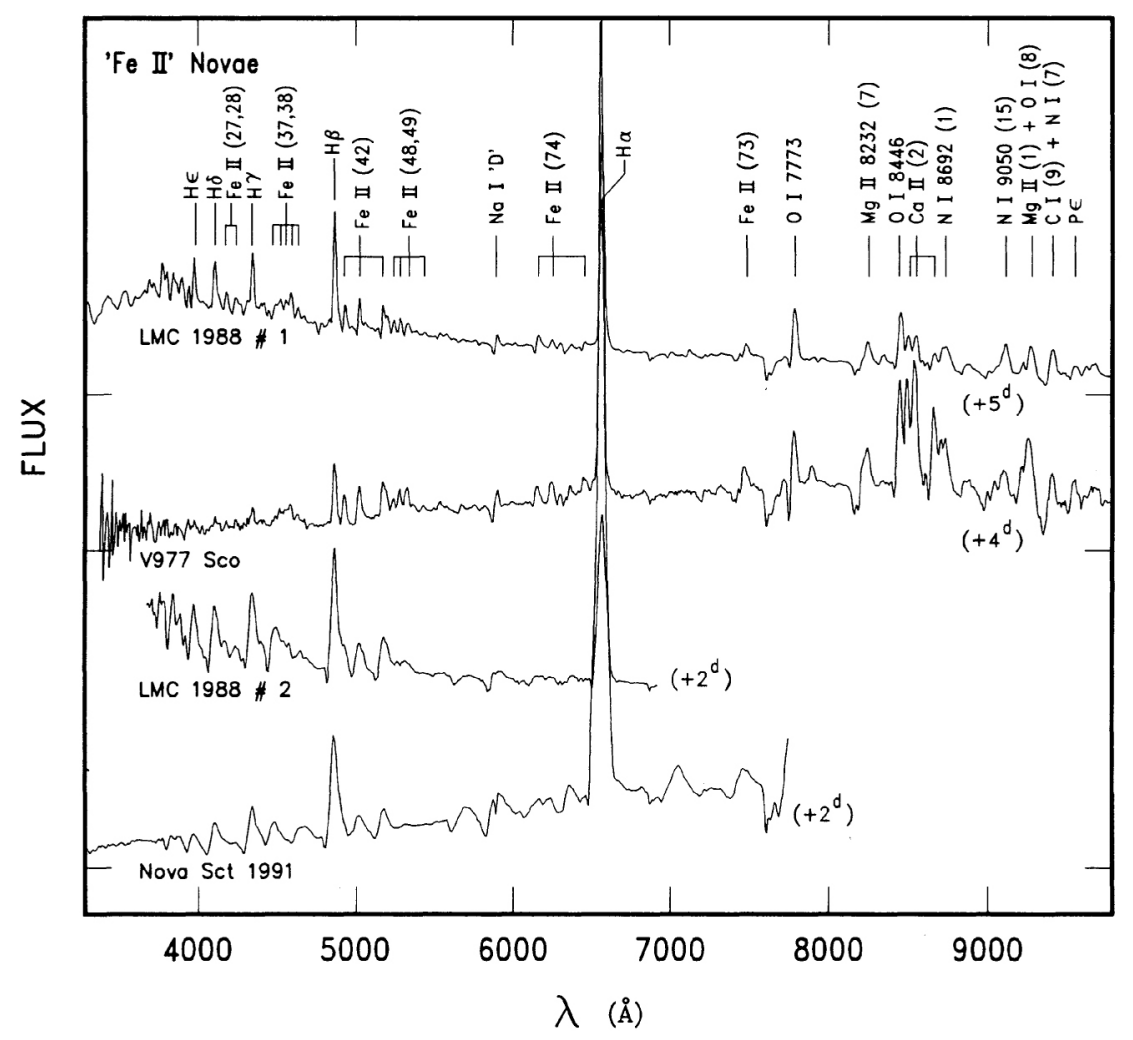

Figura 1.4: Exemplos de espectros característicos de novas do tipo "Fe II" Williams, 1992. 


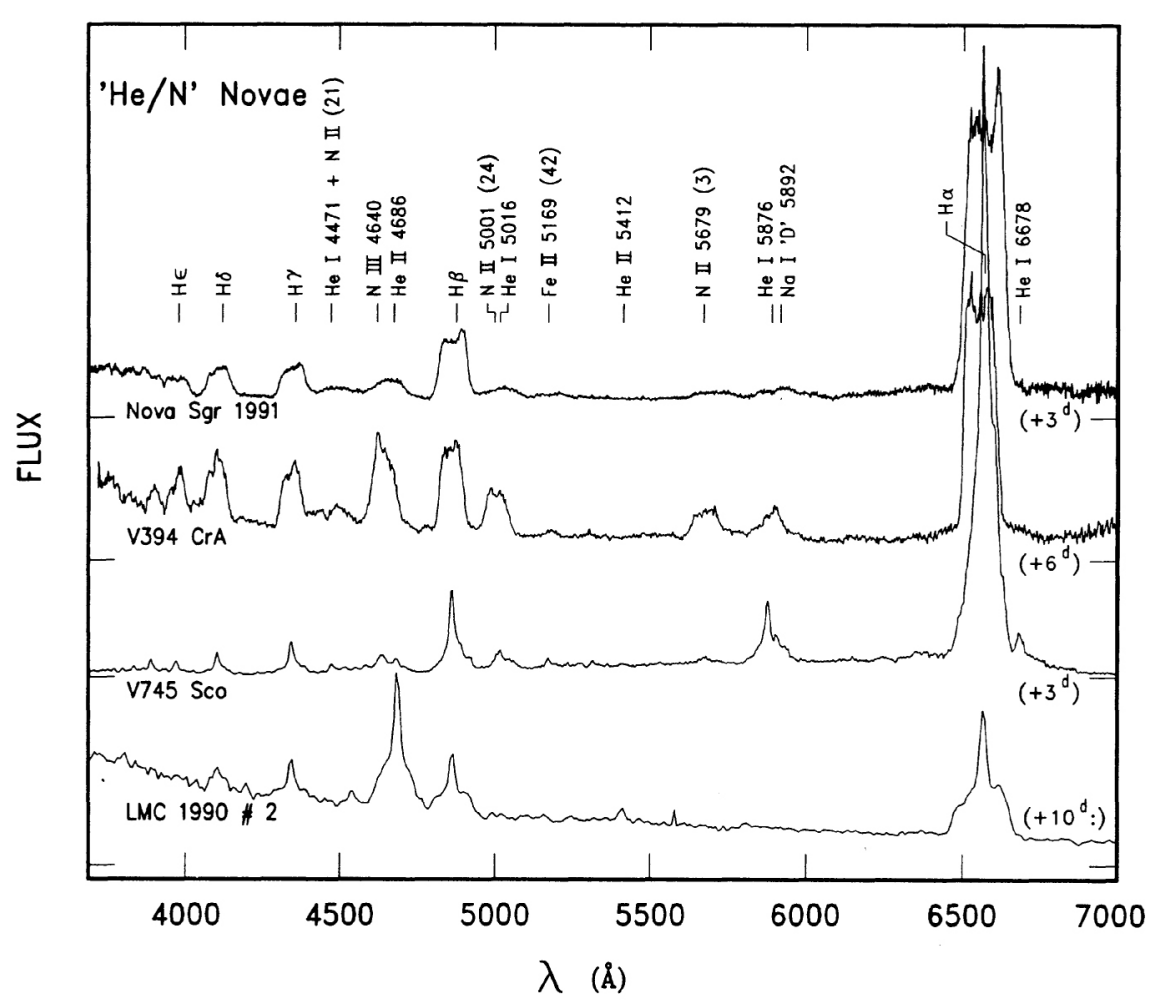

Figura 1.5: Exemplos de espectros característicos de novas do tipo "He/N" Williams, 1992).

no espectro: "Fe IIn" e "Fe IIb". O primeiro corresponde aos objetos que apresentam tipicamente as linhas estreitas e o segundo, aos que apresentam linhas mais largas (pelo menos na base). Já as novas "He/N" possuem linhas de emissão com pico achatado, pouca absorção e decaimento mais rápido. Os espectros característicos das novas do tipo "Fe II" e "He/N" são mostrados nas figuras $1.4 \mathrm{e} 1.5$.

Conforme o envelope se expande, a densidade do gás diminui e o espectro pode apresentar linhas proibidas. O espectro tardio que apresentar transições proibidas pode ser classificado nas classes Standard, Neon e Coronal. A classe Standard corresponde ao espectro que apresenta linhas de transições nebulares, Coronal ao que apresenta linhas de transições coronais e Neon ao que é dominado por linhas de neônio. Os caminhos evolutivos para os espectros "Fe II" e "He/N" são distintos, como mostra o diagrama na figura 1.6. É possível que todas as novas apresentem linhas proibidas em seus espectros tardios, mas que o baixo fluxo emitido em tal época não possa ser detectado por alguns telescópios.

É extremamente importante acompanhar a evolução espectral de novas porque os espectros refletem as condições físicas do sistema binário. Assim, é possível associar as 


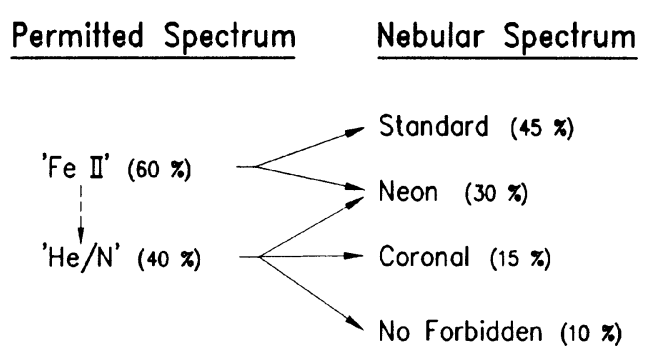

Figura 1.6: Diagrama da evolução espectral para as novas, do espectro permitido ao nebular (Williams, 1992 .

mudanças nos fluxos e perfis de linhas a alterações de densidade, velocidade e configuração da nova.

\subsubsection{Perfis de linha}

Além da composição química, o espectro das novas evoluídas pode fornecer informações sobre o sistema binário por meio dos perfis de linha. Nas novas recentes, assim como durante a erupção, o espectro é dominado pelas linhas de emissão do envelope ejetado. No início da erupção, as linhas são largas, devido à alta velocidade de ejeção, e saturadas, como mostra a figura 1.7. Logo após a erupção, as linhas mudam constantemente como reflexo de uma combinação complexa de profundidades ópticas, emissividades e campos de velocidades (Shore et al., 2011).

Quando em quiescência, o espectro da pré-nova é dominado pelo espectro do disco, pois ele é mais brilhante. Nele são formadas linhas de emissão, principalmente de hidrogênio. O alargamento dessas linhas está diretamente relacionado à velocidade macroscópica do gás em rotação e apresenta diferentes aspectos dependendo da inclinação do sistema orbital. Para altas inclinações, as componentes de velocidade tangencial do gás do disco se encontram na linha de visão do observador. Portanto, as linhas de emissão do disco serão largas e apresentarão um duplo pico correspondente ao deslocamento Doppler do gás. Para baixas inclinações, as linhas do disco serão estreitas e com um único pico (figura 1.8).

\subsubsection{Velocidade radial}

A interpretação de dados de velocidade radial no espectro de novas recentes depende de vários aspectos. Devido à complexidade do campo de velocidades do gás em expansão, e aos efeitos de autoabsorção, não é possível distinguir as diferentes componentes das linhas. 


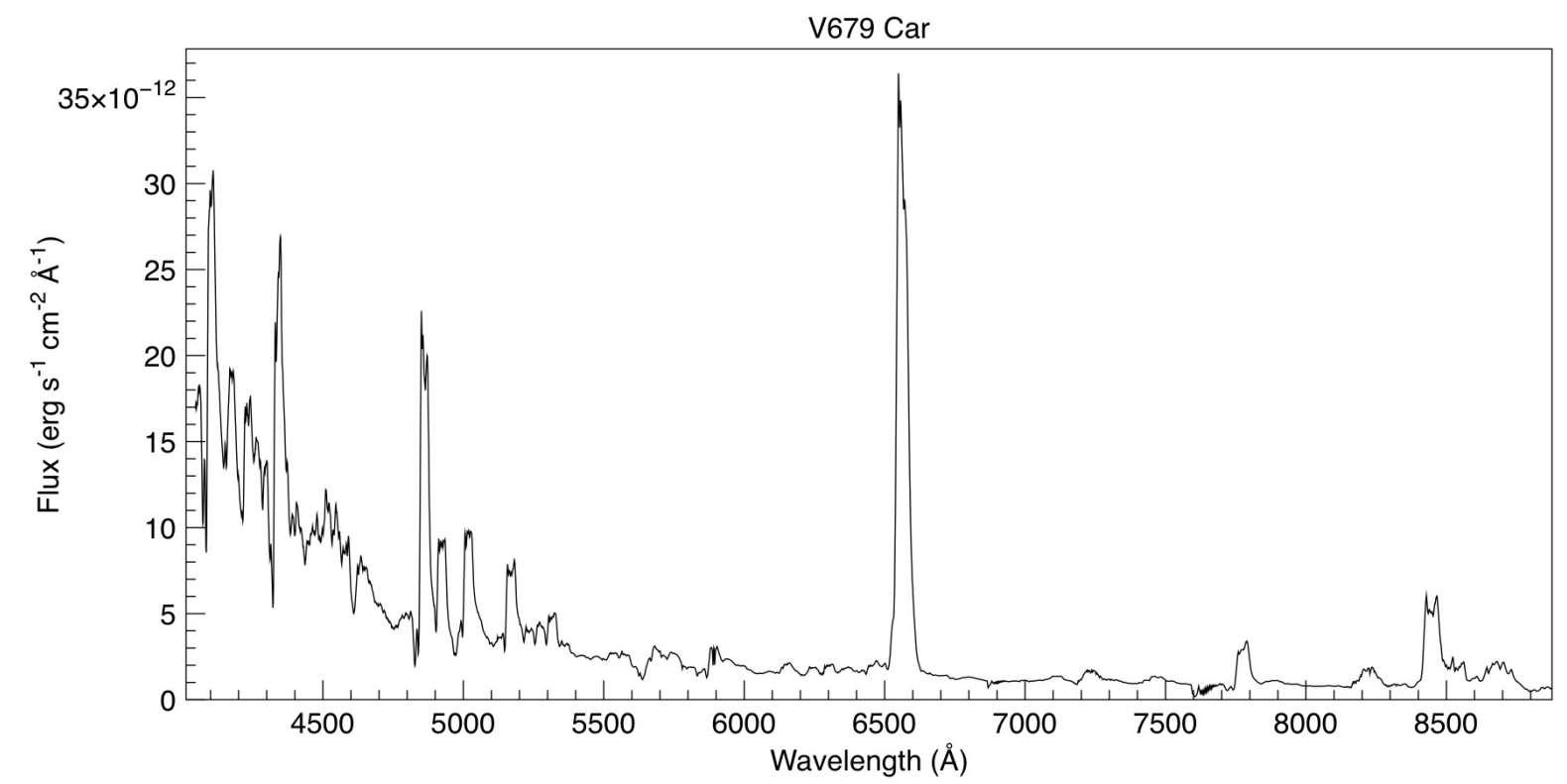

Figura 1.7: Exemplo de espectro inicial da erupção da Nova Car 2008 (V679 Car) observado em dezembro de 2008 pelo SOAR Telescope Synoptic Survey of Novae.

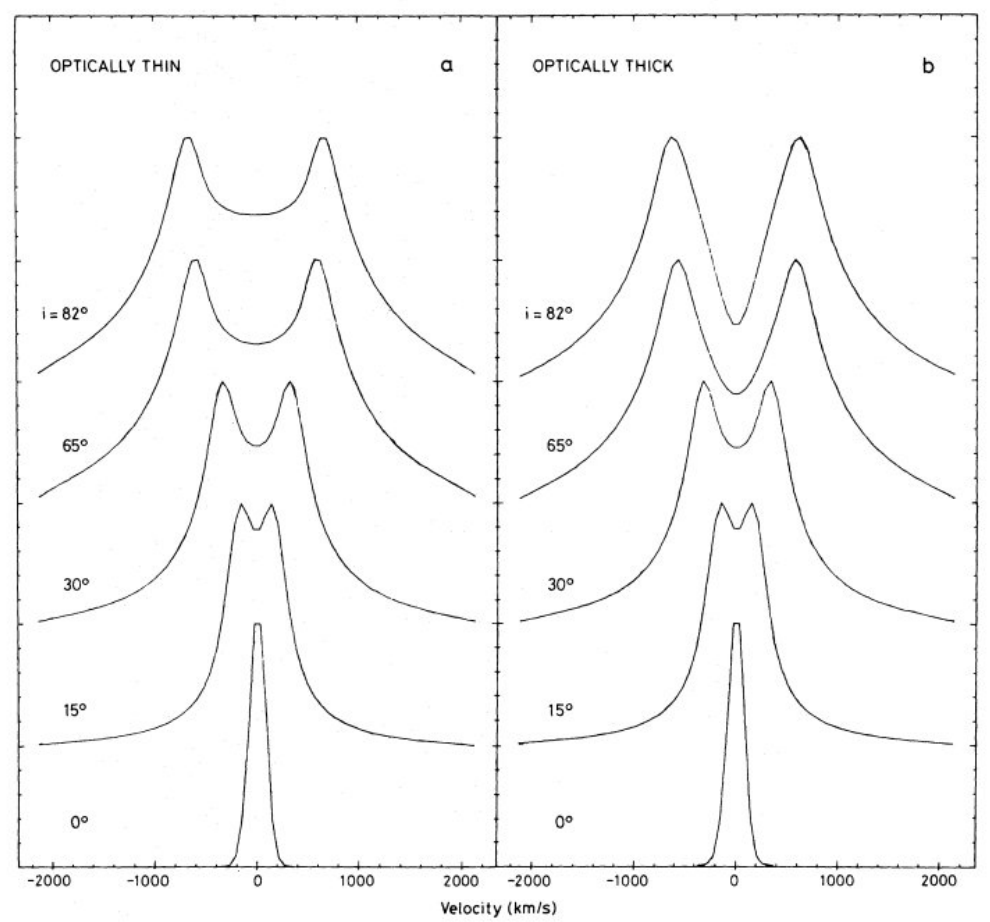

Figura 1.8: Perfis sintéticos de linhas de emissão de um disco de acreção kepleriano conforme sua inclinação orbital (Horne e Marsh, 1986). 
Mesmo as linhas de absorção, de perfil P Cygni, por exemplo, podem ser mal medidas e interpretadas de maneiras incorretas (Payne-Gaposchkin, 1964).

Para um mapeamento adequado do campo de velocidades de uma nova, é necessária uma tomografia Doppler (Calvelo et al. 2009). Assim, é possível distinguir as velocidades do gás em diferentes regiões.

\subsubsection{Componentes estreitas transientes}

Componentes estreitas em espectros de novas durante e após a erupção são muito comuns e podem ser atribuídas a diferentes fatores. Algumas novas, especialmente as do tipo "Fe II" apresentam principalmente linhas estreitas. Nesse caso, a largura moderada das linhas é atribuída à baixa velocidade de expansão do gás durante a erupção. Modelos estáticos com geometrias complexas também podem explicar a presença de certas componentes estreitas. Em simulações para a nova V2672 Oph (Nova Oph 2009), Munari et al. (2011) conseguiram reproduzir os perfis de linha do espectro observado, incluindo as componentes estreitas. Para isso eles usaram como geometria um esferóide prolato, com ejeção de gás pelos polos e um anel equatorial. O perfil da componente estreita pode ser reproduzido com a emissão do gás do anel. Outros elementos do sistema de novas comumente atribuídos à emissão de linhas estreitas são o disco de acreção e a secundária.

Em 2010, foi detectada uma erupção da nova recorrente U Sco, a décima erupção registrada desse objeto. U Sco é uma nova rápida e com o menor intervalo de recorrência entre as erupções já registrado para os objetos da mesma classe, de cerca de 10 anos. A massa da componente primária é próxima ao limite de Chandrasekhar e a nova é considerada uma candidata a progenitora de supernova do tipo Ia (Starrfield et al., 1985). Diferentemente das erupções anteriores, a de 2010 foi acompanhada por diversos telescópios durante um grande período de tempo, permitindo um registro da evolução espectral da nova. Os espectros obtidos durante essa erupção mostraram uma característica peculiar: a presença de linhas estreitas transientes. De maneira distinta dos espectros característicos de novas do tipo "Fe II", o de U Sco apresentou linhas com componentes largas e estreitas. As componentes estreitas apareceram nos primeiros dias $\left(t-t_{0}=9(d)\right)$ após a erupção e foram sobrepostas pelas componentes largas semanas depois $\left(t-t_{0}=51(d)\right)$. Além disso, foram detectadas modulações de velocidade que foram atribuídas ao movimento orbital (Diaz et al., 2010; Mason et al., 2012). A figura 1.9 mostra a variação da posição do pico 


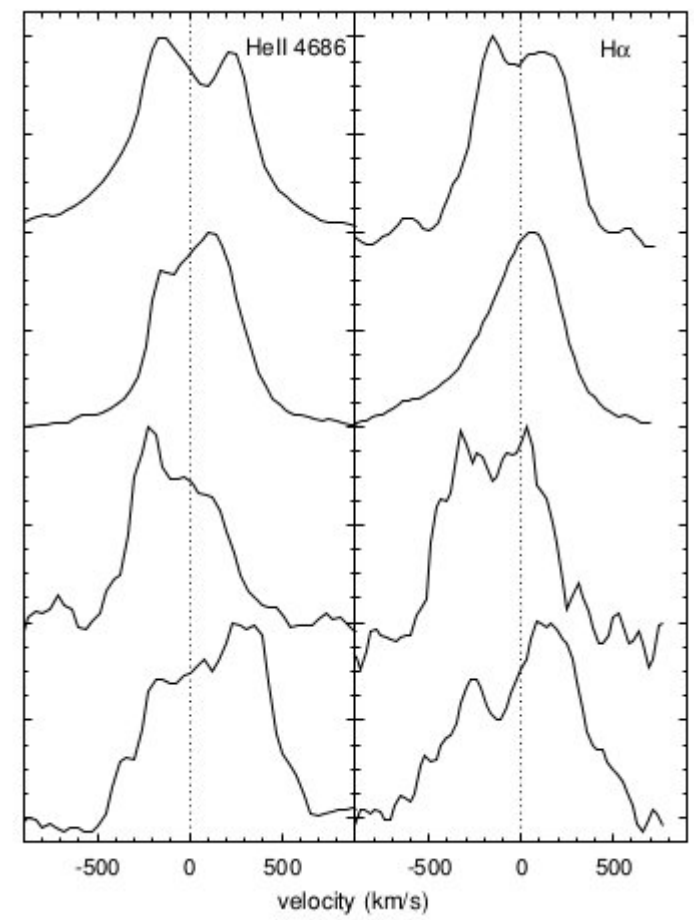

Figura 1.9: Sequência temporal das componentes estreitas de H $\alpha$ e de He II $4686 \AA$ na evolução espectral de U Sco em 2010 (Diaz et al. 2010). É possível observar a variação de velocidade radial em relação à posição da linha no dia 06/02/2010, representado pela linha tracejada.

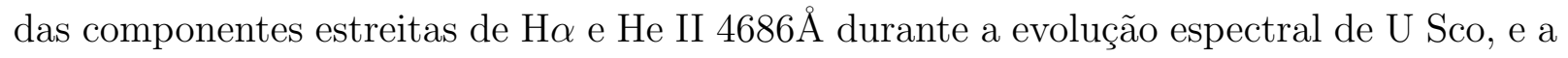
figura 1.10 mostra as modulações de velocidade radial das componentes estreitas das linhas de He II 4686§ em função da fase orbital. Devido à velocidade radial, a fonte de emissão das componentes estreitas deve estar conectada ao sistema orbital. A estrela secundária foi inicialmente sugerida como região responsável por tal emissão por Diaz et al. $(2010)$. Por outro lado, o disco de acreção também foi indicado como possível fonte da emissão por Mason et al. (2012). No entanto, nenhum modelo de fotoionização foi realizado para comprovar se alguma das sugestões estavam corretas.

O intuito deste trabalho é justamente identificar a fonte física responsável pela emissão dessas componentes estreitas transientes, que apareceram no espectro de U Sco e depois foram identificadas em outros objetos. Análises estatísticas e modelos de fotoionização dessas novas são apresentados, junto com uma discussão sobre as possíveis regiões emissoras.

No próximo capítulo serão apresentados os principais catálogos usados como fonte de dados espectrais nesse trabalho. No capítulo 3 serão apresentados os métodos de redução de dados e os códigos de fotoionização utilizados nos modelos. O capítulo 4 mostrará toda a análise estatística feita com as novas que apresentam componentes estreitas transientes, 


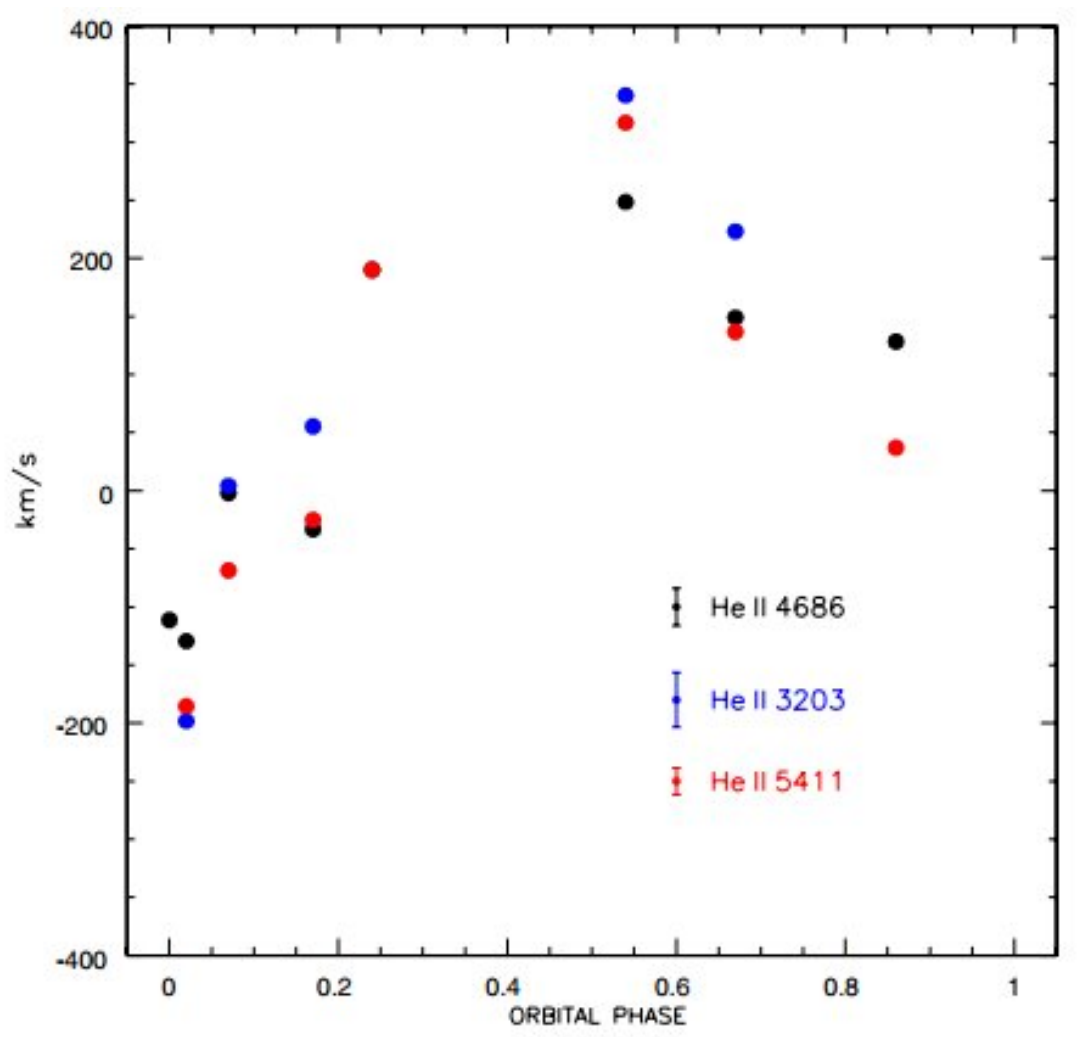

Figura 1.10: Variação de velocidade radial das linhas de He II $4686 \AA$ do espectro de U Sco na erupção de 2010 (Mason et al., 2012). 
a descrição dos modelos, os resultados da pesquisa e uma discussão detalhada sobre as possíveis regiões emissoras da radiação responsável pela formação dessas linhas peculiares. Por fim, o capítulo 5 será um resumo das conclusões do projeto. 
Capítulo 2

\section{Base de dados}

\subsection{Nova Surveys}

Observações de erupção de novas são particularmente complexas devido ao fato de serem eventos rápidos, transientes e imprevisíveis. Para garantir que as novas sejam observadas e acompanhadas durante todas as fases após a erupção, são feitos projetos de observações sinópticas que resultam em catálogos. As principais fontes de dados usadas nesse trabalho foram os catálogos do CTIO Nova Survey (Williams et al., 1991, 1994), do SOAR Telescope Synoptic Survey of Novae e do Stony Brook/SMARTS Atlas of (mostly) Southern Novae (Walter et al., 2012).

O CTIO Nova Survey contém dados espectroscópicos de novas com erupções observadas entre 1987 e 1994. Nesse catálogo foram usados os telescópios de 1 m, 1,5 m e 4 m de abertura, dependendo do brilho da nova observada. Os espectros possuem longa cobertura em comprimento de onda (de $3000 \AA$ a $10.000 \AA$, dependendo do objeto), porém baixa resolução espectral (entre $5 \AA$ e $16 \AA$ ). As novas foram observadas até atingirem magnitude $V \sim 15$, com algumas exceções.

O SOAR Telescope Synoptic Survey of Novae contém observações feitas entre 2007 e 2011, e registrou a evolução espectral de 16 novas. O telescópio do SOAR possui abertura de 4,1 m. As observações foram realizadas com o espectrógrafo Goodman. A cobertura em comprimento de onda é ligeiramente menor do que a do CTIO Nova Survey (de $3500 \AA$ a $9000 \AA$ ), e a resolução espectral em torno de $2 \AA$ a $3 \AA$. As novas deste catálogo foram seguidas até magnitude $V \sim 16$.

O Stony Brook/SMARTS Atlas of (mostly) Southern Novae é um projeto atual, ativo desde 2003. Até o momento, o catálogo possui dados de mais de 60 novas, com extensa 
resolução temporal e resolução espectral que varia entre $0.1 \AA$ e $17.2 \AA$ de acordo com o espectrógrafo usado. Os dados de baixa dispersão foram obtidos com o espectrógrafo RC no telescópio de 1,5 m. Já os dados de alta dispersão foram feitos com o Bench-Mounted Echelle ou o Chiron Echelle. O limite de magnitude das novas observadas nesse catálogo foi $V \sim 18$.

Com os dados desses catálogos foi possível fazer uma busca de objetos que apresentassem componentes estreitas de linhas emissão semelhantes às observadas em U Sco 2010. Como são componentes transientes, são necessários espectros com resolução temporal de dias ou poucas semanas, além de resolução espectral suficiente para distinguir as componentes estreitas das largas. Um dos grandes problemas encontrados nessa pesquisa foi a falta de cobertura temporal, o que pode ter afetado diretamente as análises estatísticas mostradas no capítulo 4 . 
Capítulo 3

\section{Metodologia}

\subsection{Redução de dados espectrofotométricos}

Os dados espectrofotométricos do SOAR Telescope Synoptic Survey of Novae foram reduzidos com o pacote IRAF (Tody, 1986). Foram feitas as calibrações básicas de flatfield e bias, a extração do espectro, a correção de velocidade radial, as calibrações em comprimento de onda e, quando possível, em fluxo.

\subsubsection{Calibração básica}

A calibração básica de um arquivo de espectro é uma série de ajustes feitos para minimizar os ruídos do arranjo instrumental. Inicialmente é removida a contribuição dos pixels quentes da câmera CCD pela subtração dos arquivos de bias. Os arquivos de bias são exposições feitas com a tampa do telescópio fechada, de modo a evitar a contagem de fótons. Dessa maneira, as contagens registradas podem ser consideradas provenientes das cargas do próprio CCD e de eventuais raios cósmicos, e devem ser removidas dos espectros das estrelas e lâmpadas. Antes da observação dos alvos, são feitas dezenas de arquivos de bias. No momento da redução de dados, eles são transformados em um único arquivo, composto por uma média dos fluxos pixel a pixel de todos os arquivos de bias. Para remover o efeito dos raios cósmicos, essa média dos arquivos é filtrada em relação à mediana para desconsiderar contagens altas que são detectadas uma única vez, provenientes de raios cósmicos. Essas operações são feitas usando a rotina combine do pacote NOAO do IRAF.

Para corrigir os efeitos de lentes e espelhos do telescópio, como manchas e irregularidades, e os efeitos de variação da eficiência quântica do detector, são usados os arquivos de flat-field. Estes arquivos são feitos a partir de múltiplas exposições de uma tela branca 
iluminada uniformemente, com todas as combinações de filtros e fendas usadas nas observações dos objetos. Aos arquivos de flat são ajustadas funções de sensibilidade que corrigem as diferenças de fluxos medidos causadas pela presença de poeira e imperfeições nos espelhos e lentes, além da própria variação de sensibilidade da câmera CCD. Usando novamente a rotina combine, esses aquivos são então escalonados de acordo com a moda dos valores dos pixels e, por fim, é feita uma média ponderada. Os arquivos finais são normalizados com a rotina response e multiplicados por todos os arquivos da observação, de acordo com o filtro, a fenda e a proximidade temporal. A aplicação dos arquivos de bias e flat-field é feita com a rotina ccdproc.

Além dessas correções ainda são feitos cortes na imagem original de 2 dimensões, para remover os efeitos de borda e a região de overscan. A região de overscan é composta por algumas fileiras de pixels destinados à uma segunda leitura do CCD sem exposição à luz. Ela é feita no início de cada exposição para registrar o nível eletrônico da observação. O corte no arquivo em 2 dimensões do espectro para extrair a parte útil é feito a partir de uma análise dos arquivos de flat-field. A aplicação dos cortes também é feita usando o ccdproc.

\subsubsection{Extração do espectro}

Após as correções básicas feitas nos arquivos, é necessário extrair o espectro de 1 dimensão para cada arquivo de objeto (alvo e lâmpada). O arquivo original é composto por um eixo espacial e um eixo de dispersão. Para realizar a extração do espectro unidimensional, foi usada a rotina apall do IRAF. Ela usa um algoritmo para identificar as linhas mais intensas no eixo espacial, e seleciona possíveis aberturas correspondentes aos espectros detectados. Ao identificar a abertura correta correspondente ao objeto, é escolhida a região de abertura de acordo com a fenda usada na observação. Para os arquivos de fenda larga, foram escolhidas regiões de abertura maiores, para captar o fluxo total da fonte, independentemente do ruído introduzido. Já no caso dos arquivos de fenda estreita, foram escolhidas regiões menores, de modo a preservar os perfis de linha e minimizar os ruídos introduzidos. Também é definida a região de céu para que o fluxo de fundo seja subtraído do fluxo em cada pixel do arquivo.

No caso dos arquivos de lâmpadas, a extração do espectro é feita na mesma região da abertura do espectro. Diferentemente da extração de espectro de estrelas, a extração do 
espectro de lâmpadas não tem remoção de contribuição do céu, já que as observações são feitas dentro da cúpula.

\subsubsection{Calibração em comprimento de onda}

Para fazer a calibração em comprimento de onda, foi usada uma lâmpada de He e Ar, que possui linhas de emissão fortes e bem conhecidas na região do visível. Usando a tarefa identify, os espectros dos arquivos das lâmpadas foram visualmente comparados com espectros da literatura para associar a posição em pixels com os comprimentos de onda. Em seguida foram ajustadas funções de legendre de ordens baixas que gerassem resíduos de até $R M S=0,03 \AA$. Os ajustes foram aplicados aos arquivos de espectro de estrelas de acordo com a proximidade temporal. Para isso foi usada a rotina refspectra. Para fazer a conversão do eixo de pixels para angstroms foi usada a tarefa dispcor. Os valores da conversão foram confirmados, e reajustados quando necessário, pelas linhas de absorção de água da atmosfera, que não sofrem influências do meio interestelar e são catalogadas em Curcio et al. (1964).

A medição de velocidades radiais nos espectros finais é altamente dependente da qualidade da calibração em comprimento de onda. Pequenas variações de posição das linhas derivadas de ajustes mal feitos podem implicar sérios erros de interpretação do sistema físico observado.

\subsubsection{Calibração em fluxo}

Para a calibração em fluxo, foram utilizados espectros de estrelas padrão, cujos fluxos são conhecidos e catalogados. Para cada espectro observado de estrela padrão, foram ajustadas funções de sensibilidade e extinção atmosférica pelo comprimento de onda. A tarefa standard associa os espectros das estrelas padrão observados aos dados de fluxo catalogados e retira a informação de massa de ar do header do arquivo. Os dados de saída desta etapa são usados pela tarefa sensfunc para determinar a curva de sensibilidade do detector e a extinção. Essas curvas podem ser modificadas de acordo com o tipo de função desejada. No caso dos dados do SOAR Telescope Synoptic Survey of Novae, foram escolhidas funções de Legendre de ordens baixas o suficiente para ajustar o espectro da padrão sem apresentar anomalias nas bordas ou tendências nos resíduos, mas altas o suficiente para produzirem resíduos pequenos, em torno de $R M S=0,03 \AA$. As funções de 
sensibilidade foram aplicadas aos espectros de estrelas com a tarefa calibrate.

A última etapa da calibração em fluxo é a compensação a perda de fluxo dos espectros de fenda estreita a partir dos espectros de fenda larga. Para isso, dividimos o espectro de fenda larga pelo espectro de fenda estreita usando a tarefa imarith. Ao contínuo do espectro dividido foi ajustada uma função de baixa ordem usando o continuum. Tal função foi multiplicada ao espectro de fenda estreita de forma a reajustar os fluxos observados. Tal procedimento foi realizado para cada estrela em cada banda observada. No caso de múltiplos arquivos do mesmo objeto, na mesma banda, com a mesma fenda no mesmo dia de observação, foi usada a tarefa scombine para obter uma média final.

\subsubsection{Correção de velocidade radial}

Ao longo do eixo de comprimento de onda, os dados espectrais apresentam pequenos deslocamentos causados pela velocidade relativa entre o objeto observado e o observador. Para corrigir esses desvios, foi usada a tarefa rvcorrect do IRAF. Com base nos dados geográficos do observatório em que foram feitas as imagens e nas datas de observação, a rotina calcula automaticamente a diferença e a aplica no header do arquivo, retificando as informações do cabeçalho. Os cálculos consideram o movimento de rotação da Terra, o movimento do baricentro Terra-Lua, a translação da Terra e o movimento do Sol em relação ao centro de massa do sistema solar.

\subsubsection{Identificação de linhas}

A identificação das linhas dos espectros foi baseada em espectros característicos de novas disponíveis na literatura. Para o mesmo espectro, principalmente logo após a erupção, os mesmos níveis de ionização eram esperados para diferentes elementos, considerando que o gás com determinadas densidade e temperatura permitisse transições eletrônicas específicas e similares. Para os espectros tardios, a existência de linhas proibidas foi considerada. Além disso, as identificações das linhas foram checadas pela presença de multipletos da mesma transição. Com base nas linhas, também foi feita a classificação de tipo espectral (ver seção 1.2.1) para cada nova observada. 


\subsection{Modelos de fotoionização}

As novas recentes são rodeadas por envelopes de gás difuso, ionizado pelos fótons da estrela primária, gerando a emissão em linhas. O equilíbrio de fotoionização em cada região do gás é determinado pelo equilíbrio entre a ionização e a recombinação de elétrons e íons (Osterbrock e Ferland, 2006). O equilíbrio de fotoionização também determina o equilíbrio térmico, em que há o aumento da temperatura do gás pela fotoionização e a perda de calor pela emissão por recombinação, pela emissão livre-livre e pela excitação colisional dos íons seguida de transições radiativas. O cálculo da radiação emitida pelo gás fotoionizado depende da densidade, das abundâncias químicas do gás e da ionização e da temperatura determinadas pelo campo de radiação. Todos esses fatores são modelados para cada elemento de volume do envelope de gás para simular o espectro emitido.

Os modelos de fotoionização são essenciais para comparar os espectros observados de novas com a previsão teórica dos processos radiativos. Para as simulações de fotoionização deste trabalho, foram utilizados dois códigos: o RAINY3D (Moraes e Diaz, 2011) e o CLOUDY v06.02b (Ferland et al., 2013). O primeiro foi usado para definir a configuração física do modelo, a geometria e a distribuição de densidade de massa no envelope das novas simuladas. Já o segundo, usado como uma subrotina, calcula a microfísica dos processos radiativos em uma dimensão.

\subsubsection{Cloudy}

O CLOUDY foi criado na década de 70, por um grupo liderado por Gary J. Ferland. Inicialmente, o código foi escrito em Fortran 77, mas após alguns anos foi atualizado e reescrito em C. As versões mais atuais utilizam a linguagem $\mathrm{C}++$. Ele é um código aberto, que recebeu contribuições de diversos pesquisadores e hoje possui cerca de $2,1 \times 10^{5}$ linhas. O CLOUDY é extensivamente usado para modelar nebulosas planetárias (por exemplo García-Hernández et al. (2012)), nuvens do meio interestelar (por exemplo Cooksey et al. (2008)), galáxias HII (exemplo (Martín-Manjón et al., 2008)), gás circumnuclear de galáxias Seyfert (exemplo (Massaro et al., 2006)) e envelopes de variáveis cataclísmicas (exemplo (Schwarz, 2002)), dentre outros objetos.

O CLOUDY é um código que simula as condições físicas fora do equilíbrio em um gás ionizado e prevê seu espectro. Ele faz o cálculo de como o gás de uma nuvem se comporta 
na presença de uma fonte ionizante e qual a radiação resultante da interação. O código considera os equilíbrios térmico e estatístico, equações que balanceiam os processos de ionização e neutralização e os processos de aquecimento e resfriamento. As populações relevantes são todas calculadas em regime NLTE.

Os parâmetros de entrada no código caracterizam a fonte central e a nuvem. É necessário determinar a luminosidade, a temperatura efetiva, a gravidade superficial e o modelo da atmosfera para a fonte central. Para a nuvem, os dados requisitados são dimensão (raio interno e externo) e densidade de hidrogênio. Demais parâmetros podem ser utilizados para melhor restringir as condições físicas do modelo. Dados os parâmetros iniciais, o CLOUDY simula a interação entre matéria e radiação em várias camadas em uma única dimensão, calculando os processos radiativos necessários para as condições locais. Como resultado, é possível prever os fluxos emitidos de determinados elementos, além de valores de temperatura eletrônica da nuvem, sua massa e outros parâmetros.

\subsubsection{RAINY3D}

O código RAINY3D é responsável pela estruturação do modelo de envelope de novas. É conhecido o fato de que os envelopes de novas apresentam distribuições complexas de densidades. Por isso, para simulações mais precisas, é necessária a utilização de distribuições complexas de densidades também. No RAINY3D é possível determinar intervalos para os valores de fração de massa e raio do envelope usados no modelo. Com base nesses parâmetros, o código transpõe os cálculos de fotoionização em uma dimensão, feitos pelo CLOUDY com as distribuições do RAINY3D, para três dimensões. O fato de o código não calcular a interação de matéria e radiação nas componentes tangenciais o torna um "pseudo-3D". Vale ressaltar que até o momento não existem códigos de fotoionização em $3 \mathrm{D}$ completos.

O RAINY3D também permite comparações entre fluxos de linhas no espectro observado e os fluxos calculados após a integração dos resultados do CLOUDY. Assim é possível utilizar intervalos dos parâmetros de entrada ao invés de valores absolutos e ajustar a melhor configuração deles aos dados observados. Tal análise é feita por um ajuste de Método dos Mínimos Quadrados (MMQ) ponderado e relativo entre os resultados de todas as combinações dos parâmetros de entrada e os fluxos das linhas observados. 
Capítulo 4

\section{Resultados e discussão}

\subsection{A busca por componentes estreitas transientes em espectros de novas}

A busca por novas que apresentassem componentes estreitas semelhantes às observadas em U Sco 2010 (Diaz et al., 2010; Mason et al., 2012) foi feita nos catálogos descritos no capitulo 2 e em espectros de publicações avulsas. Nos espectros foram procuradas componentes estreitas, com $500<\mathrm{FWHM}<1000 \mathrm{~km} / \mathrm{s}$, sobrepostas às componentes largas durante o intervalo de tempo após a erupção $1<\Delta t<5 t_{3}$. Também foram buscadas modulações de velocidade radial, como as encontradas em U Sco (2010), apesar da dificuldade em obter uma série temporal de alta resolução espectral para os objetos estudados. Para as medições de velocidade relativa, foram usadas as linhas de Na I D do meio interestelar como referência de comprimento de onda.

\subsection{Análise estatística}

Foram analisadas as evoluções espectrais de 78 novas, cujos dados estão dispostos na tabela 4.1. Para 21 novas, a falta de uma cobertura temporal da evolução espectral impossibilitou a identificação das componentes estreitas, de modo que elas não podem ser consideradas candidatas a apresentar tal característica, e tampouco excluídas da análise. Das 57 novas restantes, em que havia cobertura temporal necessária da evolução espectral, apenas 11 novas se mostraram candidatas a apresentar as mesmas componentes de U Sco (além da própria U Sco): as novas recorrentes V394 CrA, Nova LMC 1990-2, Nova LMC 2009, YY Dor; e as clássicas Nova LMC 1988-2, Nova Oph 2009, DE Cir, V444 Sct, KT Eri, Nova Sco 2007 e Nova Sco 2011b. Nesse caso, KT Eri foi considerada uma nova clássica apesar da suspeita de ela ser recorrente (Jurdana-Šepić et al., 2012). As evoluções 
espectrais das novas candidatas estão dispostas no anexo.

Do ponto de vista estatístico, as novas recorrentes se mostraram mais propícias do que as clássicas a apresentar as componentes estreitas transientes no espectro. São 5 novas recorrentes com as componentes identificadas, correspondente a $56 \%$ da amostra de espectros de 9 objetos da classe. Para as clássicas, foram 7 de 48 objetos que mostraram as componentes estreitas, ou seja, cerca de $15 \%$ da amostra.

Tabela 4.1 - Propriedades básicas das novas pesquisadas.

\begin{tabular}{ccccccccc}
\hline \hline Nova & Type & Observed & $V_{\text {max }}$ & $t_{2}$ & $t_{3}$ & $P_{\text {orb }}$ & Presence of & Measured radial \\
& & eclipses & & (d) & (d) & (h) & narrow components & velocity
\end{tabular}

\begin{tabular}{|c|c|c|c|c|c|c|c|c|}
\hline N Aql 2005 (V1663 Aql) & $\mathrm{C}$ & no & & & 64 & & no & no \\
\hline N Car 2008 (V679 Car) & $\mathrm{C}$ & no & & & 127 & & no & no \\
\hline N Car 2009 & $\mathrm{C}$ & no & & & & & no & no \\
\hline N Cen 2007 (V1065 Cen) & $\mathrm{C}$ & no & & & 361 & & no & no \\
\hline N Cen 2009 (V1213 Cen) & $\mathrm{C}$ & no & & & 300 & & no & no \\
\hline N Cen 2012a & $\mathrm{C}$ & no & & 16 & 34 & & no & no \\
\hline N Cen $2012 b$ & $\mathrm{C}$ & no & & 12.3 & 19.8 & & no & no \\
\hline V868 Cen & $\mathrm{C}$ & no & 10.2 & 55 & & & no & no \\
\hline N Cir 2003 (DE Cir) & $\mathrm{C}$ & no & & & 10 & & yes & no \\
\hline V394 CrA & $\mathrm{R}$ & yes & 7.2 & & 5.5 & 36.48 & yes & no \\
\hline KT Eri & $\mathrm{C}$ & no & 5.4 & 6.2 & 14.3 & 17688 & yes & no \\
\hline V838 Her & $\mathrm{C}$ & no & 5.4 & 2 & 5 & 7.14384 & no & no \\
\hline N LMC 1937 (YY Dor) & $\mathrm{R}$ & no & & 4 & 10.9 & & yes & no \\
\hline N LMC 1988b & $\mathrm{C}$ & no & 10.5 & 5 & 10 & & yes & no \\
\hline N LMC 1990b & $\mathrm{R}$ & no & 10.9 & & 5.5 & 12240 & yes & no \\
\hline N LMC 1991 & $\mathrm{C}$ & no & & 5 & 8 & & no & no \\
\hline N LMC 2005 & $\mathrm{C}$ & no & & & & & no & no \\
\hline N LMC 2009 (N LMC 1971b) & $\mathrm{R}$ & no & 13 & & & 28.56 & yes & no \\
\hline N LMC 2009b & $\mathrm{C}$ & no & & & & & no & no \\
\hline N LMC 2012 & $\mathrm{C}$ & no & & 1.1 & 2.1 & & no & no \\
\hline N Mus 2008 (QY Mus) & $\mathrm{C}$ & no & & & & & no & no \\
\hline N Nor 2005 (V382 Nor) & $\mathrm{C}$ & no & & & & & no & no \\
\hline N Nor 2007 (V390 Nor) & $\mathrm{C}$ & no & & & & & no & no \\
\hline N Oph 1898 (RS Oph) & $\mathrm{R}$ & no & 6.5 & & 10 & 10937 & no & no \\
\hline N Oph 2004 (V2574 Oph) & $\mathrm{C}$ & no & & & & & no & no \\
\hline N Oph 2006b (V2576 Oph) & $\mathrm{C}$ & no & & & & & no & no \\
\hline N Oph 2007 (V2615 Oph) & $\mathrm{C}$ & no & & & 75 & & no & no \\
\hline N Oph 2008 (V2670 Oph) & $\mathrm{C}$ & no & & & & & no & no \\
\hline N Oph 2008b (V2671 Oph) & $\mathrm{C}$ & no & & & & & no & no \\
\hline N Oph 2009 (V2672 Oph) & $\mathrm{C}$ & no & & 2.3 & 4.2 & & yes & no \\
\hline N Oph 2012 & $\mathrm{C}$ & no & & & & & no & no \\
\hline
\end{tabular}

Continua na próxima página... 
Tabela 4.1 - Continuação

\begin{tabular}{|c|c|c|c|c|c|c|c|c|}
\hline Nova & Type & $\begin{array}{l}\text { Observed } \\
\text { eclipses }\end{array}$ & $V_{\max }$ & $\begin{array}{l}t_{2} \\
(\mathrm{~d})\end{array}$ & $\begin{array}{l}t_{3} \\
(\mathrm{~d})\end{array}$ & $\begin{array}{c}P_{o r b} \\
(\mathrm{~h})\end{array}$ & $\begin{array}{c}\text { Presence of } \\
\text { narrow components }\end{array}$ & $\begin{array}{c}\text { Measured radial } \\
\text { velocity }\end{array}$ \\
\hline N Oph 2012b & $\mathrm{C}$ & no & & & & & no & no \\
\hline V2214 Oph & $\mathrm{C}$ & no & 8.5 & 56 & 92 & 2.82036 & no & no \\
\hline V2264 Oph & $\mathrm{C}$ & no & 9.9 & 19 & 45 & & no & no \\
\hline N Pup 2004 (V574 Pup) & $\mathrm{C}$ & no & & 13 & $<27$ & & no & no \\
\hline V351 Pup & $\mathrm{C}$ & no & 6.4 & 10 & 26 & & no & no \\
\hline V597 Pup & $\mathrm{C}$ & no & & & & & no & no \\
\hline V598 Pup & $\mathrm{C}$ & no & & & & & no & no \\
\hline T Pyx & $\mathrm{R}$ & no & 6.5 & & 88 & 1.829 & no & no \\
\hline N Sco 2004b (V1187 Sco) & $\mathrm{C}$ & no & & & & & no & no \\
\hline N Sco 2005 & $\mathrm{C}$ & no & & & & & no & no \\
\hline N Sco 2007 (V1280 Sco) & $\mathrm{C}$ & no & & & 34 & & yes & yes \\
\hline N Sco 2008 (V1309 Sco) & $\mathrm{C}$ & no & & & & & no & no \\
\hline N Sco 2011b (V1313 Sco) & $\mathrm{C}$ & no & & $5.8-8.5$ & $13-18$ & & yes & no \\
\hline U Sco & $\mathrm{R}$ & yes & 8 & & 7 & 29.53 & yes & yes \\
\hline V745 Sco & $\mathrm{R}$ & no & 18.6 & & 14.9 & 12240 & no & no \\
\hline V977 Sco & $\mathrm{C}$ & no & 9.4 & 3 & 8 & & no & no \\
\hline V443 Sct & $\mathrm{C}$ & no & 8.5 & 19 & 28 & & no & no \\
\hline V444 Sct & $\mathrm{C}$ & no & 10.5 & 6 & 10 & & yes & no \\
\hline N Sgr 2002c (V4743 Sgr) & $\mathrm{C}$ & no & 5 & & & 6.7 & no & no \\
\hline N Sgr 2006 (V5117 Sgr) & $\mathrm{C}$ & no & & & & & no & no \\
\hline V3890 Sgr & $\mathrm{R}$ & no & 8.4 & & 17 & 29.52 & no & no \\
\hline V4157 Sgr & $\mathrm{C}$ & no & 7 & 10 & 22 & & no & no \\
\hline V4160 Sgr & $\mathrm{C}$ & no & 7 & 6 & 14 & & no & no \\
\hline N TrA $2008(\mathrm{NR} \operatorname{Tr} \mathrm{A})$ & $\mathrm{C}$ & yes & 8.5 & & & 5.25 & no & no \\
\hline CSS081007:030559+0547 & $\mathrm{C}$ & no & & & & & no & no \\
\hline XMMU J115113.3-623730 & $\mathrm{C}$ & no & & & & 8.6 & no & no \\
\hline
\end{tabular}

Referências: Ritter Cataclysmic Binaries Catalog, ed. 7.19 (Ritter e Kolb, 2003); Stony Brook/SMARTS Atlas of (mostly) Southern Novae (Walter et al., 2012); CTIO Nova Survey (Williams et al., 1991, 1994)

A figura 4.1 mostra as linhas de emissão na região de $\mathrm{H} \alpha$ para as novas que apresentam componentes estreitas transientes. A velocidade sistêmica foi removida das linhas com o intuito de facilitar a comparação das velocidades das componentes. Os dados espectrais da nova KT Eri foram publicados apenas em formato gráfico, de modo que não foi possível incluir a nova na comparação. Os dados da Nova LMC 2009 usados para classifica-la como candidata a apresentar componentes estreitas transientes não são os mesmos da figura 4.1. Na figura foram usados os dados do SOAR, que foram observados no momento em 


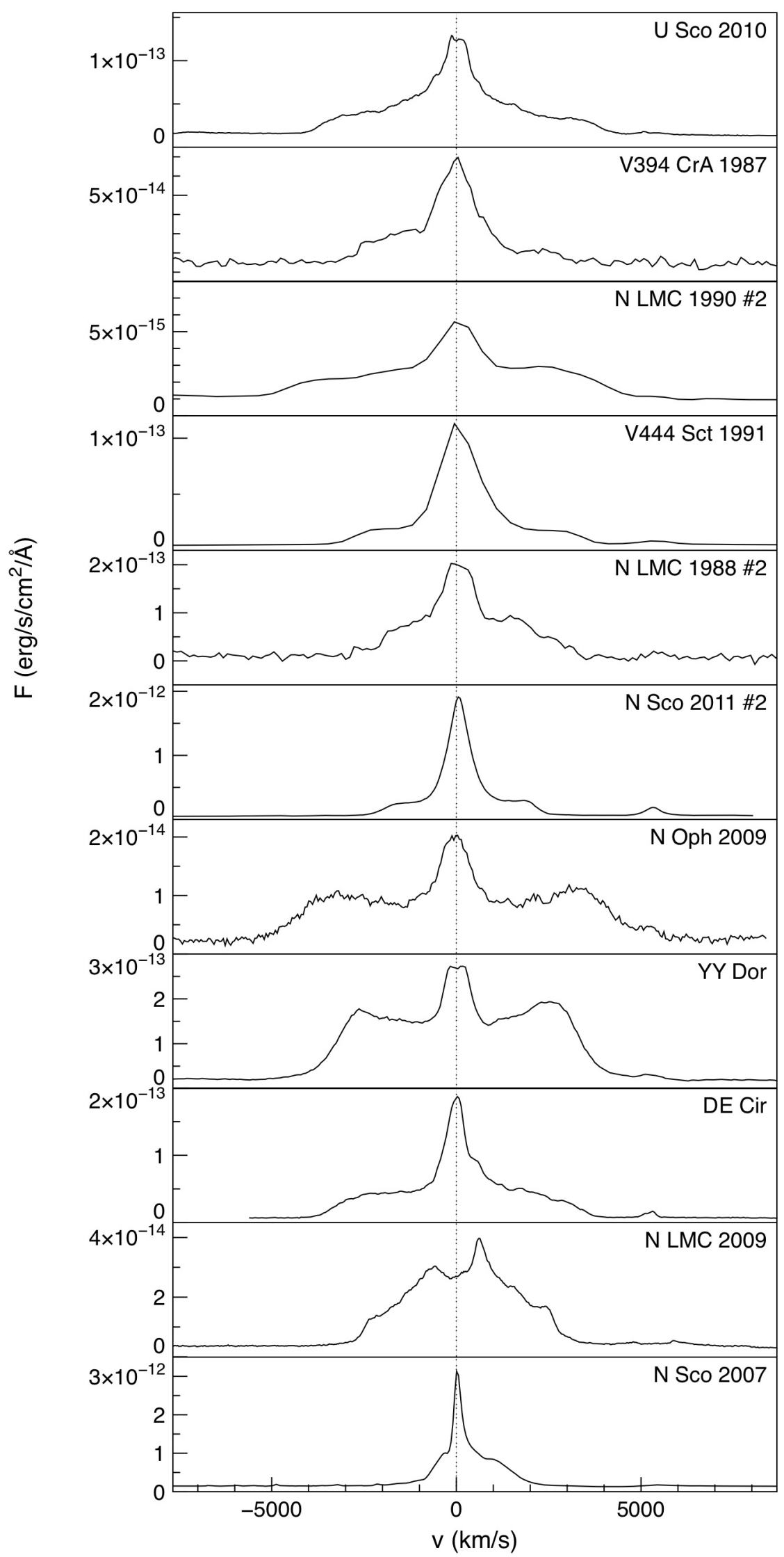

Figura 4.1: Espectros na região de $\mathrm{H} \alpha$ para as novas que apresentam componentes estreitas transientes (com exceção de KT Eri, que não possui dados públicos disponíveis), dos bancos de dados do CTIO Nova Survey, Stony Brook/SMARTS Atlas e do SOAR Telescope Synoptic Survey of Novae. As velocidades sistêmicas foram removidas para facilitar a comparação das larguras das linhas. 


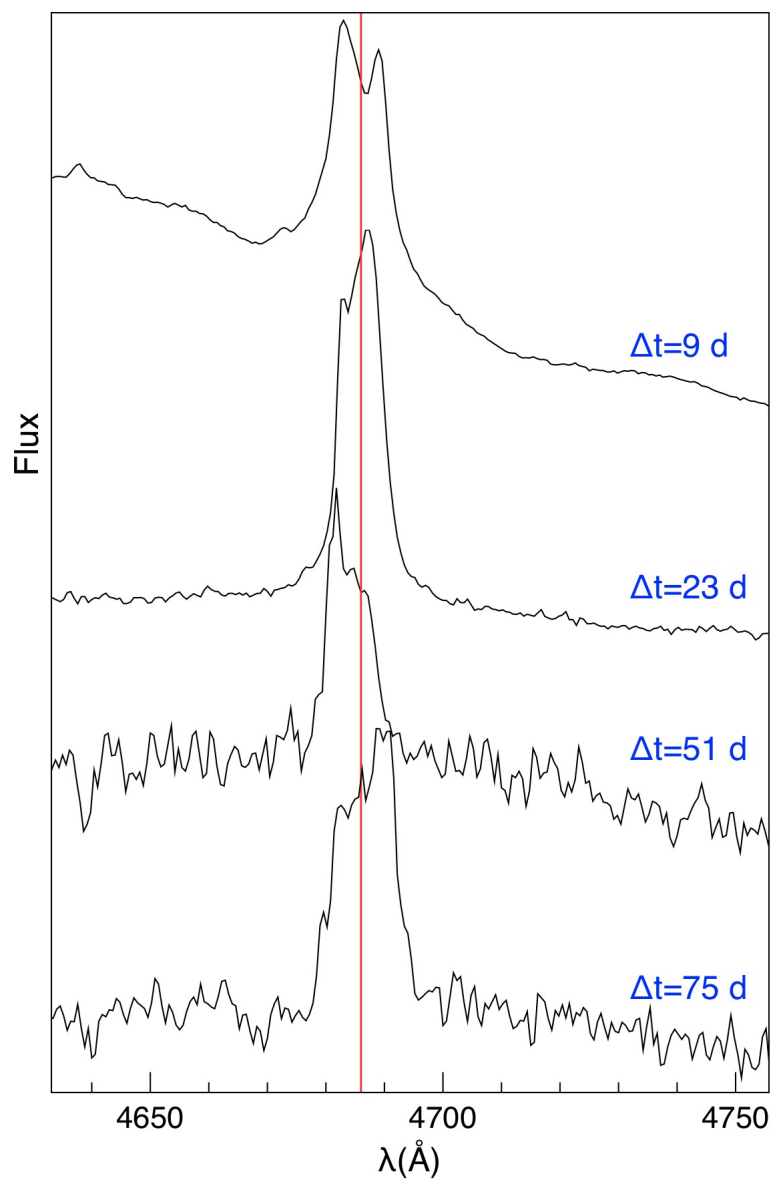

Figura 4.2: Evolução espectral da linha de He II 4686Å de U Sco na erupção de 2010 feita com os dados do SOAR. A linha vermelha indica o comprimento de onda $4686 \AA$, mostrando a variação de posição das componentes estreitas.

que as componentes estreitas se misturam com as largas. No anexo está o espectro de forma gráfica que foi usado para a classificação, que mostra mais semelhanças com as outras candidatas. Na figura 4.1 também é possível observar que, apesar das diferenças de largura das componentes largas, as componentes estreitas são extremamente similares. No caso de Nova Sco 2007, observa-se que tanto a componente larga quanto a estreita apresentam valores menores de velocidade do que as outras novas.

Dentre as novas candidatas, foi possível medir modulações de velocidade nas componentes estreitas apenas em U Sco (2010) e Nova Sco 2007 (ver figuras 4.2 e 4.3). Além das limitações instrumentais, é provável que a inclinação orbital contribua para a não detecção da velocidade das componentes estreitas, uma vez que ela não ocorre para sistemas com altas inclinações (próximas a $0^{\circ}$ ).

Para as novas que exibem componentes estreitas, foram medidos os fluxos das compo- 


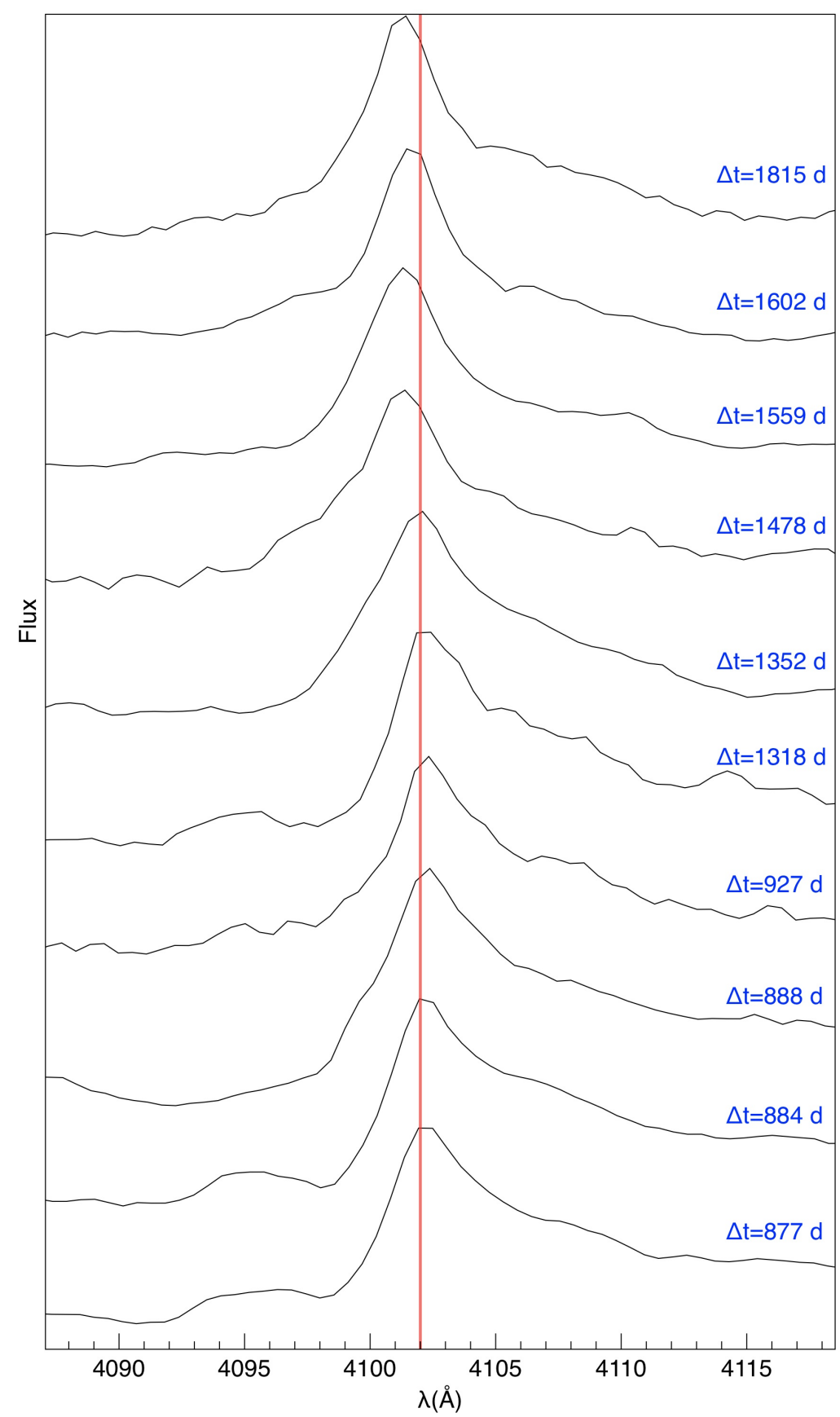

Figura 4.3: Evolução espectral da linha de $\mathrm{H} \delta$ com espectros de alta resolução do Stoony Brook/SMARTS Nova Atlas. A linha vermelha indica o comprimento de onda $4102 \AA$, mostrando a variação de posição das componentes estreitas. 


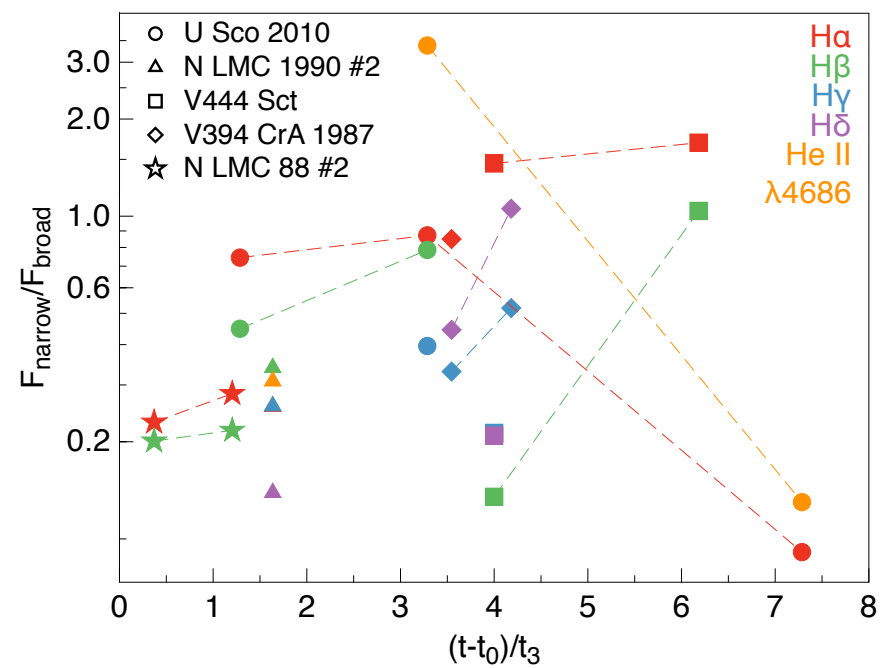

Figura 4.4: Razão entre o fluxo das componentes estreitas e o fluxo total das linhas em função do tempo normalizado por $t_{3}$.

nentes largas e estreitas a fim de identificar alguma relação entre eles em função do tempo. O resultado está disposto na figura 4.4. Como é possível observar na figura, para cada objeto foram obtidos diferentes valores de fluxos relativos, e os valores de fluxo das componentes estreitas variam de $0,1 F_{\text {broad }}$ até $3,5 F_{\text {broad }}$. Valores mais baixos para a razão de fluxos podem existir em espectros de novas, mas seriam dificilmente detectados. A falta de uma relação visível entre a razão dos fluxos em função do tempo favorece a interpretação de que a fonte emissora das componentes larga e estreitas pode não ser a mesma.

\subsubsection{Comparação com propriedades básicas das novas}

Nós buscamos possíveis correlações entre a presença das componentes estreitas transientes no espectro de novas com suas propriedades básicas: tempo de decaimento $\left(t_{2}, t_{3}\right.$, tabela 4.2), velocidade de expansão do envelope, magnitude visual no máximo, amplitude da erupção e período orbital. De todos esses parâmetros, a única relação relevante encontrada foi com o tempo de decaimento. Dentre as 12 novas que apresentam componentes estreitas transientes, 11 são rápidas ou muito rápidas, em contraste a 1 única lenta (Nova Sco 2007). O resultado indica que as novas mais rápidas têm maior propensão a apresentar as componentes estreitas. Os histogramas da figura 4.5 mostram a distribuição de $t_{3}$ e amplitude para as novas com componentes estreitas. Como comparação, no mesmo histograma estão dispostas as distribuições para todas as novas e as 78 novas com espectros 
analisados.

Tabela 4.2 - Classificação de novas de acordo com o tempo de decaimento utilizada. (PayneGaposchkin, 1964)

\begin{tabular}{lc}
\hline \hline Classificação de velocidade & Definição \\
\hline Very fast & $t_{2}<10(d)$ \\
Fast & $11<t_{2}<25(d)$ \\
Moderately fast & $26<t_{2}<80(d)$ \\
Slow & $81<t_{2}<150(d)$ \\
Very slow & $151<t_{2}<250(d)$ \\
& \\
\hline
\end{tabular}

Além dessas comparações, as curvas de luz das novas também foram analisadas. Para as novas que apresentam componentes estreitas transientes, não há nenhuma característica destoante nas curvas de luz no período de surgimento destas componentes. A figura 4.6 mostra o exemplo de U Sco (2010), que indica as datas da presença das componentes estreitas na curva de luz. As componentes estreitas aparecem durante o decaimento inicial, a fase de transição e o declínio final, que são momentos que correspondem a diferentes temperaturas, densidades e níveis de ionização do gás do envelope.

Por fim, nós tentamos relacionar a presença das componentes estreitas transientes com o tipo espectral da nova (ver Introdução). Das 12 novas que apresentam tais componentes, 9 são do tipo "He/N", 2 do tipo "Fe IIb" (Nova LMC 1988-2 e V444 Sct), e apenas 1 do tipo "Fe II" (Nova Sco 2007). Apesar do nome, a classe "Fe IIb" está mais relacionada à classe "He/N" do que à "Fe II" , pois a formação do espectro e sua evolução são semelhantes (Williams et al., 1991). Portanto, consideramos que as novas do tipo "He/N" estão mais propensas a apresentarem componentes estreitas do que as do tipo "Fe II". O caso de Nova Sco 2007 será discutido adiante, com uma breve análise comparativa entre as características de suas componentes estreitas e as de U Sco (2010).

\subsubsection{Testes de compatibilidade}

Para checar a compatibilidade entre as distribuições das novas que apresentam componentes estreitas transientes e outros subgrupos de novas, foram usados testes Kolmogorov- 

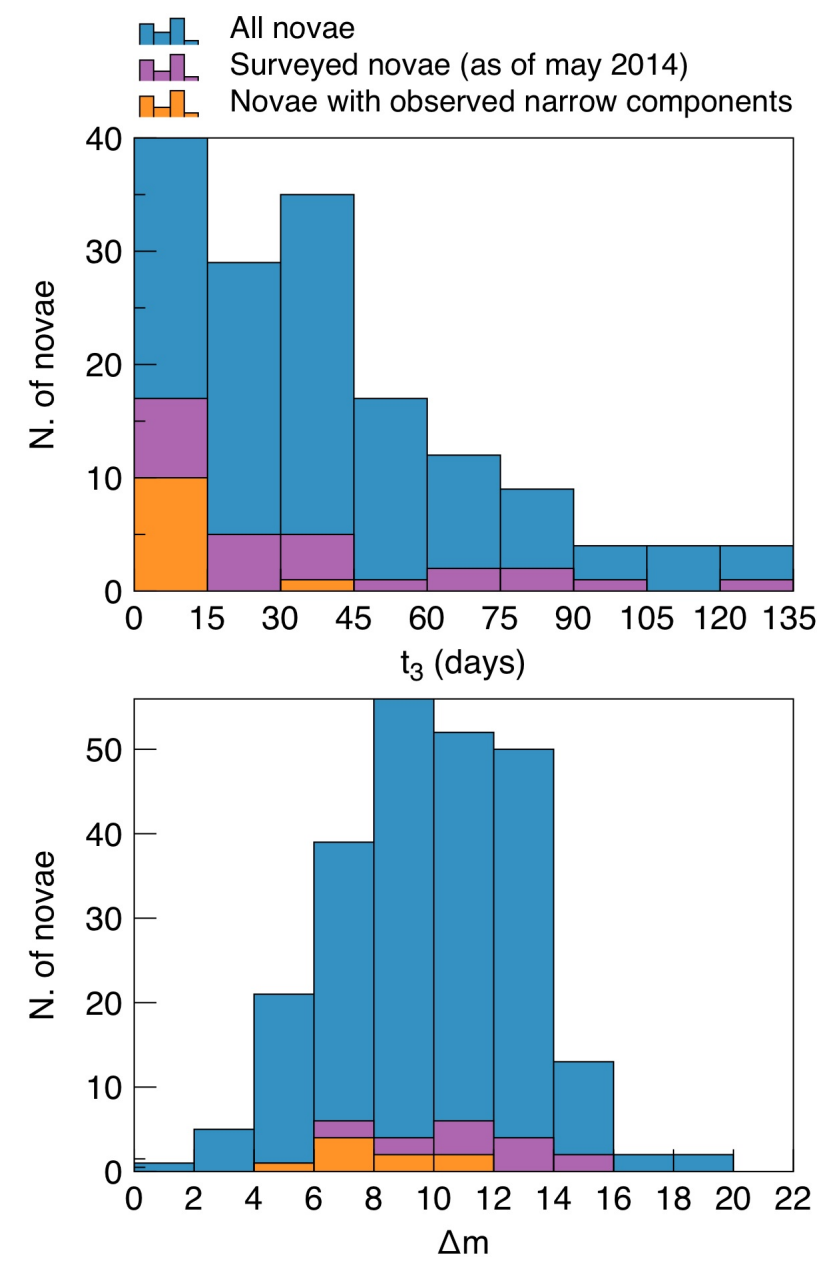

Figura 4.5: Distribuição de tempo de decaimento e distribuição de amplitude para as novas que apresentam componentes estreitas transientes, em contraste com as novas com espectros disponíveis na literatura e com as distribuições de todas as novas. 


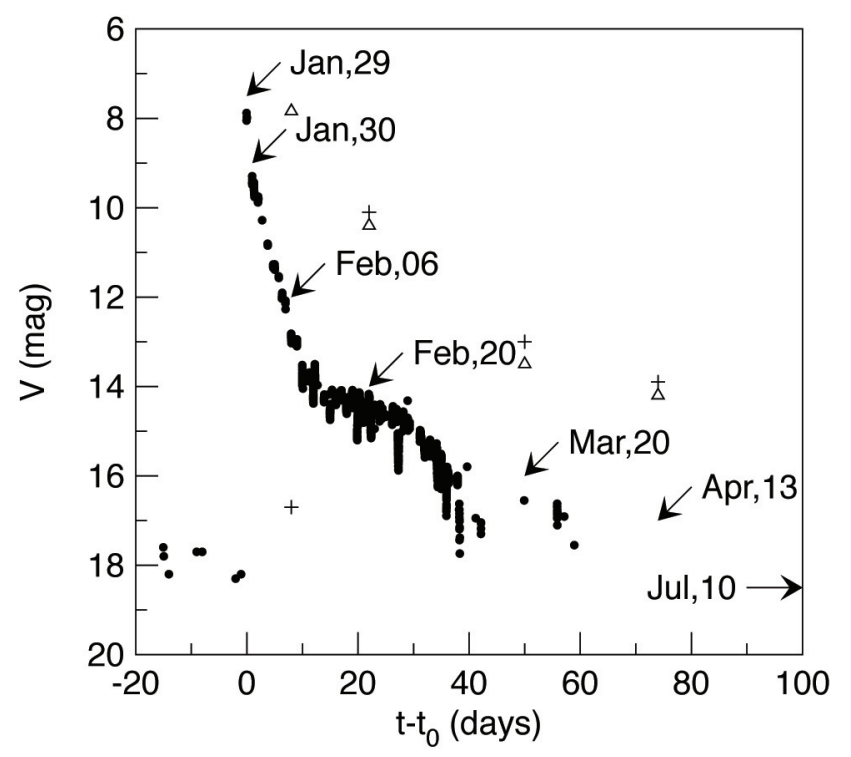

Figura 4.6: Curva de luz de U Sco (2010) na banda V, de acordo com os dados do AAVSO. Nas datas marcadas de 06/02/2010 a 20/03/2010, o espectro mostrou componentes estreitas (Diaz et al., 2010).

Smirnov. O teste K-S compara duas distribuições e calcula a probabilidade de elas pertencerem à mesma população. No caso, comparamos as distribuições de amplitude e de $t_{3}$ para as novas recorrentes e as novas que apresentam componentes estreitas transientes. Como resultado, obtivemos uma compatibilidade de $50 \%$ para o teste de amplitude e $84 \%$ para o de $t_{3}$.

Os mesmos testes foram aplicados às distribuições de todas as novas e às distribuições das novas que apresentam componentes estreitas transientes. Para o caso da amplitude, as distribuições não são compatíveis, pois a probabilidade de elas pertencerem ao mesmo grupo é de apenas 10\%. Da mesma maneira, as distribuições de tempo de decaimento também têm baixa probabilidade de serem compatíveis, com $P=5,1 \%$.

Apesar de as amostras de novas recorrentes e novas que apresentam as componentes estreitas serem pequenas, é possível observar a tendência das componentes estreitas a aparecerem em novas rápidas ou muito rápidas.

\subsubsection{Nova Sco 2007}

A Nova Sco 2007 é uma nova clássica lenta e caracterizada pela intensa formação de poeira. Sua erupção foi acompanhada pelo Stony Brook/SMARTS Atlas de 2007 a 2012. Apesar de sua curva de luz ter sido registrada com extensa cobertura temporal, as oscilações 
de brilho devido à própria poeira impossibilitam a determinação do tempo de decaimento de 2 ou 3 magnitudes (Naito et al., 2012b). A massa de sua estrela primária é estimada em $M_{W D} \sim 0,6 M_{\odot}$, assumindo que o halt pré-máximo da curva de luz é determinado pela luminosidade de Eddington. Tal valor de massa da primária é compatível com a evolução extremamente lenta da nova. A baixa velocidade da nova também afetou o início da fase nebular, que demorou cerca de 50 meses após a erupção. A nova também apresentou uma duração atípica do vento, que durou mais de 1500 dias.

Devido a todas as peculiaridades da Nova Sco 2007, ao fato de suas componentes de emissão serem mais estreitas do que as outras novas que apresentam componentes estreitas transientes, sendo a única nova do tipo "Fe II" e a única lenta na análise estatística, é possível que o fenômeno responsável pela formação de componentes estreitas não seja exatamente o mesmo que ocorre em U Sco. Além disso, as componentes estreitas e largas das linhas de emissão apresentam uma tendência a serem mais largas na direção do vermelho, o que não ocorre para as outras novas candidatas e pode ser resultado de uma distribuição não homogênea de poeira.

\subsection{Simulações de fotoionização}

Os modelos de fotoionização foram divididos em duas partes. A primeira, que utiliza a configuração de geometria fechada (figura 4.7), foi usada para modelar o gás presente no lóbulo de Roche da primária. A segunda, que utiliza uma configuração de geometria aberta, foi usada para modelar uma região em torno do ponto externo de Lagrange $L_{3}$. Os detalhes das simulações, suas justificativas e resultados se encontram nos próximos tópicos.

\subsubsection{Geometria fechada}

Para identificar a fonte física responsável pela emissão das componentes estreitas observadas, nós modelamos 3 novas usando o código de fotoionização RAINY3D (Moraes e Diaz, 2011), que usa o código CLOUDY v06.02b (Ferland et al., 2013) como subrotina. O intuito das simulações foi verificar se os fluxos observados das componentes estreitas poderiam ser produzidos pelo gás dentro do lóbulo de Roche da primária. Tal análise restringe as regiões candidatas a emitirem a radiação responsável pela formação das linhas estreitas transientes. O lóbulo de Roche da primária foi escolhido como limite porque seu volume 


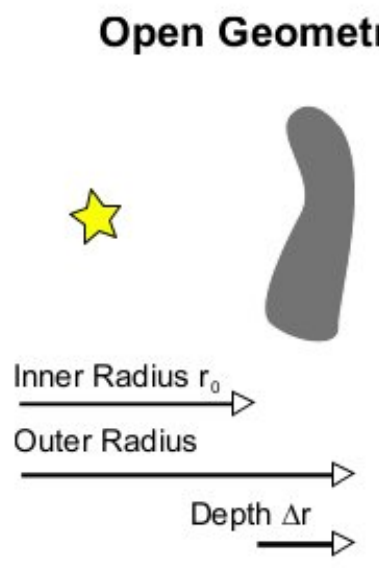

\section{Closed Geometry}

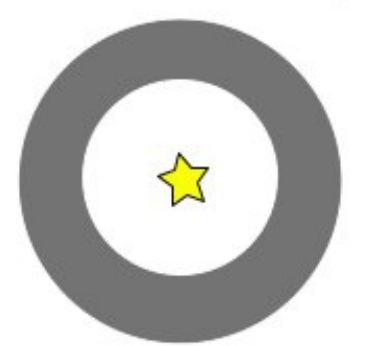

Figura 4.7: Esquema ilustrativo da diferença entre os modelos de geometria aberta e fechada do CLOUDY (Ferland, 2006).

é maior do que a cromosfera da secundária e a atmosfera do disco de acreção. Ao mesmo tempo, o fluxos das linhas estreitas transientes são relativamente altos e, portanto, devem ser geradas dentro de um volume relativamente grande (Rybicki e Lightman, 1979).

Foram feitos modelos das novas U Sco na erupção de 2010, V394 CrA em 1987 e KT Eri em 2009. Para todas as simulações, nós assumimos uma nuvem esférica com gás homogêneo completamente preenchido (filling factor $=1$ ) como região emissora, visando maximizar a emissividade do gás. Nós estimamos os valores dos raios dos lóbulos de Roche por meio da aproximação de Eggleton descrita na Introdução, calculados a partir dos valores de períodos orbitais das novas. Nós também estimamos os valores para as primárias com base em modelos de curvas de luz publicados. As devidas fontes são mostradas com as descrições dos modelos a seguir.

A geometria fechada foi usada para simular o caso da fonte ionizante estar no centro da região emissora, permitindo que a radiação do gás na direção da fonte central pudesse interagir com o gás do lado oposto. Os próximos itens apresentam uma breve compilação de informações importantes das novas modeladas e da escolha de parâmetros usados nas simulações. A tabela 4.3 mostra todos os parâmetros de entrada utilizados tanto nas simulações do gás dentro do lóbulo de Roche da primária, quanto nas simulações da região em torno de $L_{3}$. 
Tabela 4.3 - Valores de entrada dos modelos

\begin{tabular}{lcccccccc}
\hline \hline Nova & $q=\frac{M_{2}}{M_{1}}$ & $\begin{array}{c}T_{\text {eff }} \\
\left(10^{3} \mathrm{~K}\right)\end{array}$ & $\begin{array}{c}L_{\star} \\
\left(\mathrm{ergs}^{-1}\right)\end{array}$ & $\begin{array}{c}\log (g) \\
\mathrm{cms}^{-2}\end{array}$ & $\begin{array}{c}\log \left(r_{\text {inn }}\right) \\
(\mathrm{cm})\end{array}$ & $\begin{array}{c}\log \left(r_{\text {out }}\right) \\
(\mathrm{cm})\end{array}$ & $\begin{array}{c}\mathrm{E}(\mathrm{B}-\mathrm{V}) \\
\mathrm{d}\end{array}$ & $\begin{array}{c}\mathrm{d} \\
(\mathrm{kpc})\end{array}$ \\
\hline U Sco (cg) & & & & & & & \\
${\text { U Sco }(\mathrm{og})^{1}}^{1}$ & $0,5-1,0$ & 84 & 36,3 & 7,5 & 10,58 & 11,28 & 0,15 & 7,5 \\
V394 CrA $^{2}$ & $0,5-1,0$ & $100-150$ & $36,0-38,0$ & 7,5 & 10,44 & 11,14 & 1,10 & 4,2 \\
KT Eri $^{3}$ & $0,5-1,0$ & $100-150$ & $36,0-38,0$ & 7,5 & 11,57 & 12,27 & 0,08 & 7,0
\end{tabular}

Notas. Os parâmetros de U Sco (cg) correspondem aos valores usados nas simulação de geometria fechada, e os de U Sco (og) nas simulações de geometria aberta.

Referências. (1) Hachisu et al. (2000); (2) Hachisu e Kato (2000); (3) Imamura e Tanabe (2012).

\subsubsection{V394 CrA}

V394 CrA é uma nova recorrente, com duas erupções observadas, em 1949 e 1987. É uma nova muito rápida, com $t_{3} \sim 5,5(d)$. Apesar de ser uma nova recorrente, a amplitude de sua erupção em 1987 é comparável às amplitudes de novas clássicas, $\Delta V \sim 11$ (Sekiguchi et al., 1989). Tanto a curva de luz de V394 CrA quanto sua evolução espectral são extremamente similares às de U Sco.

Para o caso de V394 CrA 1987, foram usados os dados espectrais do CTIO Nova Survey do dia 28 após o máximo da erupção. Para realizar o desavermelhamento, foi utilizado o valor de extinção $\mathrm{E}(\mathrm{B}-\mathrm{V})=1,10$ (Hachisu e Kato, 2000). A luminosidade da fonte central foi limitada ao intervalo de valores típicos para novas $36<\log (L)<38 \mathrm{erg} / \mathrm{s}$, uma vez que não há observações em raios-X na literatura para uma determinação mais precisa. Os fluxos dos modelos foram calculados para uma distância de 4,2 kpc (Hachisu e Kato, 2000).

Os resultados estão na figura 4.8. Os símbolos dos gráficos superiores correspondem ao fluxo das linhas de $\mathrm{H} \alpha$ medidos em função da densidade do hidrogênio no gás dentro do lóbulo de Roche, e os símbolos dos gráficos inferiores correspondem ao fluxo somado das linhas medidas, também em função da densidade de hidrogênio. As linhas pretas correspondem aos fluxos observados nos espectros, assumindo erros superestimados de $40 \%$. Os erros dos fluxos observados são consequência da tentativa de separar as componentes estreitas das largas nas linhas de emissão. É possível observar que independentemente dos 


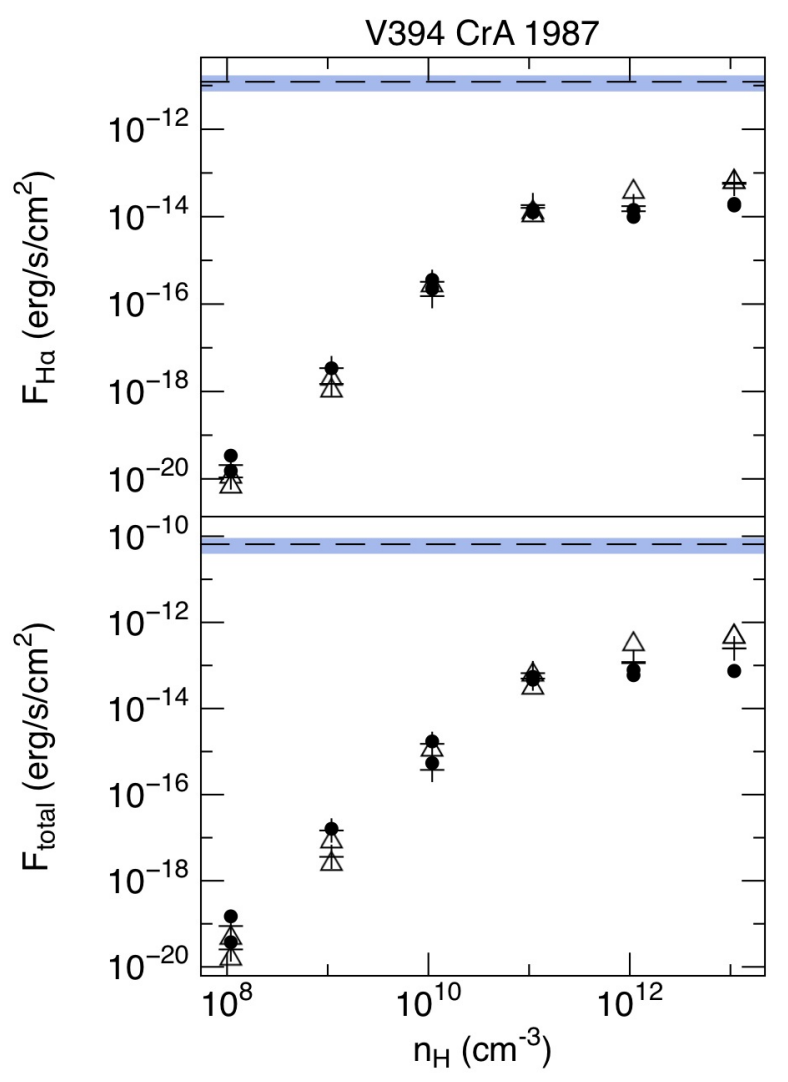

Figura 4.8: Resultados dos modelos para a nova V 394 CrA em 1987. Os símbolos de pontos, cruzes e triângulos representam os modelos para $\log (L)=36, \log (L)=37$ e $\log (L)=38 \mathrm{erg} / \mathrm{s}$, respectivamente. As linhas pretas tracejadas indicam os fluxos observados, com barras de erro de $40 \%$ em azul.

dados de entrada dos modelos, nenhuma combinação resulta em fluxos compatíveis com as observações.

\subsubsection{KT Eri}

KT Eri é uma nova clássica, observada apenas em 2009. Assim como V394 CrA, é uma nova muito rápida, com $t_{3} \sim 14,3(d)$. No entanto, suas características se assemelham às de novas recorrentes, o que leva à suspeita de que ela poderá ter uma nova erupção em alguns anos. Os longos períodos orbitais estimados para KT Eri indicam que a secundária é uma gigante vermelha.

Para os modelos de KT Eri 2009, foram usados os espectros do Stony Brook/SMARTS Atlas do dia 22 após o máximo da erupção. O avermelhamento foi corrigido com E(B-V) $=0,08$ (Ragan et al., 2009). Da mesma maneira feita para os modelos de V394 CrA, a luminosidade da fonte central também foi restrita ao intervalo $36<\log (L)<38 \mathrm{erg} / \mathrm{s}$, 


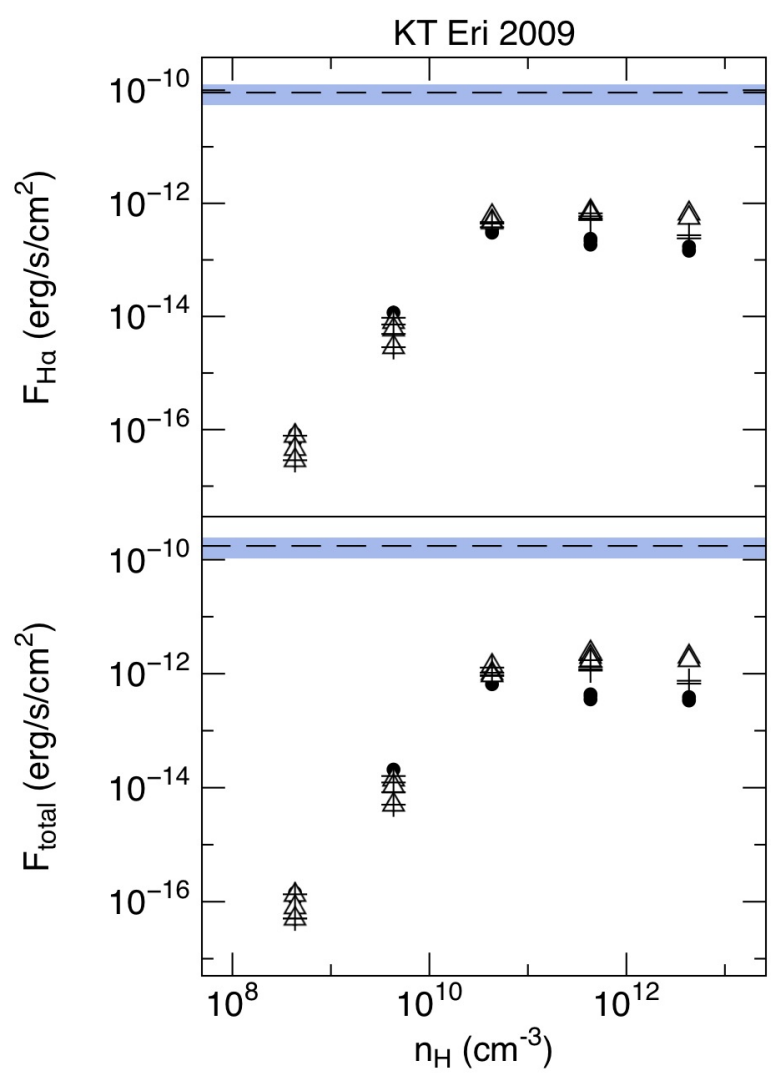

Figura 4.9: Resultados dos modelos para a nova KT Eri em 2009. Os pontos, as cruzes e os triângulos representam as simulações feitas com $\log (L)=36, \log (L)=37$ e $\log (L)=38 \mathrm{erg} / \mathrm{s}$. As $\operatorname{linhas}$ pretas tracejadas indicam os fluxos observados, com barras de erro de $40 \%$ em azul.

devido à falta de dados em raios-X nesse período da evolução espectral. O valor de distância adotado foi $7,5 \mathrm{kpc}$ (Imamura e Tanabe, 2012). O período orbital de 737 dias adotado é controverso. Alguns autores, como Hung et al. (2011) sugerem um período orbital menor, de 56 dias. No entanto, um valor menor de período acarretaria em um valor menor do raio do lóbulo de Roche e, portanto, em um volume menor. Escolhendo o maior valor de período orbital, nós otimizamos o modelo para que reproduzisse maiores fluxos.

Os resultados estão na figura 4.9, seguindo a mesma configuração dos resultados de V394 CrA. Também da mesma maneira que V394 CrA, os modelos não atingem os fluxos observados quando limitados pelo volume do lóbulo de Roche da primária.

\subsubsection{U Sco}

U Sco é a nova recorrente mais observada, com 10 erupções registradas, sendo a mais recente ocorrida em 2010. Ela é uma nova eclipsante, com grande amplitude fotométrica 
durante as erupções. A massa da primária é próxima ao limite de Chandrasekhar e a secundária é menos massiva (Thoroughgood et al., 2001).

Os modelos de U Sco 2010 foram baseados nos dados espectrais do SOAR Telescope Synoptic Survey of Novae de 9 dias após o máximo da erupção. O avermelhamento foi corrigido com $\mathrm{E}(\mathrm{B}-\mathrm{V})=0,15$ (Diaz et al. 2010 ). A luminosidade da fonte central foi determinada a partir das observações em raios-X feitas no período próximo à data do espectro (Schlegel et al., 2010), 36,3< $\log (L)<37,3 \mathrm{erg} / \mathrm{s}$. A distância ao sistema binário utilizada para o cálculo dos fluxos foi de 7,5 kpc (Hachisu et al., 2000).

Além das simulações de gás homogêneo para U Sco, também foram feitos modelos com condensações no gás, de modo a determinar a influência de emissão de gás não homogêneo nos fluxos resultantes. Os glóbulos de gás foram ajustados para 30\%, 70\% e 80\% da massa do envelope, com 10\% a $80 \%$ do raio do envelope, distribuídos em uma função Gaussiana randômica (Diaz et al., 2010).

Os resultados estão dispostos nas figuras 4.10 e 4.11. Novamente os fluxos modelados estão pelo menos uma ordem de grandeza menores do que os observados. No caso dos modelos para gás não homogêneo, era esperado que não houvesse um aumento nos fluxos das linhas, uma vez que os nódulos de gás de alta densidade são opticamente espessos nas linhas.

\subsubsection{Influência de parâmetros principais nos resultados}

Os maiores erros considerados nos cálculos dos modelos têm origem na dificuldade de separação das componentes largas e estreitas. Como nós não modelamos as linhas para realizar os ajustes das componentes, estimamos os erros de medidas de fluxo em $40 \%$. Tal valor deve ser alto o suficiente para cobrir os erros de medida e ainda assim não são suficientes para explicar as diferenças de fluxos simulados e observados no caso dos modelos fechados.

Os erros nos valores de distância, E(B-V), luminosidade da fonte central e razão de massas também não são capazes de explicar a diferença entre os fluxos observados e os modelados no lóbulo de Roche da primária. Nós testamos intervalos de valores plausíveis para esses parâmetros e nenhuma combinação foi suficiente para reproduzir os fluxos observados. 


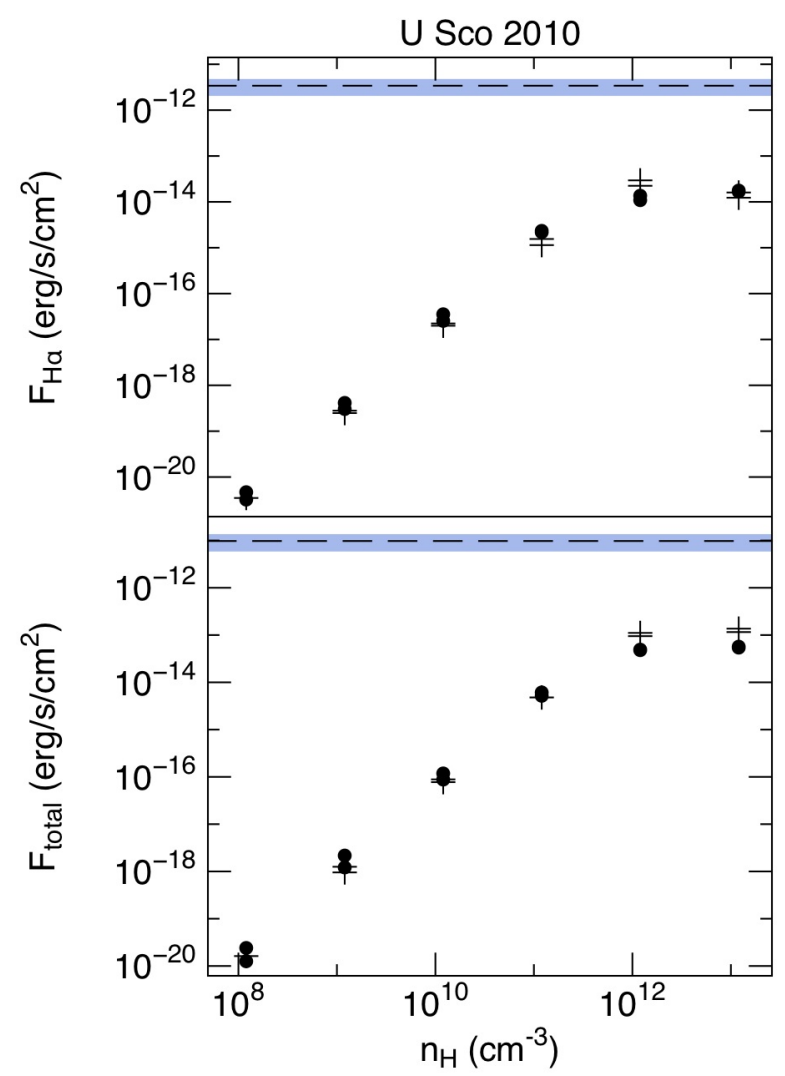

Figura 4.10: Resultados dos modelos para a nova U Sco em 2010. Os pontos e cruzes representam os modelos com $\log (L)=36,3$ e $\log (L)=37,3 \mathrm{erg} / \mathrm{s}$. As linhas pretas tracejadas indicam os fluxos observados, com barras de erro de $40 \%$ em azul. 


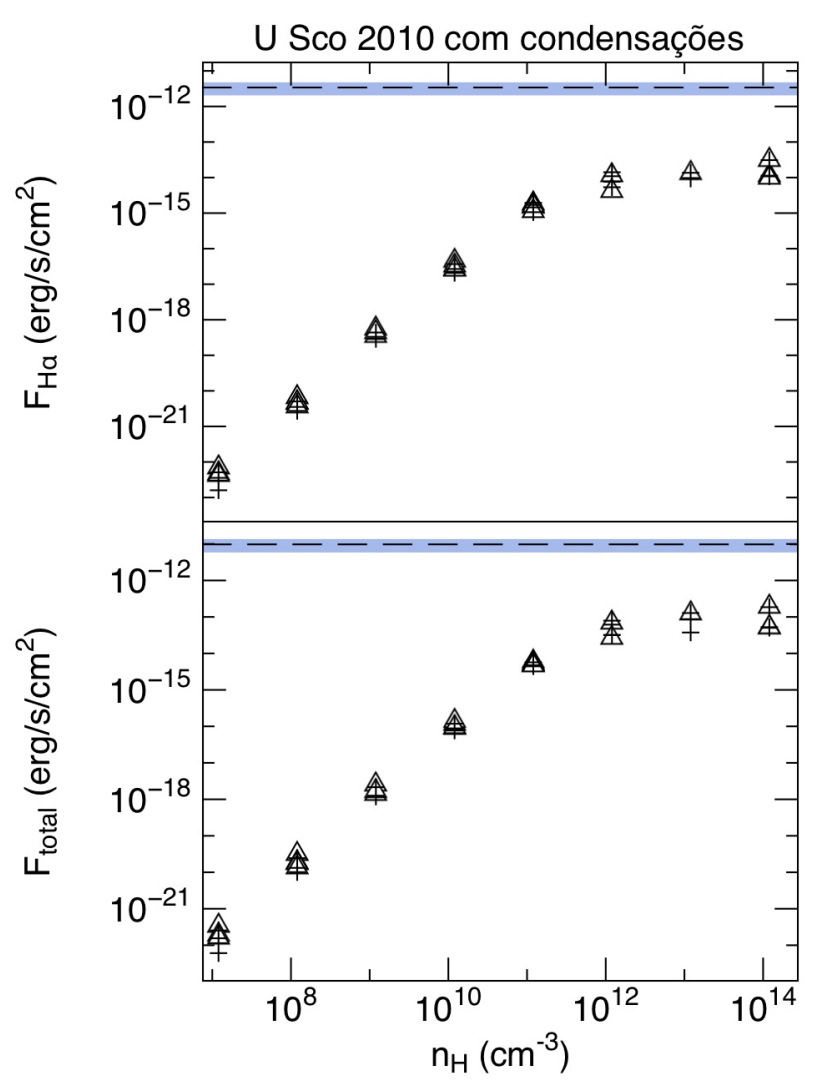

Figura 4.11: Resultados dos modelos para U Sco (2010) com gás não homogêneo. Os símbolos de triângulos e cruz correspondem aos modelos com glóbulos de gás de $30 \%$ e $80 \%$ da massa total do envelope, respectivamente. As linhas pretas indicam os fluxos observados com barra de erro de $40 \%$. 


\subsubsection{Geometria aberta}

Como o volume do lóbulo de Roche da primária se mostrou insuficiente para reproduzir os altos fluxos das componentes estreitas observadas, nós procuramos uma região emissora alternativa. Devido ao fato de as componentes apresentarem velocidade orbital, nós buscamos uma estrutura associada ao sistema binário. Além da primária, da secundária e do disco de acreção, as componentes clássicas do sistema orbital que restam são os pontos externos de Lagrange.

Dentre os quatro pontos externos de Lagrange, escolhemos o $L_{3}$ como o mais provável a abrigar o gás emissor das componentes estreitas. Os pontos $L_{4}$ e $L_{5}$ foram desconsiderados pela sua instabilidade e pela ausência de picos duplos nas componentes estreitas. Como estes pontos são simétricos em relação ao eixo que passa pelo centro das estrelas, não há motivos para o qual apenas uma região acumule gás. Supondo então que os dois pontos acumulem o gás e que eles sejam responsáveis pela emissão das linhas estreitas, dever-se-ia esperar um pico duplo no perfil das linhas, devido ao deslocamento Doppler em diferentes sentidos. Tal caso não seria observado apenas em sistemas com alta inclinação orbital. No entanto, como em nenhuma das candidatas foi identificado pico duplo nas componentes estreitas, os pontos $L_{4}$ e $L_{5}$ não foram modelados. O ponto $L_{2}$ também foi desconsiderado, uma vez que a secundária poderia facilmente ocultar a região da radiação ionizante e eventualmente poderia evitar que o vento da nova fluísse por $L_{2}$.

Por fim, nós modelamos uma nuvem densa centralizada em $L_{3}$ (Kopal, 1978), sendo iluminada por fora pela fonte ionizante. A geometria da nuvem foi determinada por uma seção de casca esférica com ângulo sólido $\pi(s r)$ como parâmetro fixo. O volume da nuvem foi restrito de forma a não invadir o lóbulo de Roche da primária. Os valores de entrada foram baseados nos dados de U Sco e em valores típicos de massa, temperatura e luminosidade da fonte central para uma nova rápida. O volume da região e a densidade de hidrogênio foram variados em grandes intervalos, como mostram as figuras 4.12 e 4.13 . Nelas, a luminosidade de $\mathrm{H} \alpha$ está disposta em função da densidade de hidrogênio e do volume. A linha pontilhada corresponde ao fluxo observado de U Sco (2010), assumindo o valor de distância de 7,5 kpc. Novamente, assumimos erros de medição de $40 \%$.

Ao contrário dos modelos do gás restrito ao lóbulo de Roche da primária, as simulações da região em torno de $L_{3}$ se mostraram compatíveis com as observações. As densidades de 


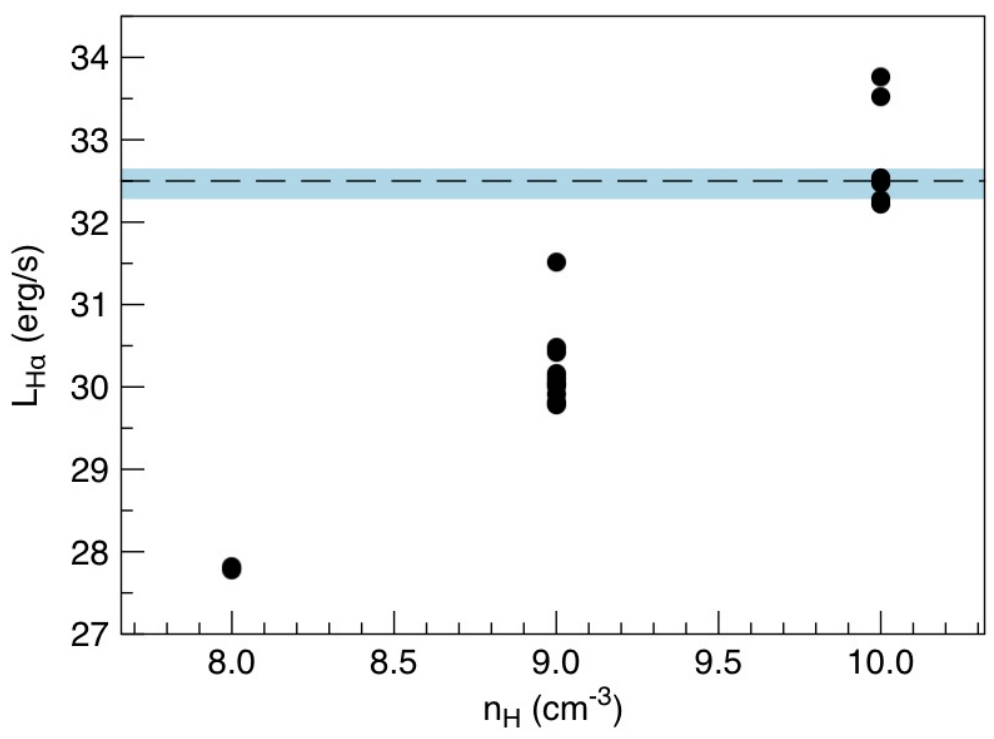

Figura 4.12: Resultados dos modelos para U Sco (2010) para os modelos abertos. As linhas pretas indicam os fluxos observados com barra de erro de $40 \%$.

hidrogênio usadas nesses modelos são altas, no intervalo de $10^{10}<n_{H}<10^{11} \mathrm{~cm}^{-3}$, mas o meio ainda é opticamente fino, de modo que as linhas não são absorvidas pela nuvem. Nuvens com densidades mais baixas, em torno de $n_{H}=10^{9} \mathrm{~cm}^{-3}$ também poderiam reproduzir os fluxos observados das componentes estreitas, mas o centro delas estaria deslocado para distâncias maiores que $L_{3}$.

\subsubsection{Proposta de cenário de formação das componentes estreitas}

Com base nos modelos descritos neste capítulo, nós propomos a região em torno de $L_{3}$ como fonte emissora da radiação responsável pelas componentes estreitas transientes. Simulações de Bisikalo (2010) suportam essa ideia, mostrando que é possível haver uma região de alta densidade ao redor de $L_{3}$. A figura 4.14 mostra a distribuição de densidades no plano equatorial do modelo de uma nova em quiescência, com $M(1)=0,6 M_{\odot}, M(2)=$ $0,56 M_{\odot}$ e $P_{o r b}=5,4 h$. Nesse modelo, há o vazamento de gás do disco de acreção por meio do ponto $L_{3}$. Nessa região, a densidade é $n_{H}>10^{12} \mathrm{~cm}^{-3}$ (assumindo que o gás é composto majoritariamente por hidrogênio). Mesmo sendo um modelo em quiescência, é esperado que durante uma erupção, os valores de densidade sejam ainda maiores.

Além disso é possível fazer uma estimativa do tempo de perda de massa para uma região de alta densidade por meio das equações 4.1 e 4.2 . Usando valores típicos de um 


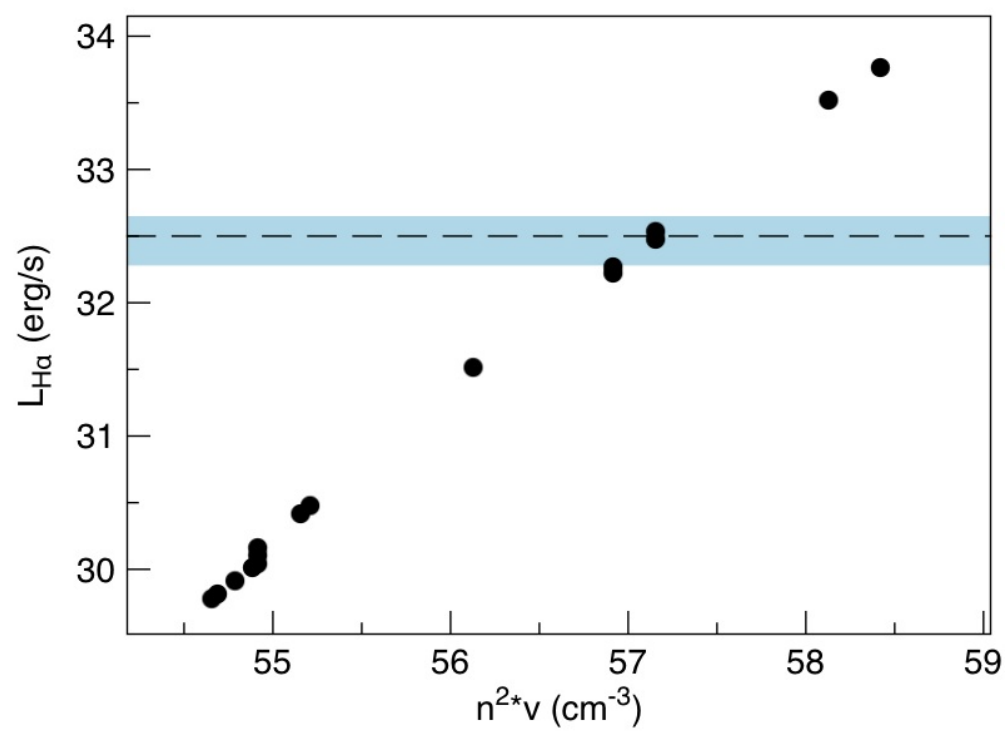

Figura 4.13: Resultados dos modelos para U Sco (2010) cpara os modelos abertos. As linhas pretas indicam os fluxos observados com barra de erro de $40 \%$.

envelope de nova da classe de U Sco, temos que para a densidade mínima que suporta nossos modelos de $n_{H}=10^{10} \mathrm{~cm}^{-3}$ a perda de massa ocorre na ordem de dias. Como essa estimativa é feita para uma região de alta densidade do tamanho do envelope, é esperado que para a região usada nos modelos, o $\dot{M}$ seja pelo menos uma ordem de grandeza menor. Portanto, o tempo para a perda de massa deve ser da ordem de semanas, o que também é compatível com o período das observações das componentes estreitas transientes.

$$
\begin{gathered}
M_{\text {shell }}=\dot{M} \Delta t \\
\dot{M}=4 \pi v \rho r^{2}
\end{gathered}
$$

Apesar dessas simulações, a forma e o tamanho exatos desta região em torno de $L_{3}$ são incertos. É possível que a emissão da erupção usual da nova seja observada (incluindo a emissão soft em raios-X) simultaneamente com a emissão das componentes estreitas transientes. No entanto, é esperado que modulações orbitais em raios-X sejam detectadas devido à inclinação orbital de sistemas como U Sco. Nesse caso, observações de raios-X resolvidas em fase são necessárias para separar a absorção da região em torno de $L_{3}$ da absorção de outras regiões internas ao lóbulo de Roche da primária. Além da absorção relativa ao eclipse da binária, os dados de U Sco de Ness et al. (2012) mostram uma 


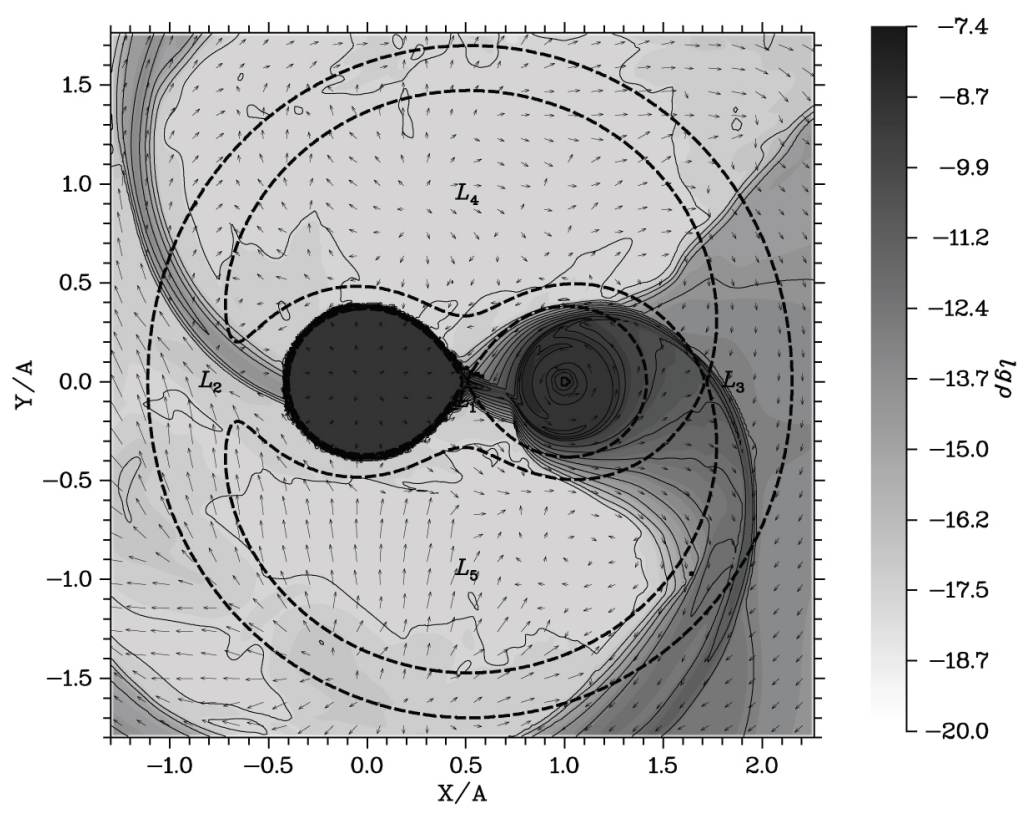

Figura 4.14: Distribuição de densidade e campo de velocidade no plano equatorial do sistema binário resultantes das simulações de Bisikalo (2010).

absorção adicional na fase $\sim 0,6$ que não está associada à passagem da estrela secundária, e pode estar associada ao gás na região de $L_{3}$. A confirmação de tal hipótese, no entanto, depende da observação de ciclos adicionais para garantir a exclusão de outras variabilidades da nova.

\subsubsection{Sobre a possibilidade de formação no disco de acreção}

A fim de excluir quaisquer dúvidas sobre a possibilidade de as linhas estreitas transientes serem formadas no disco de acreção, nós adicionamos uma análise detalhada com 4 tópicos de cálculos e demonstrações que mostram que linhas brilhantes como as observadas não podem ser formadas em um disco recém formado.

1. Emissividade x Volume.

A emissividade de linhas de recombinação no regime opticamente fino são descritas por Osterbrock e Ferland (2006):

$$
4 \pi j_{n n^{\prime}}=h \nu_{n n^{\prime}} n_{p} n_{e} \alpha_{n n^{\prime}}^{e f f}
$$

Supondo que a densidade de prótons seja aproximadamente igual à densidade de elétrons, uma vez que o gás é composto majoritariamente por hidrogênio, podemos 
considerar que a emissividade é proporcional ao quadrado da densidade. Nos modelos limitados pelo lóbulo de Roche da primária é possível observar essa tendência no intervalo entre $8<\log \left(n_{H}\right)<12 \mathrm{~cm}^{-3}$. Para densidades mais elevadas, o gás começa a ficar opticamente espesso e, portanto, ao invés de a emissividade aumentar com a densidade, ela permanece praticamente constante. Portanto, para que os modelos com geometria fechada pudessem reproduzir os fluxos observados, o volume emissor teria que ser muito maior. Para o caso de U Sco, modelos extrapolados mostraram que o volume mínimo para reproduzir os fluxos observados é derivado de um raio 10 vezes maior que o raio do lóbulo de Roche da primária. Como o volume do lóbulo de Roche da primária já é maior do que a atmosfera de um disco de acreção e do que a cromosfera da estrela secundária, nós descartamos essas regiões como possíveis fontes da emissão de linhas estreitas transientes.

2. Observação de discos brilhantes de Variáveis Cataclísmicas.

As luminosidades de linhas de hidrogênio de discos de acreção brilhantes de VCs são bem determinados por observações. Um dos discos mais brilhantes já observados é o de V3885 Sgr. A distância do sistema binário é conhecida, determinada por paralaxe. Portanto, os fluxos observados da linha de emissão de $\mathrm{H} \alpha$ sugerem uma luminosidade em torno de $L(H \alpha) \sim 7 \times 10^{29} \mathrm{erg} / \mathrm{s}$ (Ribeiro e Diaz, 2007). Tal valor é pelo menos 3 ordens de magnitude menor do que as luminosidades das componentes estreitas transientes de $\mathrm{H} \alpha$. Outro exemplo, é o disco da própria U Sco. Em quiescência, momento em que o espectro é dominado pela emissão do disco, a magnitude é em torno de $V \sim 20$, enquanto as componentes estreitas transientes possuem magnitude em torno de $V \sim 8$.

3. Modelos de discos luminosos de VCs.

As atmosferas de discos de VCs com alta viscosidade e alta transferência de massa têm sido modelados detalhadamente na última década. Simulações recentes são capazes de resolver a transferência radiativa em NLTE sobre a fotosfera de um disco com vento, reproduzindo o contínuo na região do UV e os fluxos e perfis das linhas emitidas (Puebla et al., 2011). Os discos luminosos de tais modelos também possuem fluxos das linhas de Balmer muito abaixo dos valores observados nas componentes estreitas transientes. 


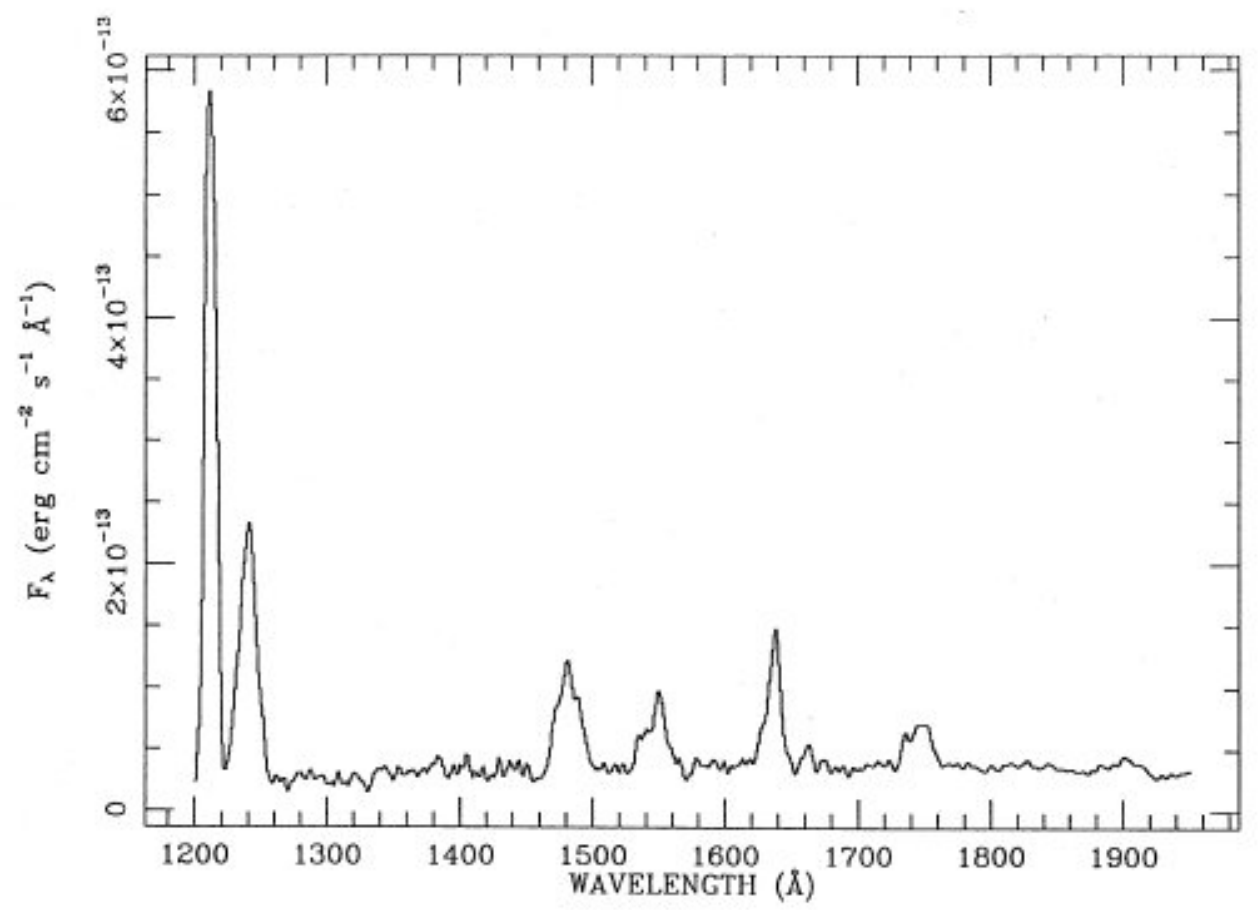

Figura 4.15: Espectro IUE da nova V394 CrA (1987) (Starrfield et al., 1988).

4. Componentes estreitas em linhas de intercombinação

Starrfield et al. (1988) publicaram espectros IUE de U Sco (1979) e V 394 CrA (1987).

Em ambos é possível observar componentes estreitas nas linhas semi-proibidas de

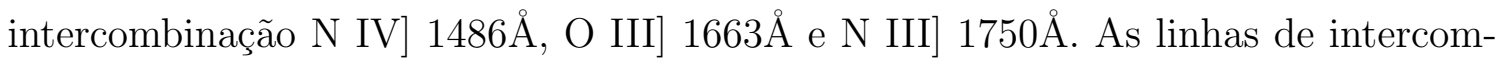
binação são formadas em densidades mais baixas do que as do disco de acreção, sendo mais um indício de que as componentes estreitas transientes não são formadas no disco. 
Capítulo 5

\section{Conclusões}

Nós encontramos 11 novas adicionais que apresentam componentes estreitas transientes com similaridades em relação às vistas em U Sco (2010). Das novas candidatas, 5 são novas recorrentes e 7 são clássicas, indicando uma tendência estatística maior à presença de componentes em novas recorrentes do que em clássicas. As análises estatísticas também mostraram que as novas rápidas e muito rápidas e dos tipos "He/N" e "Fe IIb" são mais propícias a apresentarem as componentes estreitas transientes. A única exceção é a Nova Sco 2007, que apesar de apresentar modulações de velocidade nas componentes estreitas das linhas de recombinação, não se assemelha às outras candidatas em nenhum outro aspecto.

Não foi possível medir a modulação de velocidade das componentes estreitas de todos os espectros devido à falta de cobertura temporal de espectros de alta resolução. A falta desses dados também impede a confirmação de que a origem das componentes estreitas seja a mesma para todos os objetos.

Nós usamos as novas U Sco, KT Eri e V394 CrA para investigar a formação das componentes estreitas transientes por meio de simulações de fotoionização. Devido aos altos valores de fluxo das componentes nos espectros observados e do momento do decaimento em que elas aparecem, já é esperado um grande volume emissor para reproduzir o espectro. Por isso, os modelos iniciais foram restritos ao lóbulo de Roche da estrela primária, que é maior do que a cromosfera da secundária e a atmosfera do disco de acreção. Tais simulações excluíram o gás difuso no interior do lóbulo de Roche como a única região emissora, uma vez que os fluxos resultantes dos modelos se mostraram mais de uma ordem de grandeza abaixo do observado.

Uma nuvem em torno de $L_{3}$ é sugerida como região emissora alternativa, uma vez que os 
pontos de Lagrange estão associados ao sistema orbital. Simulações de fotoionização desta região mostram que é possível o gás de alta densidade produzir fluxos tão altos quanto os observados. Por não se conhecer o tamanho e a forma exatos da nuvem, ou as condições do outflow do gás na região, nós escolhemos modelos com geometrias simplificadas. Não se sabe exatamente qual a influência que geometrias mais complexas teriam sobre os resultados dos modelos. No entanto, simulações de Bisikalo (2010) indicam a existência um vazamento de matéria pelo $L_{3}$, que aumenta a densidade na região ao redor do ponto. $\mathrm{O}$ gás acumulado nessa região pode apresentar densidades compatíveis com aquelas inferidas nos modelos de fotoionização.

Nós reconhecemos as limitações de nossos modelos de geometria simplificada e nós não descartamos a existência de outras fontes contribuintes para a emissão das componentes estreitas. Para obter mais informações sobre a formação das componentes estreitas transientes seria fundamental obter uma tomografia Doppler de uma nova logo após a erupção que se encaixasse no perfil de U Sco. Assim seria possível mapear o campo de velocidades da emissão e observar o vazamento de gás pelo $L_{3}$. 


\section{Capítulo 6}

\section{Perspectivas}

A maior dificuldade ao identificar a fonte emissora das componentes estreitas transientes nas novas é a falta de previsibilidade. As erupções de novas já são difíceis de acompanhar por longos períodos com grandes telescópios, pois a localização da binária e o momento da erupção não podem ser antecipados. Além disso, não há como supor quais novas apresentarão componentes estreitas transientes. Tal diagnóstico só é possível após a observação de uma série de espectros. Porém, após a erupção da nova é difícil obter tempo de observação em telescópios, devido ao prazo de análise de projeto.

Não foi possível realizar observações mais precisas de novas com componentes estreitas transientes dentro do prazo de apenas 2 anos do mestrado. No entanto, esperamos que futuramente nós possamos identificar uma nova similar à U Sco e rapidamente iniciar uma série de observações no Observatório Pico dos Dias, em que temos um acesso mais fácil. Uma longa série temporal com amostragem da ordem de poucas dezenas de minutos com o espectrógrafo Coudé, de alta resolução espectral, deve ser suficiente para confirmar se as modulações de velocidade são realmente de origem orbital. As observações também devem fornecer mais informações sobre a mudança nos perfis de linha no intervalo de tempo de minutos.

Caso haja oportunidade de realizar uma tomografia Doppler de uma nova com componentes estreitas transientes durante a erupção, será possível mapear o campo de velocidades próximo à $L_{3}$ usando métodos de imageamento indireto. Assim, poderemos confirmar se há um vazamento pelo ponto $L_{3}$ e, se sim, como ele ocorre. 


\section{Referências Bibliográficas}

Bisikalo D., 3D Modeling of Accretion Disks and Circumbinary Envelopes in Close Binaries. In Binaries - Key to Comprehension of the Universe, vol. 435 of Astronomical Society of the Pacific Conference Series, 2010, p. 287

Calvelo D. E., Vrtilek S. D., Steeghs D., Torres M. A. P., Neilsen J., Filippenko A. V., González Hernández J. I., Doppler and modulation tomography of XTEJ1118+480 in quiescence, MNRAS, 2009, vol. 399, p. 539

Cooksey K. L., Prochaska J. X., Chen H.-W., Mulchaey J. S., Weiner B. J., Characterizing the Low-Redshift Intergalactic Medium toward PKS 1302-102, ApJ, 2008, vol. 676, p. 262

Curcio J. A., Drummeter L. F., Knestrick G. L., An Atlas of the Absorption Spectrum of the Lower Atmosphere from $5400 \AA$ A to $8520 \AA$, Appl. Opt., 1964, vol. 3, p. 1401

Diaz M. P., Williams R. E., Luna G. J., Moraes M., Takeda L., The Spectral Evolution and Ejecta of Recurrent Nova U Sco in the 2010 Outburst, AJ, 2010, vol. 140, p. 1860

Eggleton P. P., Approximations to the radii of Roche lobes, ApJ, 1983, vol. 268, p. 368

Ferland G. J., Hazy, A Brief Introduction to Cloudy 06.02. University of Kentucky Internal Report, 565 pages, 2006

Ferland G. J., Porter R. L., van Hoof P. A. M., Williams R. J. R., Abel N. P., Lykins M. L., Shaw G., Henney W. J., Stancil P. C., The 2013 Release of Cloudy, Rev. Mexicana Astron. Astrofis., 2013, vol. 49, p. 137 
Frank J., King A., Raine D., Accretion Power in Astrophysics. Cambridge University Press, 2002

García-Hernández D. A., Villaver E., García-Lario P., Acosta-Pulido J. A., Manchado A., Stanghellini L., Shaw R. A., Cataldo F., Infrared Study of Fullerene Planetary Nebulae, ApJ, 2012, vol. 760, p. 107

Gehrz R. D., The infrared temporal development of classical novae, ARA\&A, 1988, vol. 26, p. 377

Hachisu I., Kato M., A Theoretical Light-Curve Model for the Recurrent Nova V394 Coronae Australis, ApJ, 2000, vol. 540, p. 447

Hachisu I., Kato M., Kato T., Matsumoto K., A Theoretical Light-Curve Model for the 1999 Outburst of U Scorpii, ApJ, 2000, vol. 528, p. L97

Horne K., Marsh T. R., Emission line formation in accretion discs, MNRAS, 1986, vol. 218, p. 761

Hung L. W., Chen W. P., Walter F. M., Optical and X-ray Observations of the Nova KT Eridani 2009. In Astronomical Society of the Pacific Conference Series, vol. 451 of Astronomical Society of the Pacific Conference Series, 2011, p. 271

Imamura K., Tanabe K., Observational Report on the Classical Nova KT Eridani, PASJ, 2012, vol. 64, p. 120

Jurdana-Šepić R., Ribeiro V. A. R. M., Darnley M. J., Munari U., Bode M. F., Historical light curve and search for previous outbursts of Nova KT Eridani (2009), A\&A, 2012, vol. 537, p. A34

Kopal Z., Dynamics of Close Binary Systems. Astronomy and Space Science Library Vol. 68, D. Reidel, 1978

Martín-Manjón M. L., Mollá M., Díaz A. I., Terlevich R., The evolution of HII galaxies: testing the bursting scenario through the use of self-consistent models, MNRAS, 2008, vol. 385 , p. 854 
Mason E., Ederoclite A., Williams R. E., Della Valle M., Setiawan J., U Scorpii 2010 outburst: a new understanding of the binary accretion disk and the secondary star, A\&A, 2012, vol. 544, p. A149

Mason E., Walters F. M., Lesson learned from (some) recurrent novae, ArXiv e-prints, 2013

Massaro F., Bianchi S., Matt G., D'Onofrio E., Nicastro F., The properties of the circumnuclear regions in the Circinus galaxy, A\&A, 2006, vol. 455, p. 153

Moraes M., Diaz M., The RAINY3D Code: The Treatment of Condensation in Nova Remnants during Nebular Phase, PASP, 2011, vol. 123, p. 844

Munari U., Mason E., Valisa P., The narrow and moving HeII lines in nova KT Eridani, A\&A, 2014, vol. 564, p. A76

Munari U., Ribeiro V. A. R. M., Bode M. F., Saguner T., Properties, evolution and morpho-kinematical modelling of the very fast nova V2672 Oph (Nova Oph 2009), a clone of U Sco, MNRAS, 2011, vol. 410, p. 525

Naito H., Mizoguchi S., Arai A., Tajitsu A., Narusawa S., Yamanaka M., Fujii M., Iijima T., Kinugasa K., Kurita M., Nagayama T., Yamaoka H., Sadakane K., Five-year optical and near-infrared observations of the extremely slow nova V1280 Scorpii, A\&A, 2012a, vol. 543, p. A86

Naito H., Mizoguchi S., Arai A., Tajitsu A., Narusawa S., Yamanaka M., Fujii M., Iijima T., Kinugasa K., Kurita M., Nagayama T., Yamaoka H., Sadakane K., Five-year optical and near-infrared observations of the extremely slow nova V1280 Scorpii, A\&A, 2012b, vol. 543, p. A86

Ness J.-U., Schaefer B. E., Dobrotka A., Sadowski A., Drake J. J., Barnard R., Talavera A., Gonzalez-Riestra R., Page K. L., Hernanz M., Sala G., Starrfield S., From X-Ray Dips to Eclipse: Witnessing Disk Reformation in the Recurrent Nova U Sco, ApJ, 2012, vol. 745 , p. 43

Ney E. P., Hatfield B. F., The isothermal dust condensation of Nova Vulpeculae 1976, ApJ, 1978, vol. 219, p. L111 
Nomoto K., Kondo Y., Conditions for accretion-induced collapse of white dwarfs, ApJ, 1991, vol. 367, p. L19

Osterbrock D., Ferland G., Astrophysics of Gaseous Nebulae and Active Galactic Nuclei. University Science Books, 2006

Payne-Gaposchkin C., The Galactic Novae. Dover Publications, 1964

Puebla R. E., Diaz M. P., Hillier D. J., Hubeny I., A Method for the Study of Accretion Disk Emission in Cataclysmic Variables. I. The Model, ApJ, 2011, vol. 736, p. 17

Ragan E., Brozek T., Suchomska K., Skalbania A., Konorski P., Galan C., Swierczynski E., Tomov T., Mikolajewski M., Wychudzki P., Optical observations of KT Eri = Nova Eridani 2009, The Astronomer's Telegram, 2009, vol. 2327, p. 1

Raj A., Banerjee D. P. K., Ashok N. M., Nova KT Eri 2009: infrared studies of a very fast and small amplitude He/N nova, MNRAS, 2013, vol. 433, p. 2657

Ribeiro F. M. A., Diaz M. P., Emission-Line Flickering from the Secondary Star in Cataclysmic Variables? A Study of V3885 Sagittarii, AJ, 2007, vol. 133, p. 2659

Ritter H., Kolb U., Catalogue of cataclysmic binaries, low-mass X-ray binaries and related objects (Seventh edition), A\&A, 2003, vol. 404, p. 301

Rybicki G., Lightman A., Radiative Processes in Astrophysics. A Wiley-Interscience publication, Wiley, 1979

Schlegel E. M., Schaefer B., Pagnotta A., Page K., Osborne J., Drake J., Orio M., Takei D., Kuulkers E., Ness J.-U., Starrfield S., et al. Emergence of the Supersoft X-ray Phase of U Sco, The Astronomer's Telegram, 2010, vol. 2430, p. 1

Schwarz G. J., A New Abundance Analysis of the ONeMg Nova QU Vulpeculae, ApJ, 2002, vol. 577 , p. 940

Sekiguchi K., Caldwell J. A. R., Stobie R. S., Buckley D. A. H., Recurrent nova in the Large Magellanic Cloud - Nova LMC 1990 No. 2, MNRAS, 1990, vol. 245, p. 28P 
Sekiguchi K., Catchpole R. M., Fairall A. P., Feast M. W., Kilkenny D., Laney C. D., Lloyd Evans T., Marang F., Parker Q. A., The recurrent nova V394 Coronae Austrinae - The 1987 outburst, MNRAS, 1989, vol. 236, p. 611

Shaviv N. J., Dotan C., Classical novae as super-Eddington steady states ., Mem. Soc. Astron. Italiana, 2012, vol. 83, p. 792

Shore S. N., Augusteijn T., Ederoclite A., Uthas H., The spectroscopic evolution of the recurrent nova T Pyxidis during its 2011 outburst. I. The optically thick phase and the origin of moving lines in novae, A\&A, 2011, vol. 533, p. L8

Starrfield S., Sonneborn G., Sparks W. M., Shaviv G., Williams R. E., Heathcote S., Ferland G., Gehrz R. D., Ney E. P., Kenyon S., Truran J. W., Wu C. C., Observations and simulations of recurrent novae: U Sco and V394 CrA. In ESA Special Publication, vol. 281 of ESA Special Publication, 1988, p. 167

Starrfield S., Sparks W. M., Truran J. W., Recurrent novae as a consequence of the accretion of solar material onto a 1.38 solar mass white dwarf, ApJ, 1985, vol. 291, p. 136

Thoroughgood T. D., Dhillon V. S., Littlefair S. P., Marsh T. R., Smith D. A., The mass of the white dwarf in the recurrent nova U Scorpii, MNRAS, 2001, vol. 327, p. 1323

Tody D., The IRAF Data Reduction and Analysis System. In Instrumentation in astronomy VI, vol. 627 of Society of Photo-Optical Instrumentation Engineers (SPIE) Conference Series, 1986, p. 733

Walter F. M., Battisti A., Towers S. E., Bond H. E., Stringfellow G. S., The Stony Brook/SMARTS Atlas of (mostly) Southern Novae, PASP, 2012, vol. 124, p. 1057

Warner B., Cataclysmic Variable Stars. vol. 28 of Cambridge Astrophysics, Cambridge University Press, 1995

Williams R. E., The formation of novae spectra, AJ, 1992, vol. 104, p. 725

Williams R. E., Hamuy M., Phillips M. M., Heathcote S. R., Wells L., Navarrete M., The evolution and classification of postoutburst novae spectra, ApJ, 1991, vol. 376, p. 721 
Williams R. E., Phillips M. M., Hamuy M., The Tololo nova survey: Spectra of recent novae, ApJS, 1994, vol. 90, p. 297 
Apêndice 



\section{Apêndice A \\ Evolução espectral das novas que apresentam componentes estreitas transientes}

Neste apêndice estão dispostas as evoluções espectrais das novas que apresentam componentes estreitas transientes nas linhas de recombinação: U Sco (figura A.1), V394 CrA A.2), KT Eri A.3 A.4), Nova LMC $1990 n^{\circ} 2$ A.5), Nova LMC $1988 n^{\circ} 2$ (A.6), Nova LMC 2009 A.7), V444 Sct A.8, DE Cir A.9), YY Dor A.10, Nova Sco $2011 n^{\circ} 2$ A.11, Nova Oph 2009 A.12 e Nova Sco 2007 A.13.

A escolha das novas está descrita detalhadamente no capítulo 4 . O capítulo 4 também mostra uma comparação dos perfis de linha de $\mathrm{H} \alpha$ para todas as novas candidatas, com exceção de KT Eri, uma vez que seus dados foram removidos do catálogo público do Stony Brook/SMARTS Nova Atlas. A classificação da Nova LMC 2009 foi baseada nos espectros da figura A.7 (Mason e Walters, 2013), uma vez que os espectros do SOAR e do SMARTS não mostram as componentes estreitas por terem sido observados em uma época mais tardia. O caso da Nova LMC 2009 ilustra bem a dificuldade de observar as componentes estreitas transientes, pois apenas um projeto de três conseguiu registra-las. 


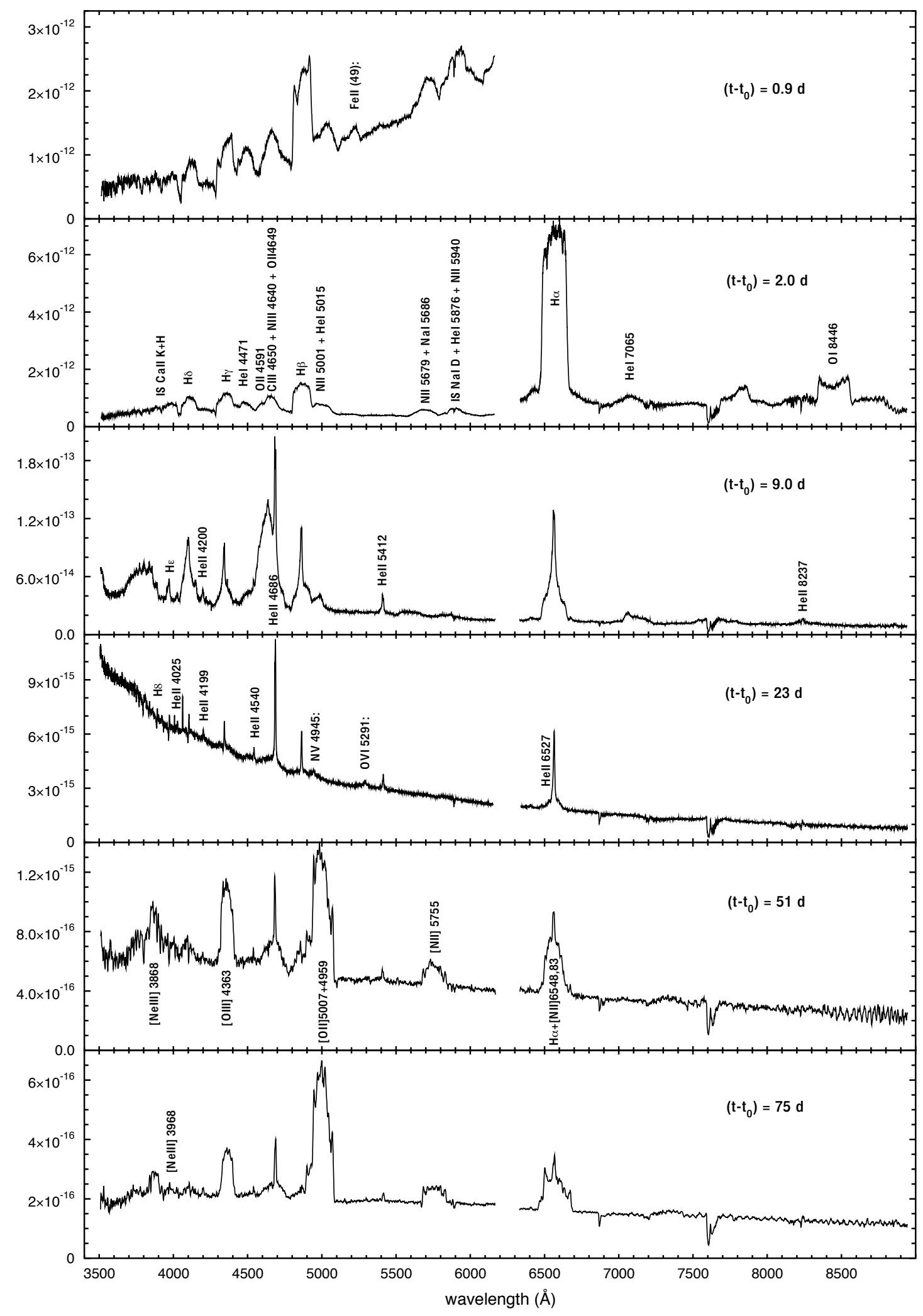

Figura A.1: Evolução espectral de U Sco na erupção de 2010, acompanhada pelo telescópio SOAR (Diaz et al. 2010). 


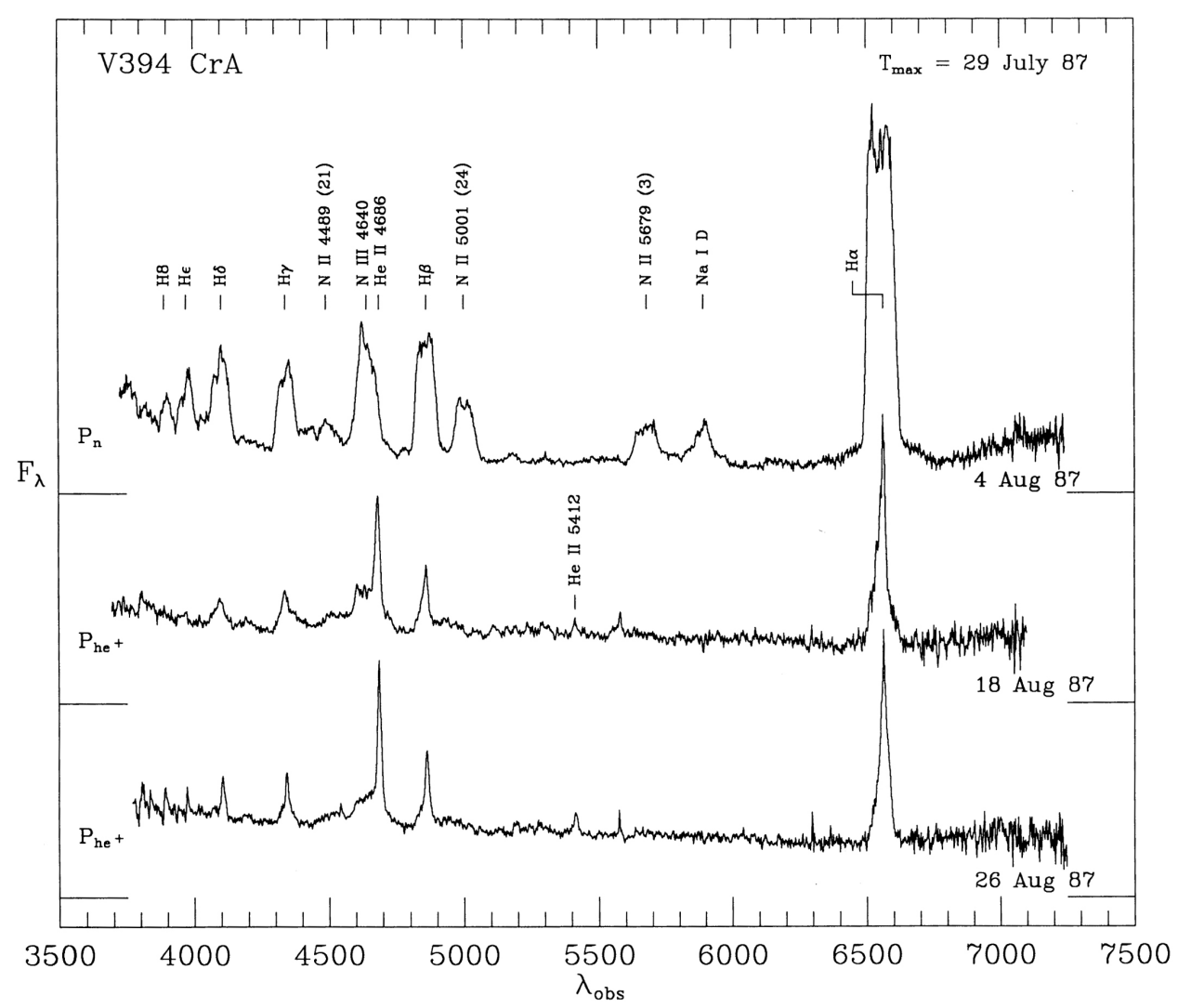

Figura A.2: Evolução espectral de V394 CrA, acompanhada pelo CTIO Nova Survey (Williams et al. 1991). 


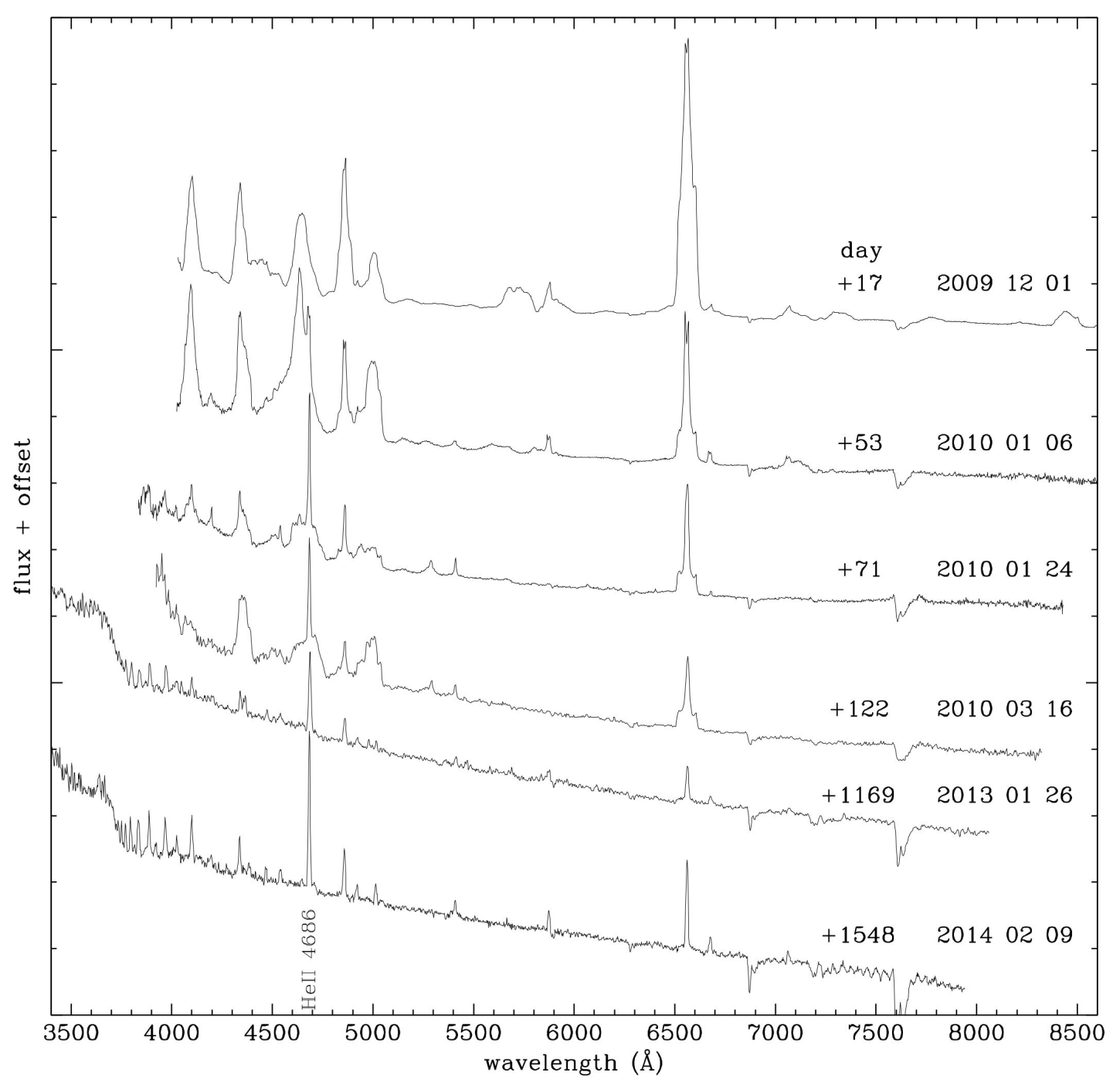

Figura A.3: Evolução espectral de KT Eri (Munari et al., 2014). 


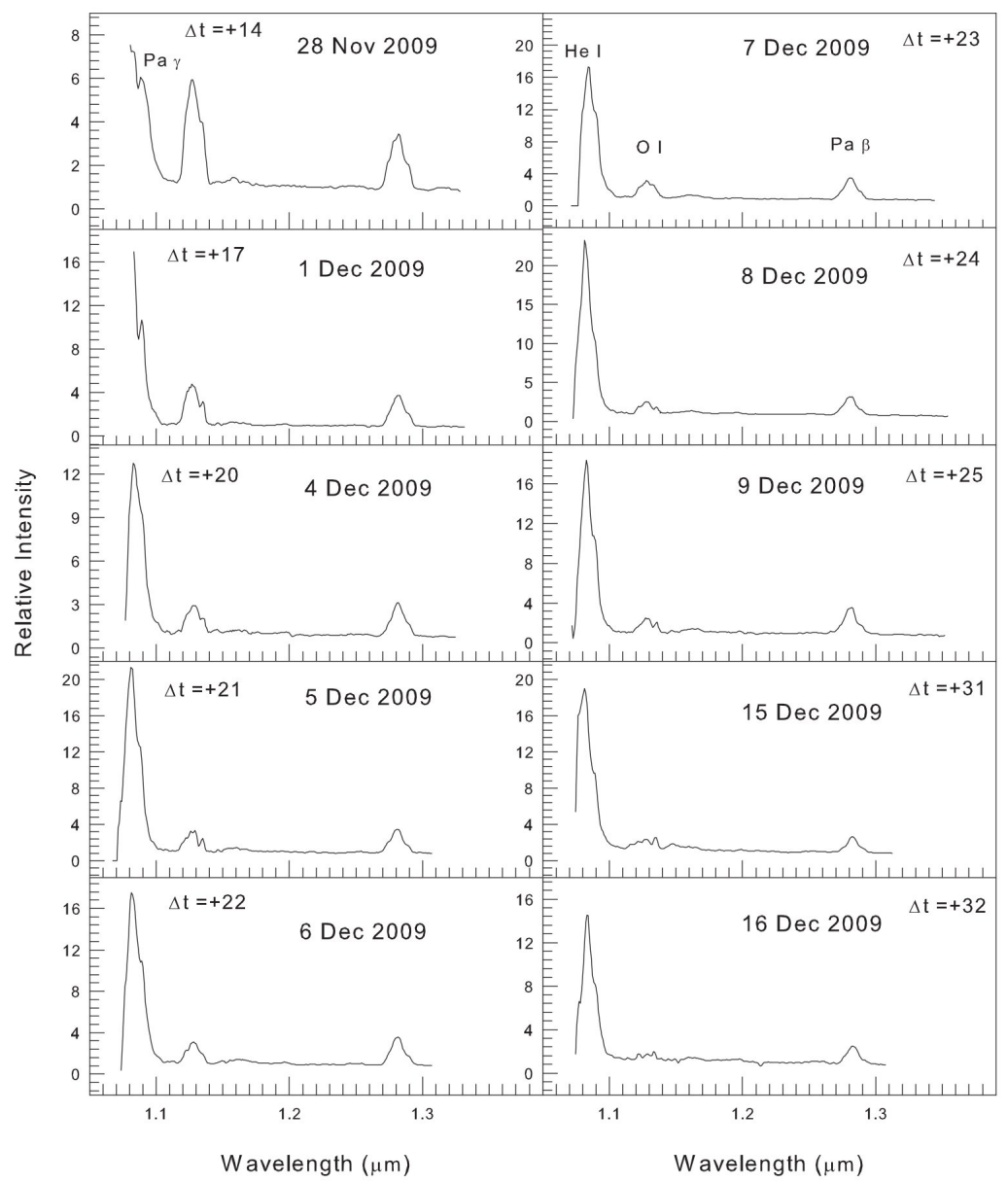

Figura A.4: Evolução espectral de KT Eri na banda J (Raj et al. 2013). 


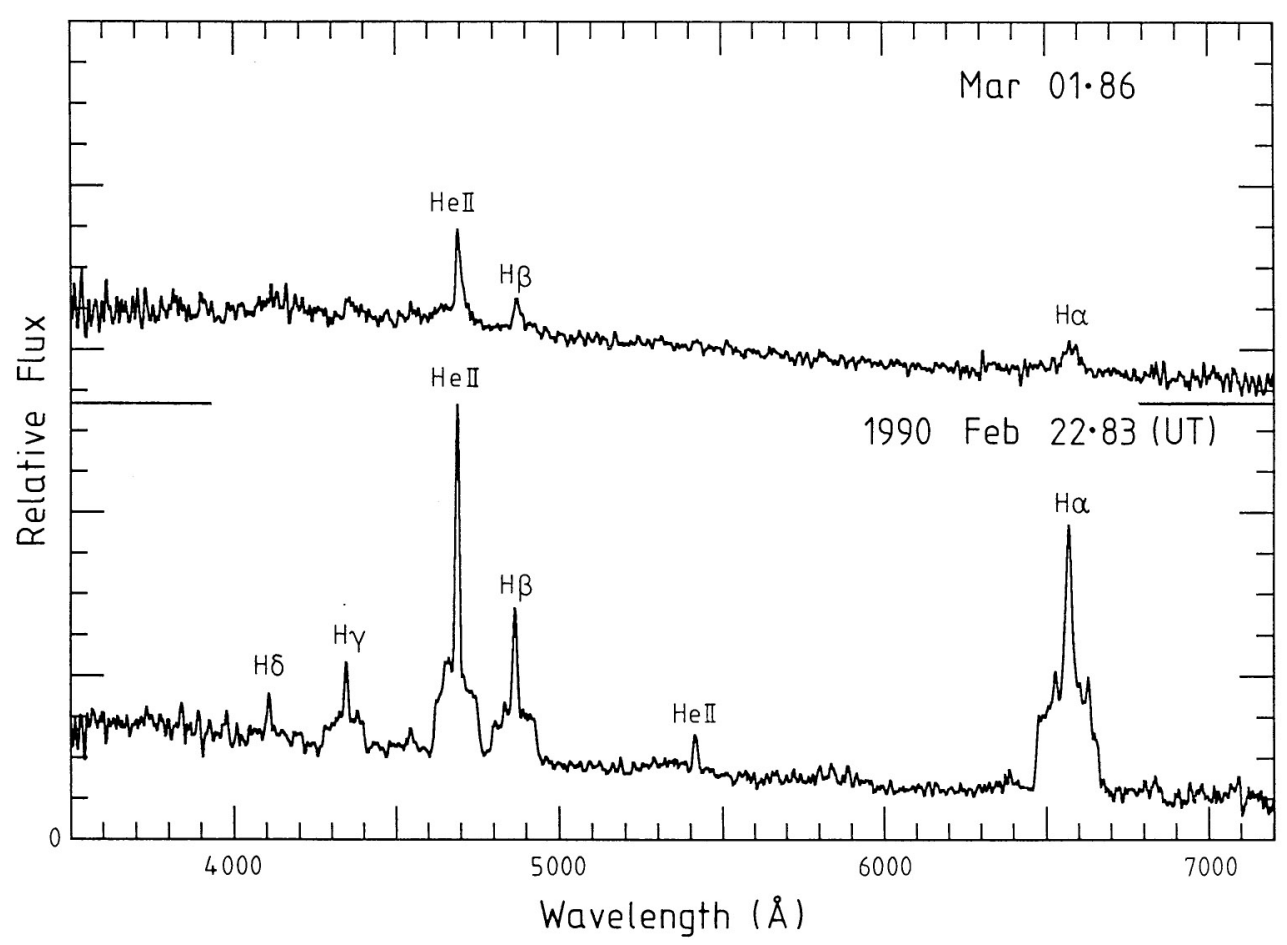

Figura A.5: Evolução espectral da Nova LMC $1990 n^{\circ} 2$, acompanhada pelo telescópio de 1,9m no SAAO (Sekiguchi et al., 1990).

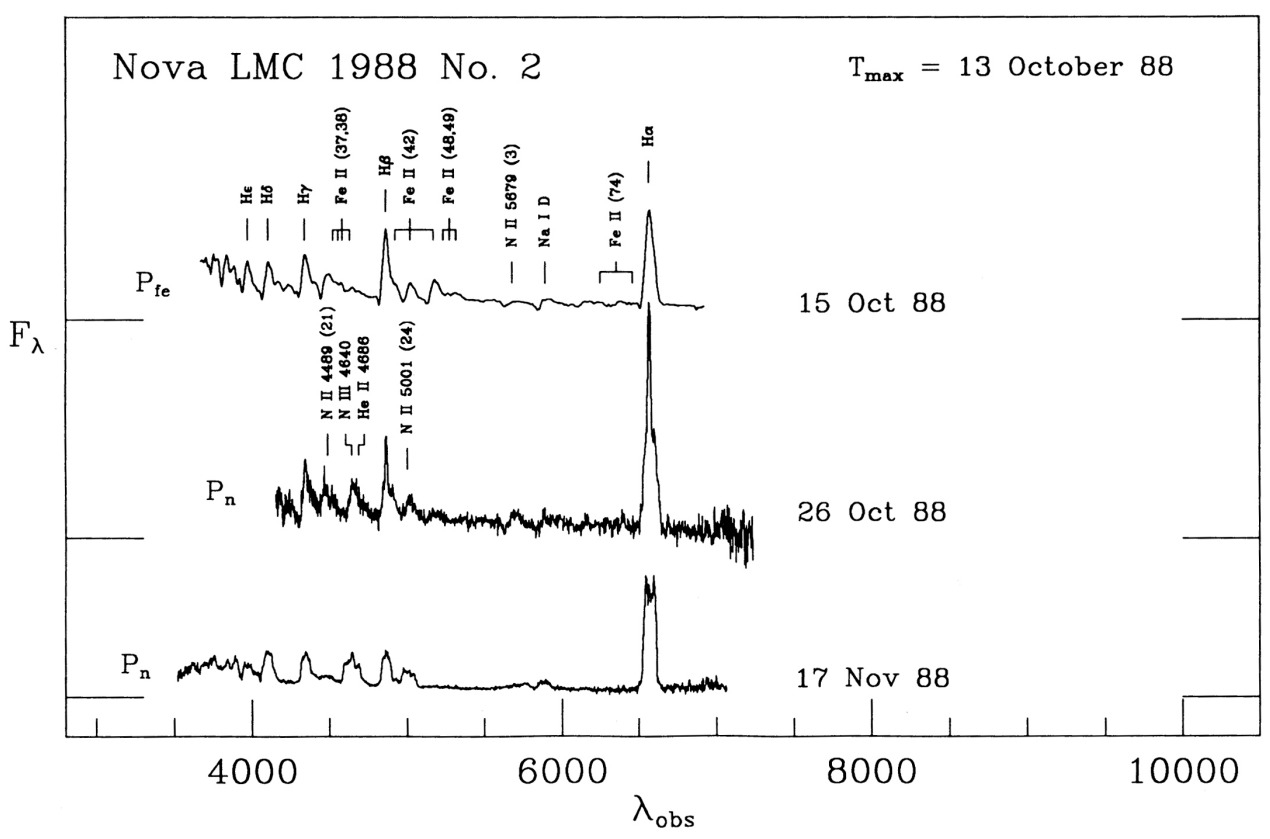

Figura A.6: Evolução espectral da Nova LMC $1988 n^{\circ}$ 2, acompanhada pelo CTIO Nova Survey Williams et al. 1991). 


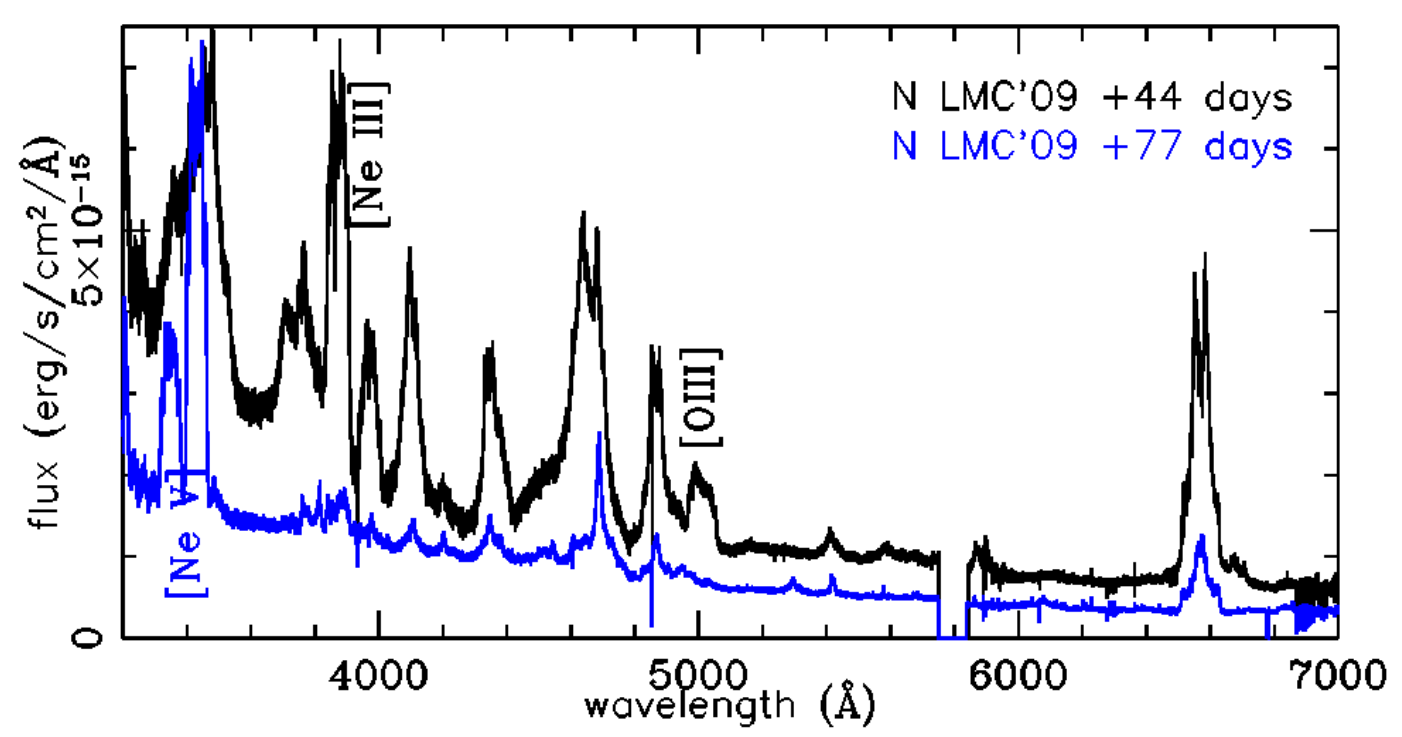

Figura A.7: Evolução espectral da Nova LMC 2009 (Mason e Walters, 2013). 


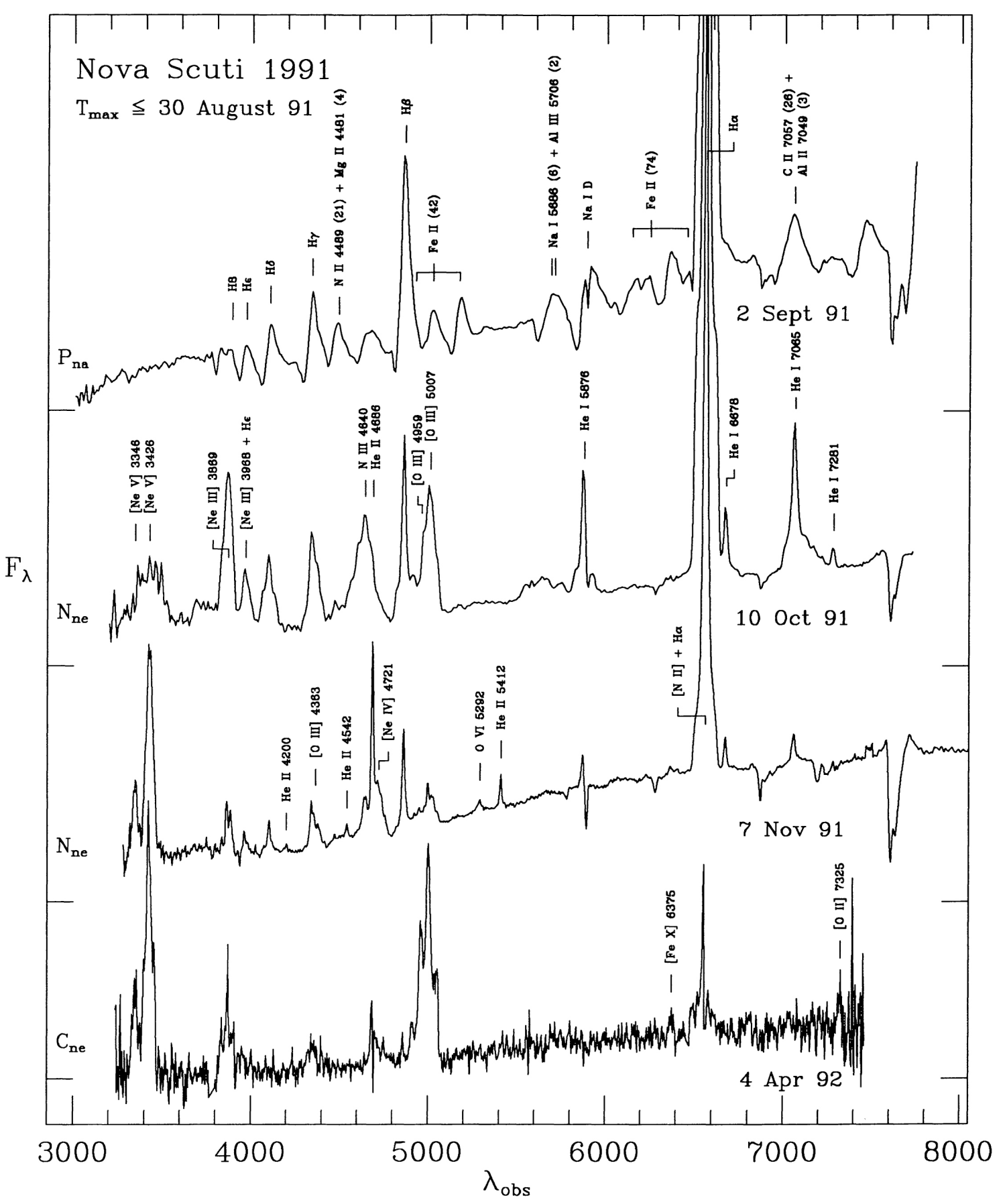

Figura A.8: Evolução espectral de V444 Sct, acompanhada pelo CTIO Nova Survey Williams et al. 1994). 


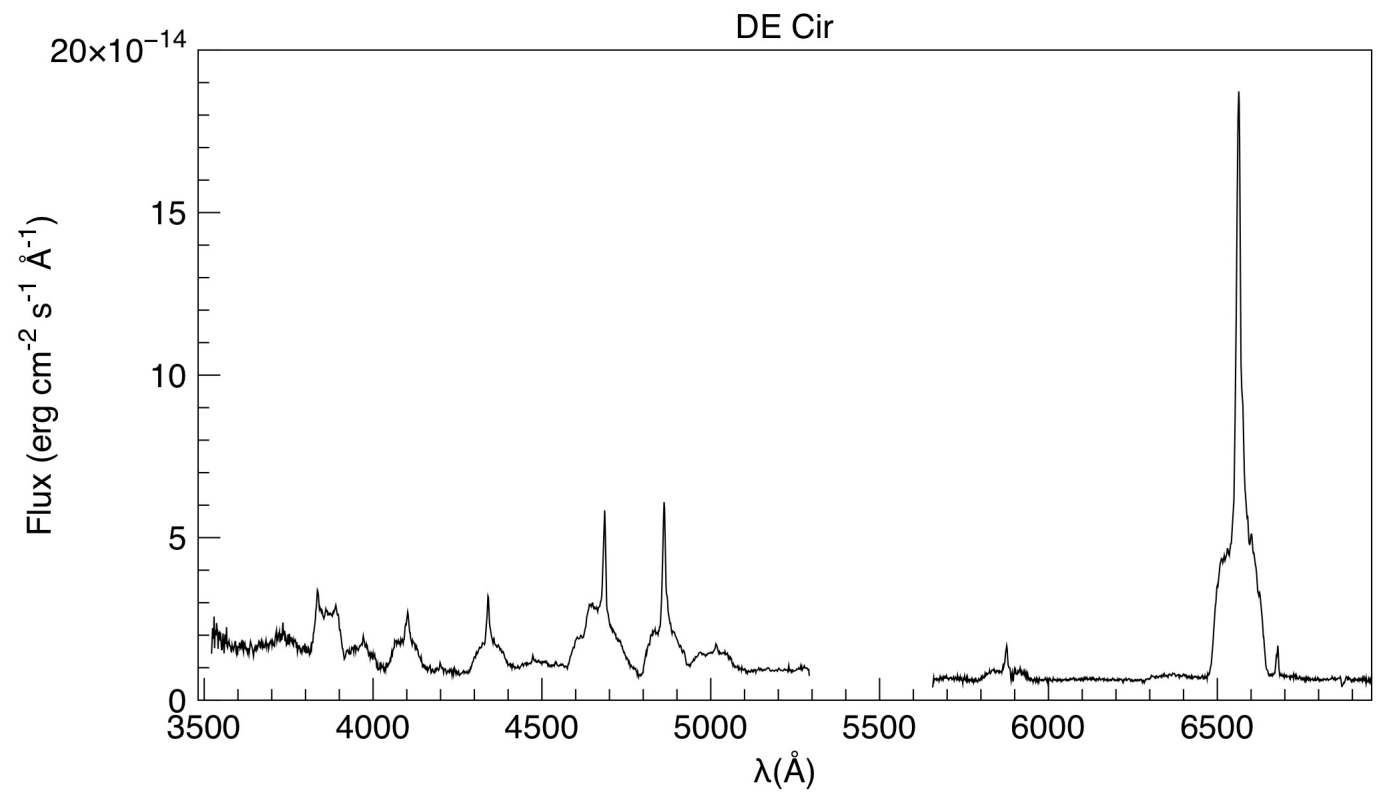

Figura A.9: Espectro de DE Cir do dia 19 de outubro de 2003, dados do Stony Brooks/SMARTS Nova Atlas. 


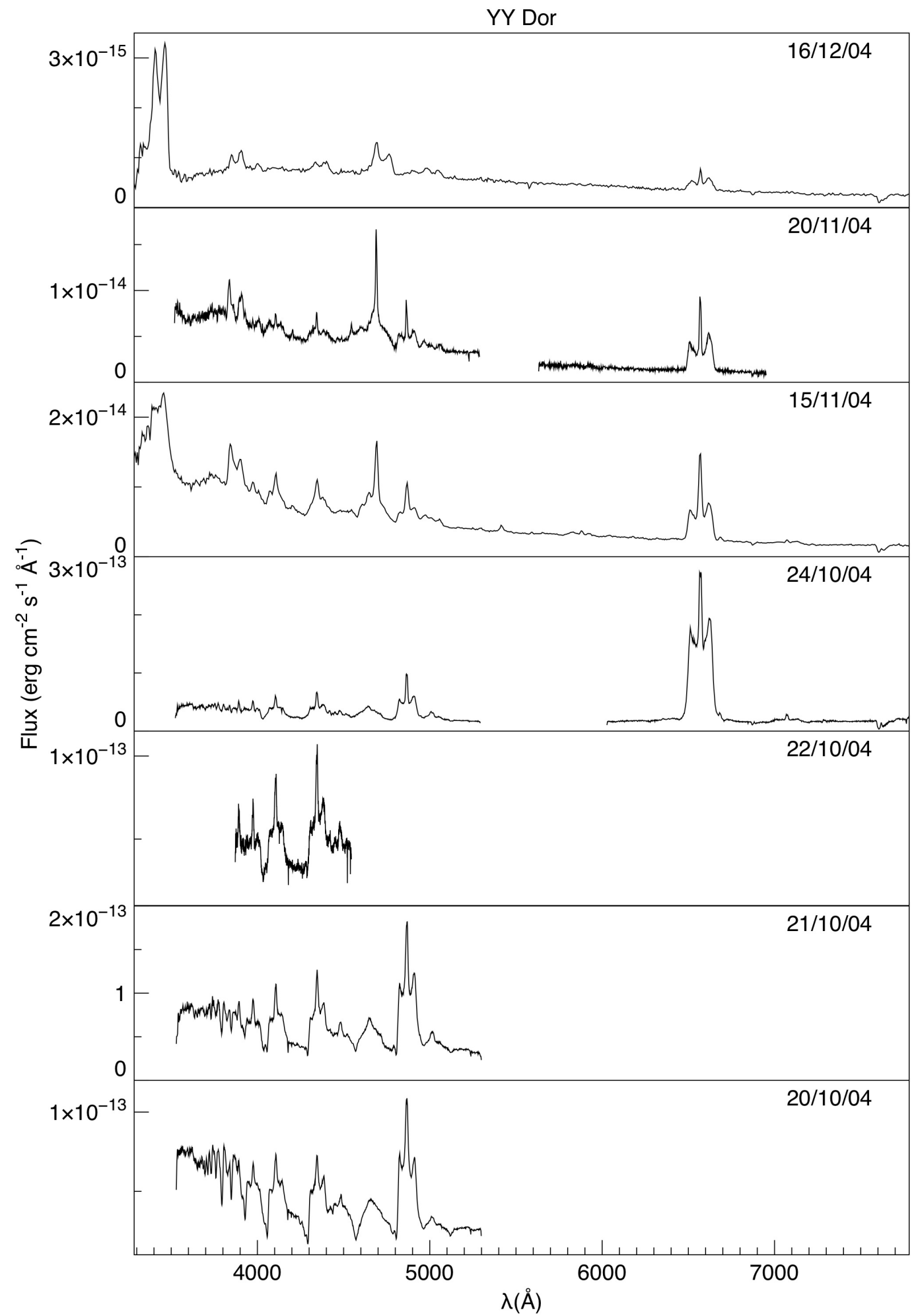

Figura A.10: Evolução espectral de YY Dor, acompanhada pelo Stony Brooks/SMARTS Nova Atlas. 


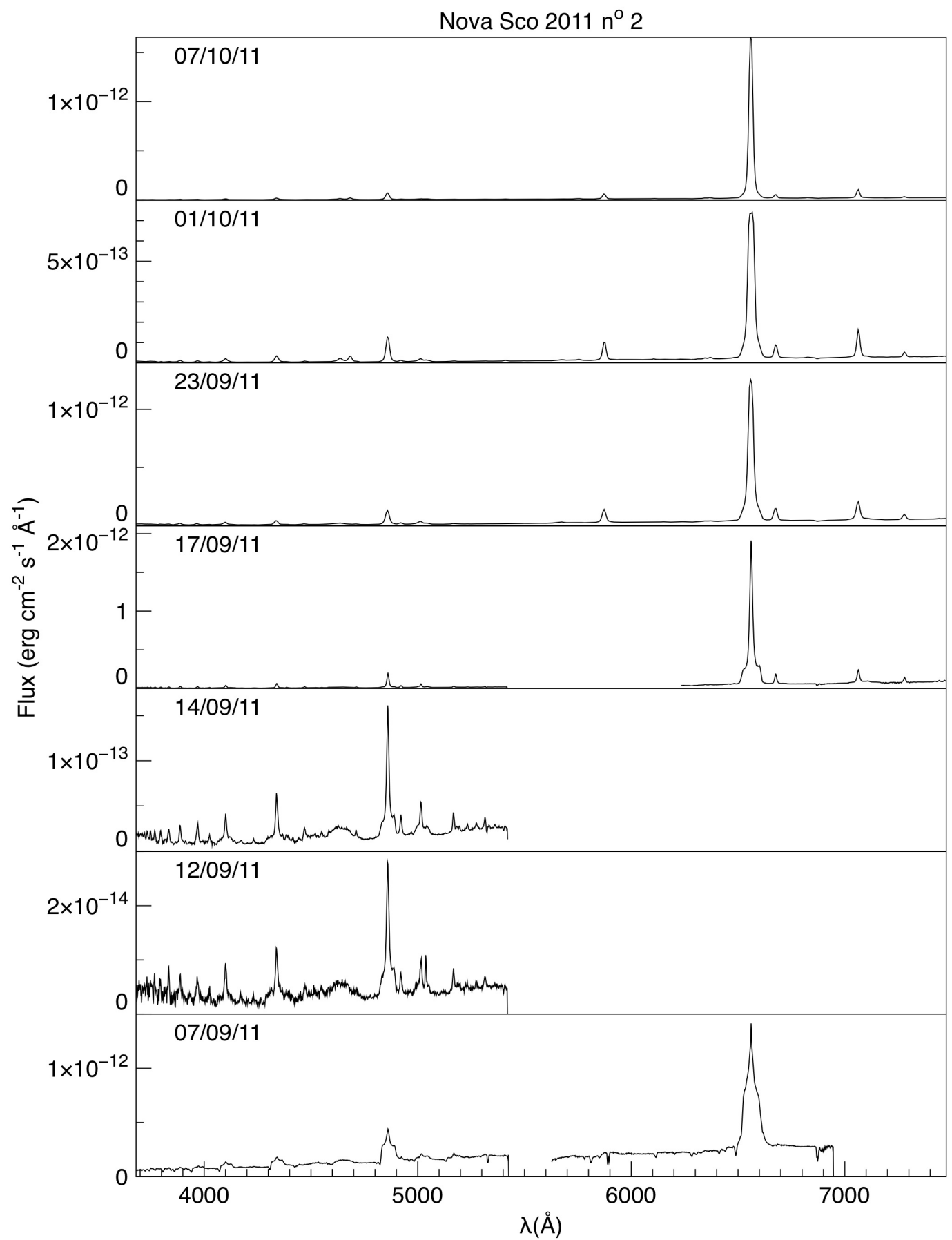

Figura A.11: Evolução espectral de Nova Sco $2011 n^{\circ} 2$, acompanhada pelo Stony Brooks/SMARTS Nova Atlas. 


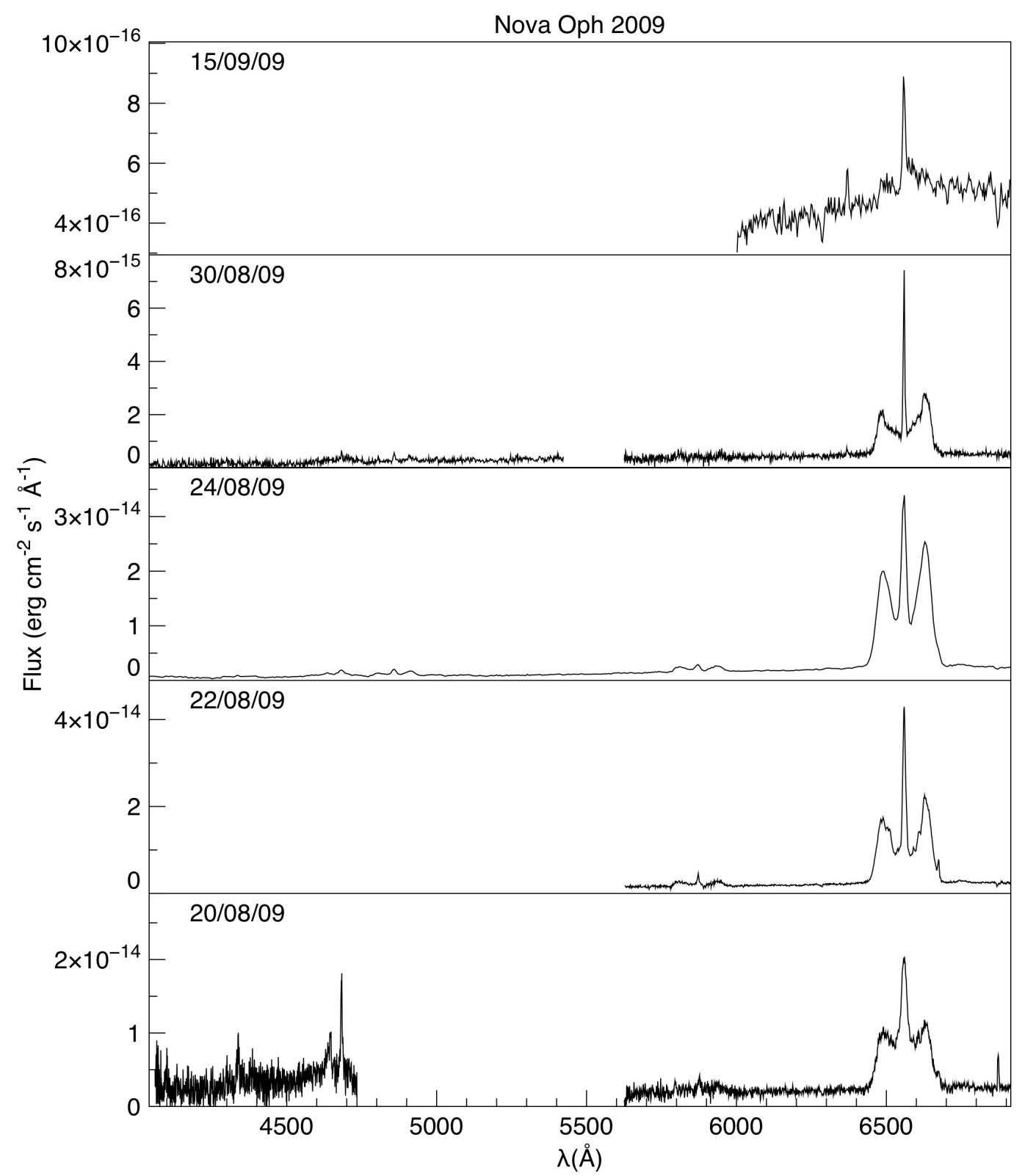

Figura A.12: Evolução espectral de Nova Oph 2009, acompanhada pelo Stony Brooks/SMARTS Nova Atlas. 


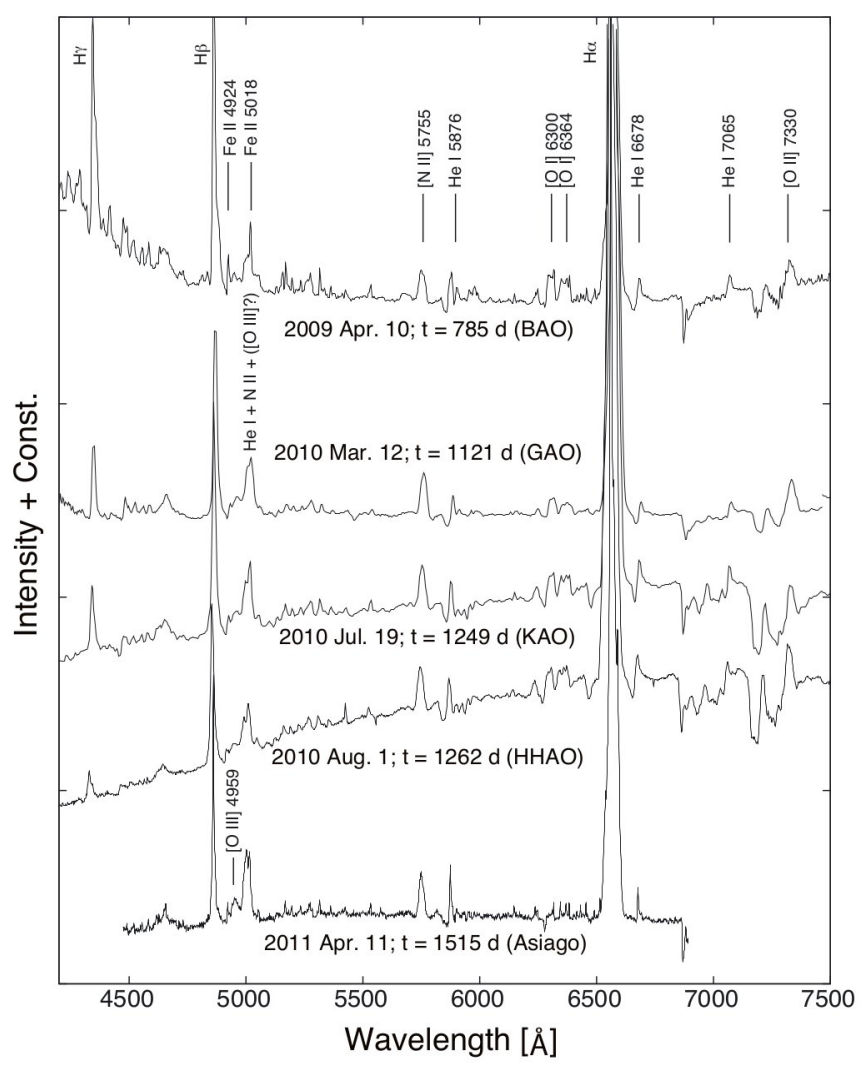

Figura A.13: Evolução espectral de V1280 Sco, ou Nova Sco 2007 (Naito et al. 2012a). 